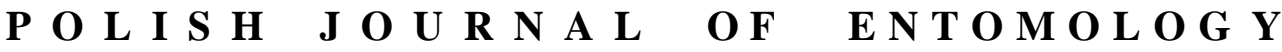

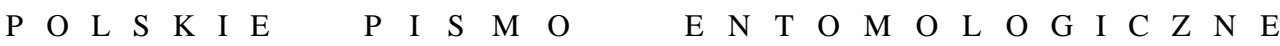

VOL. 86: $347-426$

Lublin

31 December 2017

DOI: $10.1515 /$ pjen-2017-0019

\section{On new taxa of Otiorhynchus GERMAR, 1822 (Coleoptera: Curculionidae: Entiminae: Otiorhynchini) from Greece and Turkey}

\author{
PIOTR Z. BIAŁOOKI
}

State Plant Health and Seed Inspectorate, ul. Na Stoku 48, 80-874 Gdańsk, Poland

\begin{abstract}
The subgenera Eunihoides subgen. n. (type species $O$. echinopterus sp. n.), and Nubidanops subgen. n. (type species Otiorhynchus tumidicollis STIERLIN, 1861) in the genus Otiorhynchus GERMAR, 1822 are newly described. The following species of Otiorhynchus GERMAR, 1822 are described: echinopterus sp. n., rhizophilus $\mathbf{s p . ~ n . ~ a n d ~ a g i l i s ~} \mathbf{s p .}$ n. from southwestern Turkey (subgenus Eunihoides subgen. n.); brevipilosus sp. n. from Turkey (subgenus Pocodalemes); nigrosetosus sp. n., flavosetosus sp. n., lacunosus sp. n., adopertus sp. n. implicatus sp. n. and sculptipterus sp. n. from Turkey (subgenus Tecutinus REITTER, 1912); forficulatus sp. n. and amplicornis sp. n. from south-western Turkey; crocotillus $\mathbf{s p .}$. from Greece (subgenus Fondajenus REITTER, 1912); crassiphallicus sp. n. from northern Turkey (subgenus Otismotilus ReITTER, 1912); agmentosus sp. n., armentalis sp. n., cappadocicus $\mathbf{s p .}$. crepuscularis sp. n., hebetes $\mathbf{s p .}$., malinkai $\mathbf{s p .}$., porculus $\mathbf{s p .} \mathbf{n}$., vavrai $\mathbf{s p .} \mathbf{n}$. and wanati $\mathbf{s p .} \mathbf{n}$. (all from Turkey, subgenus Odelengus); spectativus sp. n. from Turkey (subgenus Aequipennis); anabolicus sp. n. and pulcher BIAŁOOKI \& FREMUTH sp. n. from Turkey (subgenus Pterygodontus); rhinorostris sp. n. and curiosus sp. n. from Greece (subgenus Podonebistus); microcornis sp. n. from Turkey (subgenus Arnoldinus DAVIDIAN, GÜlteKIN \& KorOTYAEV, 2017). Otiorhynchus (Eunihus) pisidicus (MAGNANO, 2003) is hereby transferred to Otiorhynchus (Eunihoides subgen. n.), Otiorhynchus tumidicollis Stierlin, 1861 from Otiorhynchus incertae sedis and Otiorhynchus (Nubidanus) torosicus DAVIDIAN \& GÜLTEKIN, 2016 to the subgenus $O$. (Nubidanops subgen. n.); all are new subgeneric placements.
\end{abstract}

KEY WORDS: Otiorhynchus, new species, new subgenera, taxonomy, Greece, Turkey.

*Corresponding author: pbialooki@poczta.onet.pl 


\section{INTRODUCTION}

The tribe Otiorhynchini, an apparently monophyletic and exclusively Palaearctic lineage, remains in a dramatically chaotic taxonomic condition. Its core, the enormously speciose genus Otiorhynchus GERMAR, 1822, is divided into large numbers of subgenera in many cases representing unclearly defined groups. However, it is still necessary (as evidenced in this paper and in contributions by e.g. BIAŁOOKI 2015a, 2015b; DAVIDIAN et al., 2017) to erect new subgenera in order to adequately reflect phylogenetic relationships within this extremely large genus. The vast majority of Otiorhynchus subgenera were established by REITTER (1912) in an artificial identification key, usually without any subsequent description or revision. Their delimitation, as well as the identification of species, pose numerous problems because depositories of many types are unknown or their availability is doubtful. As a consequence of this situation it is unsurprising that new species are still being described, even from well explored Europe. The new taxa from Greece and Turkey now follow.

\section{MATERIAL AND METHODS}

The width of the rostrum is consistently defined as the pterygial span, i.e. the distance between the outer margins of the pterygia, even though the basal width of the rostrum in front of the eyes may sometimes be longer. Other basic terms, "frons" in particular, were defined in BIAŁOOKI (2015a). "Eyes/pterygia projecting" means "eyes/pterygia extending from the outline of the head/rostrum in the dorsal view", regardless of whether the eyes are convex or flat. The length of the funicle segments, as well as the club, is taken without the basal condyle (except for the first segment). The multilayered photos were taken with a Leica M205C stereomicroscope with an attached JVC KYF75 digital camera and subsequently montaged using the AutoMontage software of Syncroscopy. Labels are always cited verbatim, comments/additions are given in square brackets []; "/” separates the labels of a given specimen, whereas "l" separates data concerning different specimens; "ht" denotes holotype; "ex.", "exx." specimen and specimens respectively.

Body length is measured as generally accepted in Curculionoidea, i.e. from the anterior margin of the eyes to the elytral apex. However, BRAUN (1988 and subsequent papers) and GERMANN $(2016,2017)$ applied a convention that included the rostrum in the standard body length solely in the subgenus Tecutinus. Since "measurements have to be comparable", indeed, in order to make the measurements in Tecutinus compatible with the rest of Curculionoidea, I analysed the relative length of the rostrum in Tecutinus. This turned out to be an extremely stable character; the rostrum in all the species analysed is 0.15 of the 
standard body length (i.e. measured from the anterior margins of eyes to the elytral apex). Thus, in order to convert the body length including the rostrum into the standard length and vice versa, one has to respectively divide or multiply by 1.15 . So, for example, the standard body length of $O$. gultekini GERMANN, 2017 is actually 6.1-7.9 mm [7.6/1.15-9.1/1.15] etc.

Acronyms: BAHR - collection of Friedhelm BAHR, Viersen, Germany; BENE collection of Stanislav BENEDIKT, Plzeň, Czech Republic; BEHN - collection of Lutz BEHNE, Müncheberg, Germany; BIAL - collection of Piotr Z. BIAŁooKI, Sopot, Poland; BMNH - British Museum (Natural History), London, United Kingdom; COLO - collection of Enzo ColonNelli, Roma, Italy; HNHM - Hungarian Natural History Museum, Budapest, Hungary; KAKI - collection of George KAKIOPOULOS, Athens, Greece; MCZR Museo Civico di Zoologia, Roma, Italy; MERE - collection of Massimo MEREgalli, University of Torino, Italy; MESS - collection of Jochen MESSUTAT, Preussisch Oldendorf, Germany; NKME - Naturkundemuseum, Erfurt, Germany; PODL - collection of Attila PODLUSSÁNY, Budapest, Hungary; SDEI - Senckenberg Deutsches Entomologisches Institut, Müncheberg, Germany; TALA - collection of Fabio TALAMELLI, San Giovanni in Marignano, Italy; VAVR - collection of Jiři VAVRA, Ostrava Museum, Czech Republic; WANA - collection of Marek WANAT, University of Wroclaw, Poland; WINK - collection of Herbert Winkelmann, Berlin, Germany; ZMLU - Zoological Museum, Lund University, Sweden.

\section{RESULTS}

Subfamily Entiminae

Tribe Otiorhynchini

Genus Otiorhynchus GERMAR, 1822 (type species Otiorhynchus rhacusensis GERMAR, 1822)

Subgenus Eunihoides subgen. n. (type species Otiorhynchus echinopterus sp. n.); gender masculine

The subgenus Eunihus ReITTER, 1912 is widely distributed in high mountains from the Pyrenees to the Caucasus: 19 species are known so far (MAGNANO \& AlONSO-ZARAZAGA 2013). It is currently represented in Turkey by two species - uludagicus MAGNANO, 2002 and pisidicus (MAGNano, 2003). Although the Catalogue of Palaearctic Coleoptera (MAGNANo \& ALONSO-ZARAZAGa 2013) reports the presence of rhilensis STIERLIN, 1888 in Turkey as well, I do not believe that this Central European species occurs in Asia Minor. Since some Eunihus species differ only minimally from each other and the subgenus is generally one of the most difficult to identify, this record is most probably due to 
misidentification. In addition, the records concerning Ukraine and Russia require confirmation.

\section{Diagnostic description}

Otiorhynchus pisidicus (MAGNANO, 2003) was originally placed in the genus Parameira (subsequently transferred to Eunihus), which is indicative of the morphological distinctness between Eunihus and pisidicus. Here, another three new species from southwestern Anatolia (pisidicus occurs in the same region), closely related to this species, are described. They all differ from Eunihus in: larger body; eyes weakly convex, not at all or hardly protruding from head convexity; head forming a more or less clear common cone together with basal part of rostrum. In Eunihus the eyes are strongly convex, distinctly projecting, and clearly separated from the rostrum. I consider these differences to be phylogenetically significant, and consequently place all of these species, including pisidicus (new subgeneric placement) in the newly established subgenus Eunihoides subgen. $\mathbf{n}$.

Body (including antennal scape and legs except for tarsi) very densely covered with widely imbricate, recumbent scales creating indistinct maculation and thin contrasting pronotal midline composed of pale scales. Elytral striae usually hardly perceptible due to scaling and very often due to subtle layer of loam.

Aedeagus very slender, parallel-sided, laterally weakly evenly arched (Fig. 10); transfer apparatus situated in proximal (i.e. close to apices of apodemes) portion of protruding part of endophallus, large, resembling elongate letter $U$ with closed end towards pedon. It is composed of large number of densely aggregated microsclerites and id very conservative within the subgenus. Shape of aedeagus displays also very little variation only in relative length/width of pedon, and subtle differences in shape of apical process. Female genitalia do not display any marked differences.

All species known so far inhabit the alpine zone, where they are collected under stones and cushion plants.

Otiorhynchus (Eunihoides) echinopterus sp. n.

(Figs. 1-3)

\section{Material examined}

Holotype male: 10.06.2011 SW Turkey, Eren Dağı S Seki [W Elmal1], leg. P. BıAŁOOKI [BIAL]. Paratypes, 434 exx. [BIAL; COLO; HNHM; WANA] 08.06.2011 SW Turkey, Uyluk Tepe, SW Gömbe, leg. P. BIAŁOOKI, 7 exx. [BIAL]. 

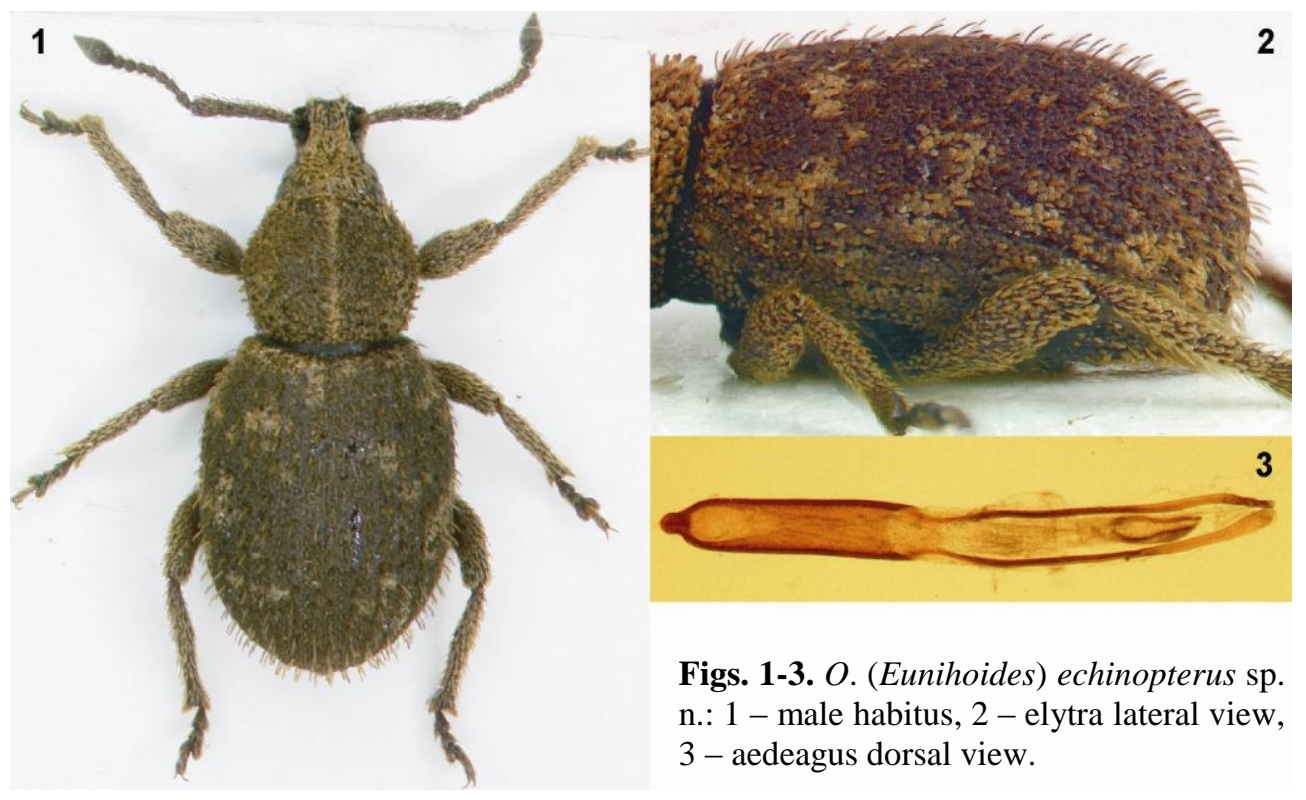

Figs. 1-3. $O$. (Eunihoides) echinopterus sp. n.: 1 - male habitus, 2 - elytra lateral view, 3 - aedeagus dorsal view.

\section{Diagnosis}

The new species (Fig. 1) is best diagnosed by the very long (distinctly longer than width of interstices), thin, parallel-sided, subperpendicularly protruding elytral scales and relatively short elytra. It differs from pisidicus in the following: scape strikingly thinner, clearly thickened apicad; strikingly wider tarsi; and from rhizophilus in: elytral scales much longer and thinner, more strongly raised and protruding; scape less robust, clearly widened apicad, covered with long thin raised scales; more elongate elytra. Instantly distinguishable from agilis sp. $\mathrm{n}$. in the shorter elytra and the markedly longer, more strongly raised elytral protruding scales. All of these species also differ from each other in details of aedeagus (see key).

\section{Description (male)}

Size range 4.0-4.7 mm, ht $4.7 \mathrm{~mm}$; body black, apical portions of tibiae, tarsi and antennae dark brown; body covered with broadly imbricate brown and creamy recumbent scales completely obscuring integument of elytra, prothorax, dorsal part of head with basal part of rostrum, legs except for tarsi, as well as antennal scape.

Head large, strongly transverse, weakly separated from basal part of rostrum; eyes small, weakly convex, hardly protruding from head convexity.

Rostrum slightly longer than pterygial span; frons $1.65 \times$ wider than rostrum dorsum between antennal insertions; epistome well developed, convex. 
Antennae relatively slender; scape straight, evenly and gradually thickened apicad, covered with semierect long scales; first funicle segment somewhat longer and thicker than second; third segment subisodiametric; segments 4-7 moderately transverse, gradually wider apically; club large, ovate with pointed apex, $1.8 \times$ longer than wide.

Prothorax $1.2 \times$ wider than long, widest in middle, at sides almost evenly moderately arched, anterior margin a little shorter than base; pronotum, except for recumbent scales, with moderately raised elongate scales; narrow midline marked with paler scales.

Elytra $1.25 \times$ longer than wide, oval, widest slightly before middle, apex broadly rounded; striae visible with difficulty owing to dense scaling, each strial puncture with relatively wide scale largely obscuring puncture surface; each interstice with single row of very long and thin semierect to subperpendicular scales (Fig. 2), densely arranged (distance between neigbouring scales on given interstice shorter than length of scales).

Ventral side of body covered with broad recumbent scales, irregularly intermixed with semierect hair-like scales; vestiture much sparser than on dorsal side, integument visible everywhere; ventrites 1-2 with vestiture distinctly sparser; ventrites 3-5 except for semierect hair-like scales with minute weakly perceptible hair-like scales; last ventrite almost flat, with large, scarcely perceptible apical depression.

Legs average, fore tibiae indistinctly arched; tarsi average, third segment markedly wider than preceding segment; second segment moderately transverse; apical comb consisting of long dense yellowish-brown setae.

Aedeagus (Fig. 3) long and slender, $4.35 \times$ longer than broad.

Female differs from male only indistinctly: in slightly wider elytra and, on average, in somewhat larger body.

\section{Ecology}

All specimens were collected under stones at altitudes above $2000 \mathrm{~m}$, far above the tree line.

\section{Etymology}

The name is coined from the Latin echinatus [= spiny] and the Greek $\varphi \tau \varepsilon \rho 0$ [latinized ptero; = wing] due to protruding elytral scales. 


\section{Otiorhynchus (Eunihoides) rhizophilus sp. n.}

(Figs. 4-6)

\section{Material examined}

Holotype male, dissected: 02.06.2010 SW Turkey, Mt. 2334 m E Kapakli, S Burdur, leg. P. BIAŁOOKI [BIAL]. Paratypes, as ht, 5 exx.[BIAL].

\section{Diagnostic description}

The new species (Fig. 4) is probably most closely related to echinopterus. The two species share relatively short elytra. $O$. rhizophilus differs from echinopterus in: elytral and pronotal protruding scales shorter, much broader and much less raised (Fig. 5); scape weakly yet clearly arched basally, slightly thicker, covered with much wider semierect scales; elytra less elongate, somewhat more strongly arched at sides; striae better pronounced, with rather small punctures bearing single short elongate scales leaving puncture surface in part uncovered; club more elongate, $1.9 \times$ longer than wide, fusiform; aedeagus $4.85 \times$ longer than broad (Fig. 6).

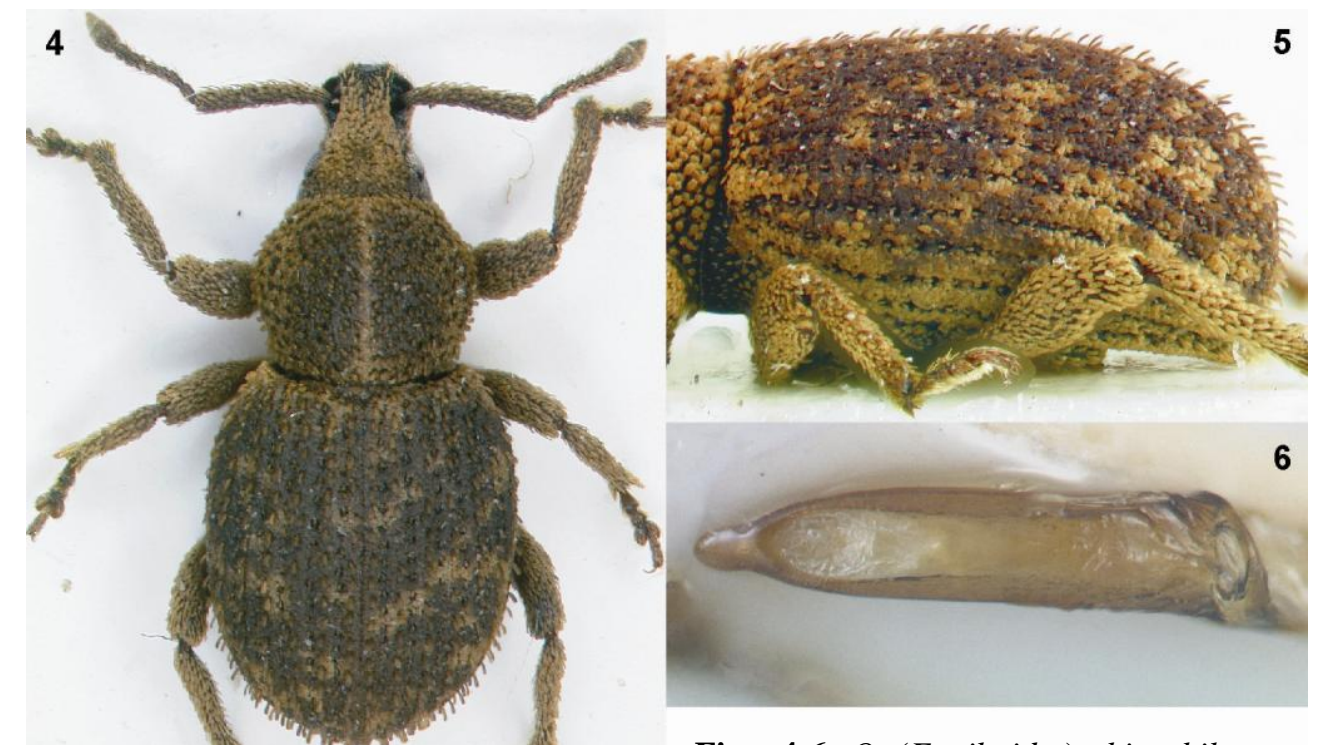

Figs. 4-6. $O$. (Eunihoides) rhizophilus sp. n.: 4 - male habitus, 5 - elytra lateral view, 6 - aedeagus dorsal view. 


\section{Ecology}

All specimens were sifted from grass roots in an alpine habitat far above the tree line at an altitude of ca. $2200 \mathrm{~m}$.

\section{Etymology}

The name is derived from the latinized Greek pi $\zeta \alpha$ [= root] and $\varphi \imath \lambda \varepsilon 0$ [= to love] to reflect the species' presumed way of life (sifted from grass roots) together with an anophthalmous carabid.

\section{Otiorhynchus (Eunihoides) agilis sp. n.}

(Figs. 7-10)

\section{Material examined}

Holotype male, dissected: 30.05.2008 SW Turkey; Mt. 2447 m; SE Uluborlu; leg. P. BIAŁOOKI [BIAL]. Paratypes: as ht, 12 exx.I 26.05.2010, SW Turkey, Boncuk Dağı 2418 m, leg. P. BıAŁooKi, 2 exx.। Turkey merid. distr. Isparta, Jos. Mertlik lgt./ Dipoyraz Daği Kurucuowa [correctly: Kurucaova] env. 4.ii.1997/ Paratypus, Parameira pisidica n.sp. design. L. MAGNANO 2001 [BIAL].

\section{Diagnosis}

The new species (Fig. 7) has similarly short (clearly shorter than width of interstices), hardly raised protruding elytral scales sparsely arranged in rows (Fig. 8), and elongate elytra like pisidicus, but is instantly distinguishable from that species by the much wider dorsal wall of the rostrum (resulting in smaller, narrower scrobes) and the markedly more slender scape. Instantly distinguishable from echinopterus and rhizophilus in the much longer elytra and sparse, short raised elytral scales.

\section{Description (male)}

Size range 4.0-4.8 mm, ht $4.1 \mathrm{~mm}$; black.

Head large, strongly transverse, weakly separated from basal part of rostrum; eyes small, weakly convex, hardly protruding from head convexity.

Rostrum slightly longer than pterygial span; frons $1.65 \times$ wider than rostrum dorsum between antennal insertions; epistome well developed, convex. 


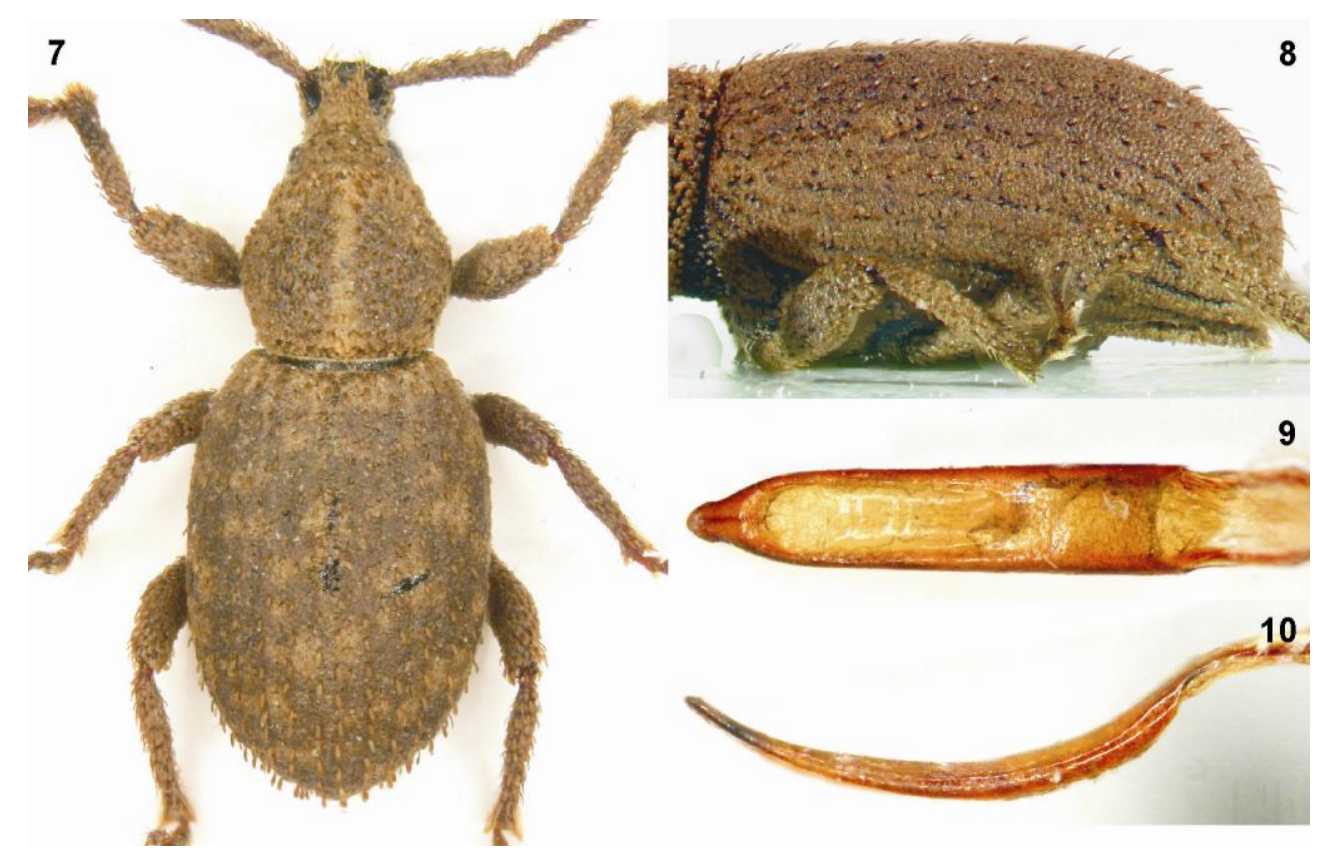

Figs. 7-10. $O$. (Eunihoides) agilis sp.n: 7 - male habitus, 8 - elytra profile, 9 - aedeagus dorsal view, 10 - aedeagus lateral view.

Antennae relatively robust; scape almost straight, evenly gradually thickened apicad, covered with recumbent and semierect scales; first funicle segment $2 \times$ longer than wide, $1.4 \times$ longer than second; second $1.4 \times$ longer than wide; segments 3-7 moderately transverse, two distal visibly larger; club large, ovate, with pointed apex, $2 \times$ longer than wide.

Prothorax $1.1 \times$ wider than long, widest in middle, at sides almost evenly moderately arched, anterior margin a little shorter than base; pronotum, except for recumbent scales, with elongate moderately raised scales; narrow midline marked with paler scales.

Elytra $1.4 \times$ longer than broad, oval, widest indistinctly before middle, apex broadly rounded; striae visible with difficulty due to dense scaling; each interstice with single row of weakly to moderately raised scales distinctly shorter than width of interstices (Fig. 8), sparsely arranged (distance between neigbouring scales on given interstice much longer than length of scales).

Ventral side of body covered with broad recumbent scales, irregularly intermixed with semierect hair-like scales; vestiture sparser than on dorsal side, integument everywhere visible; last ventrite almost flat, with large, hardly perceptible apical impression. 
Legs average, fore tibiae straight; tarsi average, third segment much wider than preceding segment; second segment moderately transverse; apical comb consisting of long dense yellowish-brown setae.

Aedeagus (Fig. 9) $4.6 \times$ longer than broad, in lateral view (Fig. 10).

Female differs from male indistinctly, in slightly wider elytra and, on average, in somewhat larger body.

\section{Ecology}

All specimens were collected under stones or under cushion plants at altitudes above $2000 \mathrm{~m}$, far above the tree line.

\section{Etymology}

The name is a Latin adjective [= lively, restless] reflecting that these beetles run very fast; some specimens were lost because of this trait, unusual for the whole tribe.

\section{Key to Eunihus and Eunihoides species of Turkey}

1. Eyes strongly convex, strongly projecting; rostrum well separated from head in dorsal view; size range (whole subgenus) $3.2-4.5 \mathrm{~mm}$. (subgenus Eunihus) uludagicus

- Eyes weakly convex, hardly or not at all protruding from head; head together with basal part of rostrum forming common cone; size range 3.9-5.5 mm (subgenus Eunihoides). ..

2. Scape extremely thick; dorsal wall of rostrum between scrobes ca. $3 \times$ narrower than pterygial span. pisidicus

- Scape moderately thick; dorsal wall of rostrum between scrobes ca. $2 \times$ narrower than pterygial span.

3. Elytra short-oval; protruding scales densely arranged, distance between neighbouring scales along given interstice subequal to length of scale. 4.

- Elytra elongate oval; protruding scales sparse, distance between neighbouring scales within given row much longer than length of scale. agilis $\mathbf{s p .} \mathbf{n}$.

4. Protruding elytral scales very thin, parallel-sided; scape covered with narrow, subparallel-sided semierect scales; aedeagus $4.4 \times$ longer than wide.

echinopterus sp. $\mathbf{n}$.

- Protruding elytral scales strikingly shorter, more or less oval; scape covered with short and broad semierect scales; aedeagus $4.8 \times$ longer than wide. rhizophilus sp. n. 
Subgenus Pocodalemes REITTER, 1912 (type species Otiorhynchus frivaldszkyi

ROSENHAUER, 1856)

The subgenus Pocodalemes so far comprises five (sub)species distributed around the Black Sea. Its concept (REITTER 1912, MAGNANO 1998) is unclear and requires thorough analysis.

Otiorhynchus (Pocodalemes) brevipilosus sp. $\mathbf{n}$.

(Figs. 11-13)

\section{Material examined}

Holotype male, dissected: 19.05.2008 S Turkey, Oyuklu Dağı, N Ermenek, leg. P. BIAŁOOKI [BIAL]. Paratypes as ht, 3 exx. \18.05.2008 S Turkey, Yunt Dağı, SW Ermenek, leg. P. BIALOOKI, 8 exx. [BIAL].

\section{Diagnosis}

The new species (Fig. 11) differs from ottomanus STIERLIN, 1861 in the following: dorsal margin of fore tibiae evenly weakly arched along its entire length (in ottomanus straight); pronotal punctures subequal to those on vertex (in ottomanus pronotal sculpture markedly coarser than on vertex); elytral and pronotal vestiture denser, scales wider; femoral teeth less developed, outcurved (in ottomanus tooth larger, subperpendicular to longitudinal axis of femur); elytral surface more strongly sculptured, not shiny; spermatheca devoid of ramus; nodulus minute.

\section{Description (male)}

Size range 5.0-6.2 $\mathrm{mm}$ (ht $5.1 \mathrm{~mm}$ ), dark brown.

Head moderately transverse, trapezoidal, sides not rounded; frons wide, clearly convex in both directions, covered with dense minute punctures; frons fovea large; eyes rather small, moderately convex, not projecting at all.

Rostrum slightly transverse; basally tapered or subparallel-sided; pterygia terminal, fairly small, projecting rather weakly; dorsal wall well separated from frons, weakly tapering from anterior margins of eyes towards antennal insertions, covered with similar punctation as frons, with very thin median keel. 


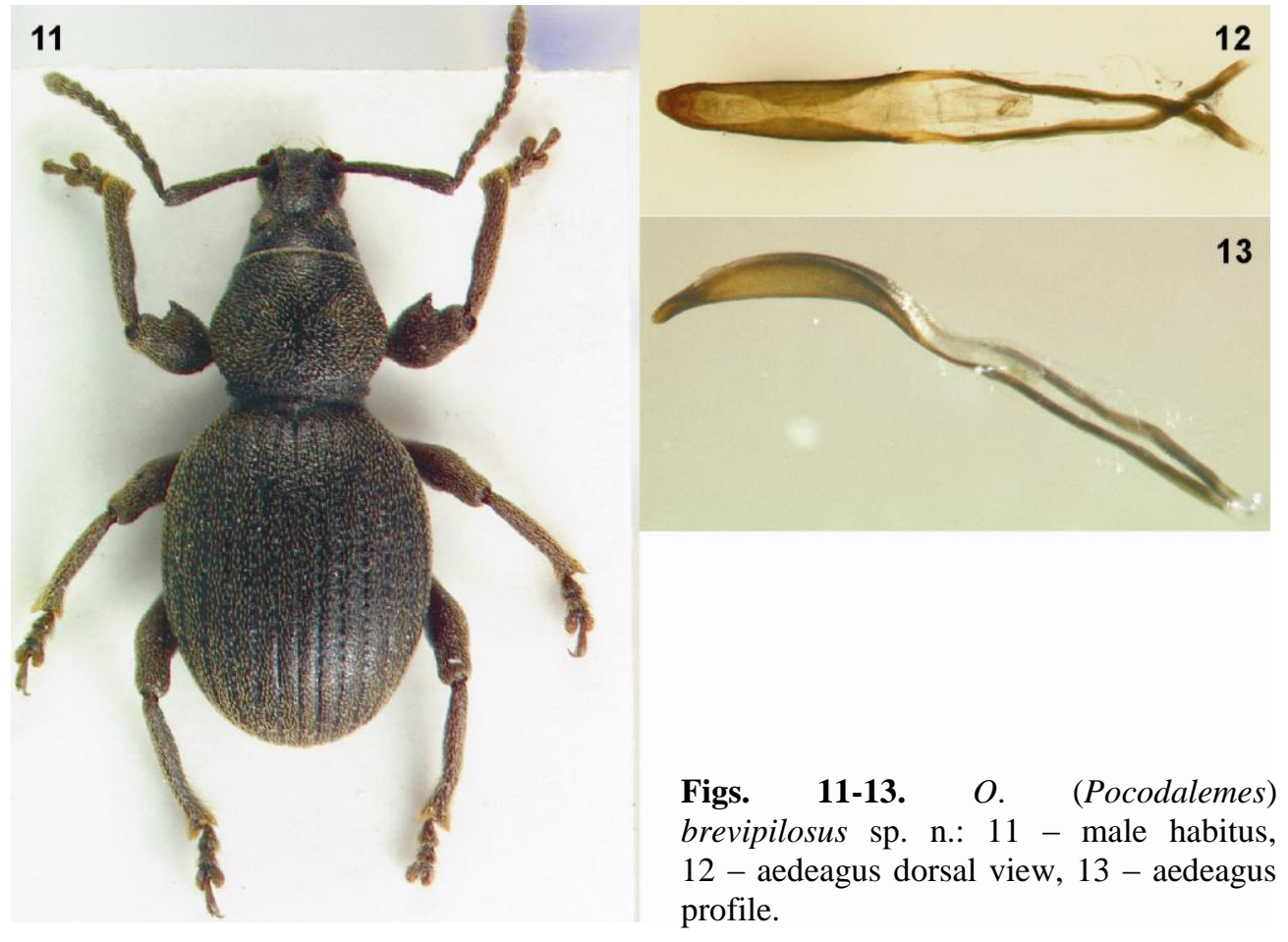

Antennae relatively robust even though all funicle segments elongate; scape straight, relatively long and slender, gradually and weakly thickening apicad; apex hardly more swollen; first two funicle segments strongly elongate, $3.2 \times$ and $2 \times$ longer than wide respectively; first $1.6 \times$ longer than second; segments 3-7 weakly elongate, gradually larger distad; club fusiform, $2.55 \times$ longer than wide.

Prothorax almost $1.25 \times$ wider than long, sides rather strongly arched; widest distinctly behind middle; basally strongly constricted; pronotum covered with dense minute punctures as large as on vertex; impunctate area weakly developed, short and very narrow; vestiture consisting of very short, recumbent, fairly dense narrow lanceolate, well visible pale brown scales.

Elytra $1.2 \times$ longer than wide, slightly ovate, widest indistinctly before middle; striae clearly impressed, punctures strikingly larger than pronotal ones, interspaces much shorter than puncture diameter; interstices subequally wide as striae, covered with very dense submicroscopic tubercles and irregular rugosity, semimatt; elytral scales similar to those on pronotum, recumbent, moderately dense, arranged in 3-4 altogether irregular rows on interstices. 
Legs long and robust; fore femora with large complex tooth directed outwards, its proximal portion in line with femur surface; middle femora with moderately large, hind one with small but well developed tooth; tarsi robust, second segment strongly transverse.

Aedeagus weakly evenly tapering to apex, subapically slightly constricted (Fig. 12); weakly evenly arched, somewhat shorter than apodemes (Fig. 13).

Female differs minimally from male in slightly wider, longitudinally somewhat more convex elytra.

Ovipositor long and slender, with relatively long subapical styli; spermatheca without ramus, nodulus minute, subisodiametric, hardly curved towards ramus.

\section{Ecology}

All the specimens were found under stones above $2000 \mathrm{~m}$.

\section{Etymology}

The name (adjective) is derived from the Latin words brevis [= short] and pilus [= hair] in reference to the vestiture.

Subgenus Tecutinus REITTER, 1912 (type species Otiorhynchus escherichi REITTER, 1898)

The subgenus Tecutinus ReITTER, 1912 so far comprises 26 species, occuring almost exclusively in Asia Minor (GERMANN 2017). They are recognizable by the unarmed femora; minute, strongly convex eyes; the dorsal wall of the rostrum strongly tapering anteriad; the body devoid of true scales; the ventral margins of the male hind and middle tibiae more or less excised subapically and/or strongly extended ventrad.

\section{Otiorhynchus (Tecutinus) implicatus sp. n.}

(Figs. 14, 15)

\section{Material examined}

Holotype male, dissected: 30.05.2010 SW Turkey, Tahtalidağı 2375 m, SW Kemer, leg. P. BIAŁOOKI [BIAL]. Paratypes: as ht, 17 exx.। 23.05.2007 SW Turkey; Alaca Dağı; NW Finike; leg. P. BIAŁOOKI, 3 exx. [BIAL; WANA]. 


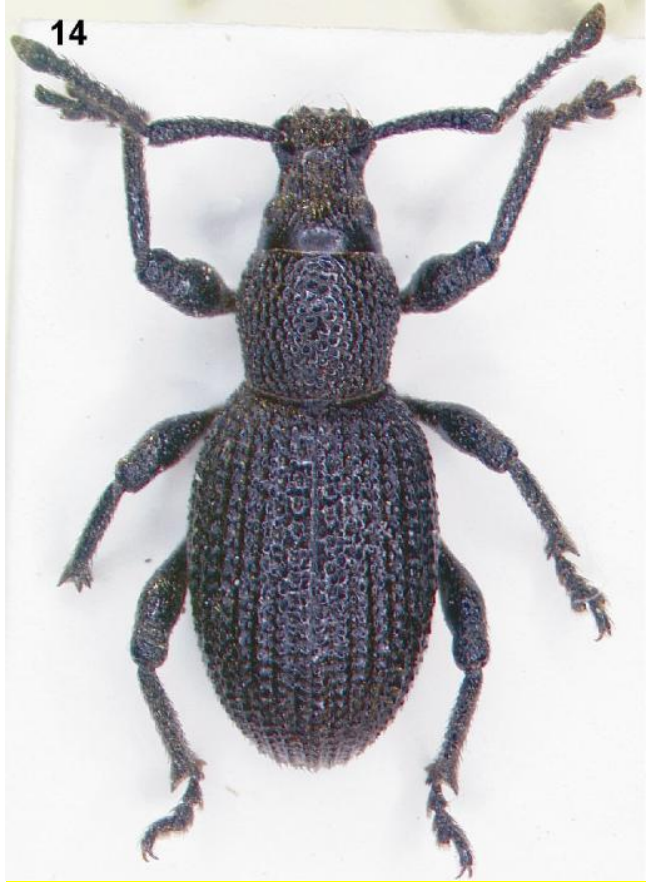

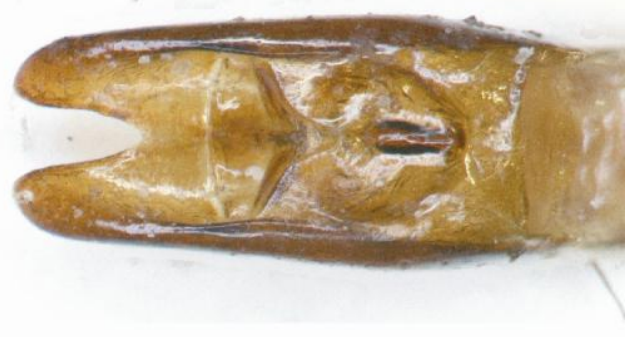

Figs. 14, 15. O. (Tecutinus) implicatus sp. n.: 14 - male habitus, 15 - aedagus dorsal view.

\section{Diagnosis}

The new species (Fig. 14) is most similar to sculptipterus (see diagnosis of that species). The two species share a similar general structure of the aedeagus, and the head/rostrum structure.

\section{Description (male)}

Size range 5.8-6.4 mm (ht $5.8 \mathrm{~mm}$ ); entirely black.

Head transverse; frons $1.45 \times$ broader than dorsal wall of rostrum between antennal insertions, coarsely punctate, interspaces shining; frons fovea not bigger than surrounding punctation; eyes moderately convex, small, its diameter half that of frons.

Rostrum $1.1 \times$ longer than wide; pterygia projecting rather weakly; dorsal wall of rostrum in a plane with frons, moderately tapered anteriad, coarsely, densely punctate, shining; median sulcus moderately deep, with well developed median keel; covered with same hairs as frons; epistome triangular, epistomal keels well developed, clearly elevated.

Antennae robust; scape stout, slightly arched, weakly gradually thickening apicad, coarsely punctate, covered with arcuate, slightly raised hairs; first funicle segment $1.4 \times$ longer than wide, clearly longer and wider than weakly elongate segment 2 ; segments 
3-7 strongly transverse; club $2.4 \times$ longer than wide, distinctly longer than distal four funicle segments combined.

Prothorax $1.1 \times$ broader than long, rather strongly convex transversally, weakly convex longitudinally, broadest before middle, anterior margin slightly narrower than base; disc covered with large, weakly or moderately convex, pupillate, shining tubercles resembling O. ovalipennis Boheman in this respect; ventral portion of pronotum with smaller, matt, more convex tubercles; hairs minute, recumbent.

Elytra oval, somewhat less than $1.4 \times$ longer than wide, apical half clearly narrower, broadest in middle, in lateral view weakly convex; declivity weakly convex, less than perpendicular; striae not impressed, punctures large, deep but with weakly defined margins, funnel-like, interspaces subequally large; interstices somewhat broader than striae; entire surface of elytra matt due to very subtle microsculpture; both strial interspaces and interstices with small, slightly convex, strongly shining tubercles arranged in single rows; each tubercle with minute, recumbent hair, somewhat protruding on apical declivity; tubercles on interstices distincly larger than on strial interspaces.

Legs; tibiae without spines, covered with recumbent or slightly raised hairs; fore tibiae slightly arcuate inwards at apex; mucro small; tarsi short, robust, second segment distinctly transverse.

Ventral part of body densely, coarsely punctate, covered with rather sparse, minute hairs; first two ventrites with large, deep joint cavity; last ventrite with broad, shallow apical impression.

Aedeagus $2.4 \times$ longer than wide, subparallel-sided, broadest in basal one fourth, apex excised in apical half (Fig. 15).

Female differs from male in slightly broader elytra; rostrum somewhat shorter, broader; first two ventrites flat; legs distinctly more slender; outer margin of apex of fore tibiae straight, ventral portion strongly expanded inwards.

The shape of spermatheca variable: ramus and nodulus approached, or moderately separate to each other.

\section{Ecology}

All specimens were collected under stones at an altitude of ca. $2300 \mathrm{~m}$ in the alpine zone with scanty vegetation.

\section{Etymology}

The name is a Latin adjective [= confused]; an allusion to the unclear taxonomic position of the species within Tecutinus. 


\section{Otiorhynchus (Tecutinus) sculptipterus $\mathbf{s p .} \mathbf{n}$.}

(Figs. 16, 17)

\section{Material examined}

Holotype male, dissected: 02.06.2011 SW Turkey, Çal Dağı [2108 m] N Fethiye, leg. P. BIAŁOOKI [BIAL]. Paratypes: as ht, 22 exx. [BIAL; WANA].

\section{Diagnosis}

The new species (Fig. 16) is most similar to implicatus sp. n. It differs from that species in the following: different details of aedeagus (Fig. 17); entire surface of elytra uniformly shiny; rostrum with fairly deep, median sulcus; eyes much smaller, their diameters $2.55 \times$ shorter than frons; dorsal margin of male fore tibiae straight, ventral margin with small but well visible spines; antennae stouter: scape thicker, funicle segments 3-7 strikingly transverse. It is apparently close to charleshuberi GERMANN, 2016 too, based on the similar structure of head and rostrum, and aedeagus, but sculptipterus can be instantly distinguished from that species by the much shorter, heavily sculptured elytra and details of the aedeagus.

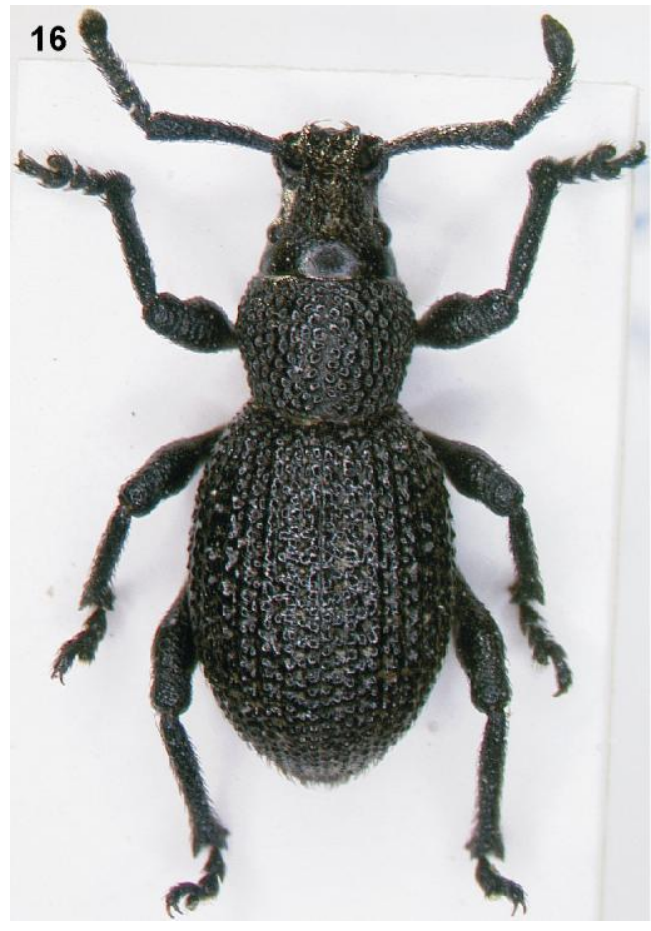

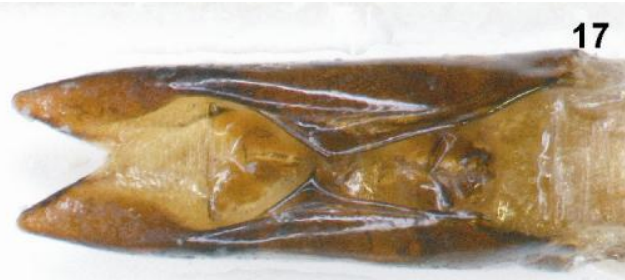

Figs. 16, 17. O. (Tecutinus) sculptipterus sp. n.: 16 - male habitus, 17 - aedeagus dorsal view. 


\section{Description (male)}

Size range 5.1-5.9 mm (ht $5.7 \mathrm{~mm}$ ); black; vestiture consisting of very short sparse recumbent dark weakly perceptible hairs distinctly raised on elytral declivity.

Head strongly transverse, at sides hardly arched; frons on a level with dorsal wall of rostrum, covered with elongate punctures; interstices thin forming irregular net; frons fovea hardly recognizable amongst punctation; eyes fairly small, weakly convex, projecting slightly.

Rostrum subisodiametric, basally tapering weakly; pterygia large, moderately projecting; epistome triangular, delimited by lateral sulci; dorsal wall tapering slightly anteriad; median keel rather weakly developed; anterior part of dorsal wall slightly declivous.

Prothorax $1.3 \times$ wider than long; sides weakly arched; widest in anterior one third; pronotum covered with fairly large tubercles - dense, strongly flattened, shiny, irregular in shape and size; lateral wall covered with much smaller tubercles covered with microsculpture.

Elytra $1.45 \times$ longer than broad, slightly ovate, widest slightly before middle; striae consisting of large deep punctures, interspaces much shorter than puncture diameter, usually with minute tubercle; interstices narrower than striae, with single row of well developed small tubercles distinctly larger than strial tubercles.

Legs short and robust; fore tibiae apically clearly curved ventrad; apical comb consists of long flattened dark-brown setae; second tarsal segment moderately transverse.

Aedeagus tapering weakly evenly, apex slightly stronger so, apically deeply excised; as a result ending in two subacute processes (Fig. 17).

Female differs weakly from male in slightly broader elytra; somewhat less robust legs; first two ventrites not impressed.

Ovipositor elongate, moderately sclerotized; spiculum ventrale twice as long as basal lamina; the latter excised apically, evenly dark brown, sclerotizations short, blurred.

\section{Etymology}

The name was derived from Latin sculptura [= sculpture] and Greek $\varphi \tau \varepsilon \rho 0$ [latinized ptero $=$ wing $]$ referring to the pronounced sculpturing of the elytra. 


\section{Otiorhynchus (Tecutinus) flavosetosus sp. n.}

(Figs. 18-20)

\section{Material examined}

Holotype male, dissected: 27.05.2008 SW Turkey; Hacibaba Dağı [2481 m]; E Karaman; leg. P. BiAŁOOKI [BIAL]. Paratypes: as ht, 40 exx.; 13.05.2008 SW Turkey; Rize Beli pass; NW Seydişehir; leg. P. BIAŁOOKI, 22 exx.I same, but 29.05.2008,10 exx. [BIAL; TALA; WANA].

\section{Diagnosis}

The new species (Fig. 18) is distinguishable at first glance by elytra covered with strongly protruding yellow-brown elytral setae, detectable even with the naked eye, extremely long, distinctly longer than width of interstices (Fig.19) and also by the similar, much shorter, recumbent and weakly raised setae.

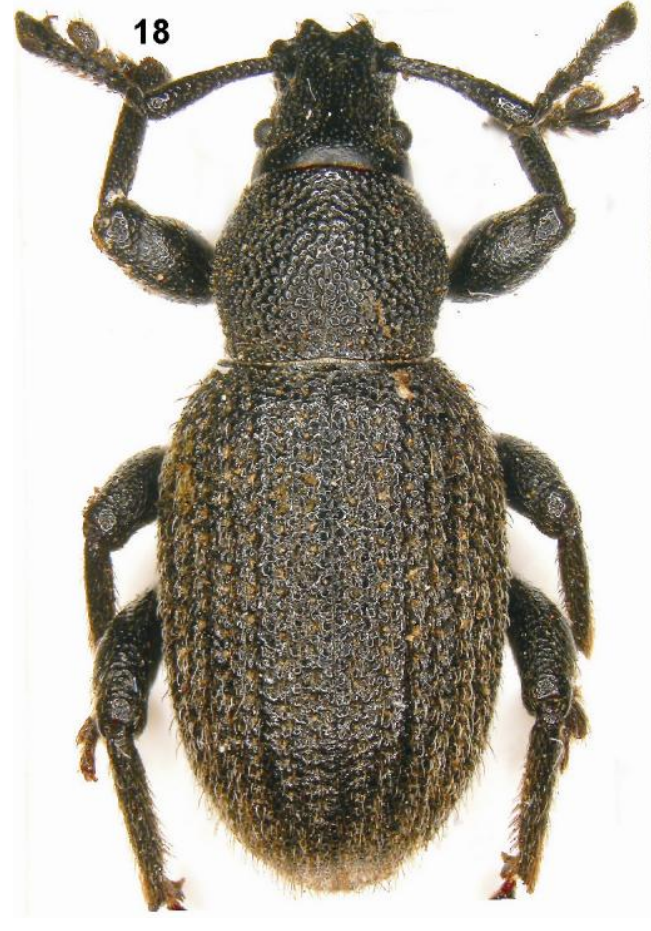

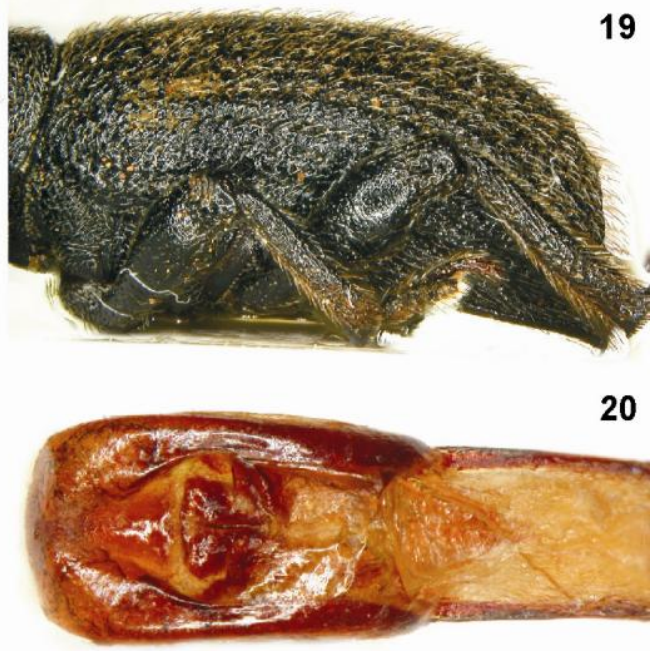

Figs. 18-20. O. (Tecutinus) flavosetosus sp. n.: 18 - male habitus, 19 - elytra lateral view, 20 - aedeagus dorsal view. 


\section{Description (male)}

Size range 7.6-8.2 $\mathrm{mm}$ (ht $7.8 \mathrm{~mm}$ ); black.

Head very short, very strongly transverse; frons convex transversally, covered with fairly large, rather weakly elongate, dense punctures; frons fovea hardly larger than surrounding punctation but clearly discernible.

Rostrum subisodiametric; pterygia moderately large, moderately projecting; pterygial span indistinctly shorter than basal width of rostrum; epistome in the form of nearly regular equilateral triangle delimited by deep sulci; dorsal wall covered with the same sculpture as frons; basal part of rostrum weakly swollen, sides hardly arcuate.

Antennae relatively slender; first two funicle segments elongate, ca. twice as long as wide, second only somewhat shorter than first; segments 3-7 rather strongly transverse; club fusiform, very slender, $2.55 \times$ longer than wide.

Prothorax $1.25 \times$ broader than wide, at sides weakly rounded; pronotum covered with rather small, irregular in shape, completely flat tubercles; lateroventral portion of prothorax covered with minute, rasp-like tubercles. pronotal disc entirely covered with well expressed, various in size tubercles.

Elytra $1.35 \times$ longer than wide; elytral protruding hairs longer than width of interstices, light brown, thick; declivity clearly less than perpendicular (Fig.19); striae broad, consist of large, round punctures, interstices distinctly less than twice as broad as striae, entirely covered with well developed, flattened, variously sized tubercles.

Legs; fore tibiae straight, slightly expanded outwards at apex; hind tibiae moderately incised, weakly arcuate dorso-ventrally; tarsi moderately robust, second segment moderately transverse.

Aedeagus short, $1.75 \times$ longer than broad, subrectangular (Fig. 20).

Female differs from male in distinctly broader elytra.

\section{Ecology}

All specimens were collected under stones at an altitude of ca. 2200-2400 m.

\section{Etymology}

The specific epithet was coined from the Latin flavus [= yellow] and the Greek ş́t $[=$ seta] to reflect the bright yellowish-brown protruding vestiture. 


\section{Otiorhynchus (Tecutinus) nigrosetosus sp. n.}

(Figs. 21-23)

\section{Material examined}

Holotype male, dissected [right hind tarsus missing]: 01.06.2011 SW Turkey, Çiçek Dağı, NE Köyceğiz, leg. P. BIAŁOOKI [BIAL]. Paratypes, as ht, 12 exx. [BIAL; WANA].

\section{Diagnosis}

The new species (Fig. 21) is readily distinguishable from all species of the subgenus in: dark, very long, strongly protruding elytral setae; elytral recumbent vestiture obsolete; eyes very small, strongly convex; male hind tibiae without subapical excision.

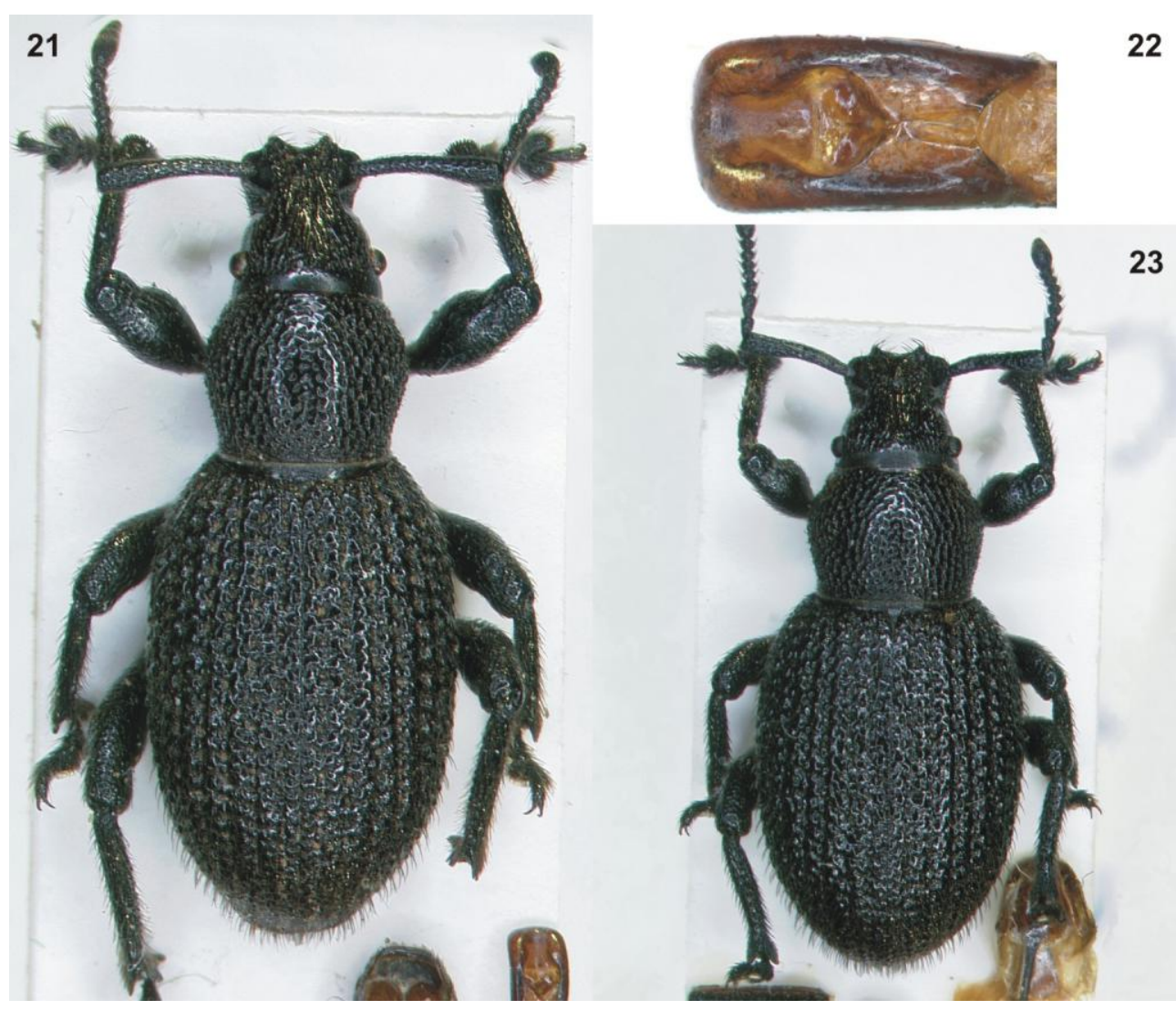

Figs. 21-23. O. (Tecutinus) nigrosetosus sp. n.: 21 - male habitus, 22 - aedeagus dorsal view, 23 - female habitus. 
The new species is most similar to $O$. flavosetosus $\mathbf{s p .} \mathbf{n}$. owing to the presence of unusually long protruding setae and very slender antennae, from which it differs mainly in: vestiture dark brown/black; recumbent elytral hairs almost completely reduced; much more slender antennae; eyes smaller, stronger convex; aedeagus.

\section{Description (male)}

Body length 7.1-8.9 mm (ht $8.0 \mathrm{~mm}$ ); black, antennae and tarsi dark brown.

Head extremely short and transverse; frons strongly convex transversally, covered with large strongly elongate punctures; frons fovea only slightly larger than surrounding punctures; eyes minute, strongly convex, subhemispherical.

Rostrum slightly elongate; pterygia moderately large, moderately projecting; pterygial span somewhat shorter than basal width of rostrum; epistome well developed, triangular, delimited by deep sulci; basal part of rostrum swollen, with arcuate sides; dorsal wall sculptured as frons.

Antennae rather very slender; funicle segments 1-3 elongate; segments 4-7 (sub)isodiametric; club fusiform, very slender, $2.7 \times$ longer than wide.

Prothorax $1.2 \times$ broader than long, distinctly heart-shaped, anterior portion more strongly arched, widest well before middle; pronotum covered with medium-sized dense, completely flat tubercles, in centre fused into coarse irregular punctation.

Elytra $1.5 \times$ longer than wide, widest in middle; strial punctures large and deep, irregular in size; interstices narrower than striae, covered with single row of big, flattened irregular tubercles fused in part into an irregular rib.

Legs moderately robust; tibiae and in part femora covered with long semierect setae; fore tibiae moderately curved ventrad apically; hind tibiae non-excised, moderately extended ventrad apically.

Aedeagus subrectangular, $1.9 \times$ longer than broad (Fig. 22).

Female (Fig. 23) differs from male in much more robust body (elytra somewhat shorter; prothorax slightly broader); rostrum wider and shorter; legs shorter, thinner, dorsal margin of fore tibiae straight.

\section{Ecology}

All specimens were collected under stones in a desert habitat with very scanty, poor vegetation at an altitude of ca. $2200 \mathrm{~m}$.

\section{Etymology}

The name is coined from the Latin nigrum [= black] and the Greek ḉz [= seta], which refers to the dark elytral setae. 


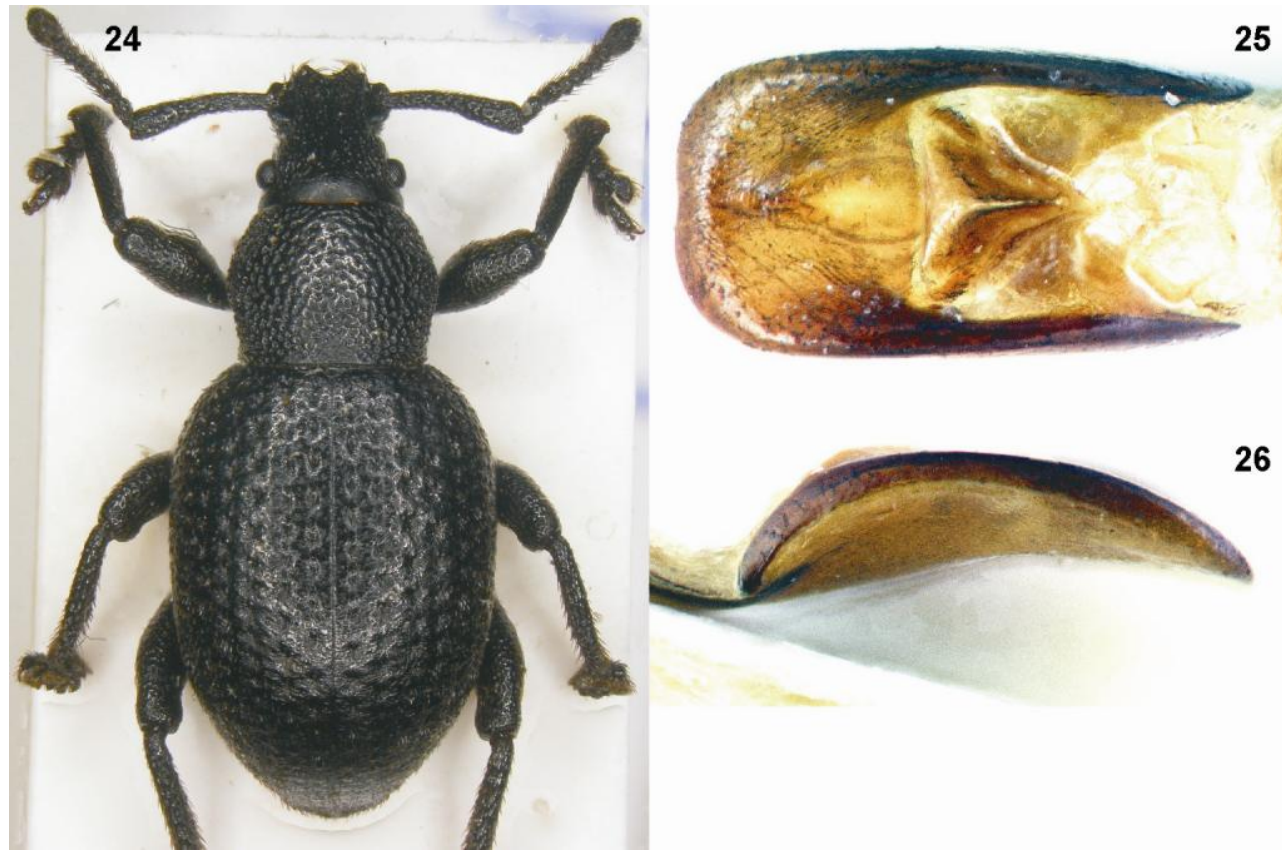

Figs. 24-26. O. (Tecutinus) lacunosus sp. n.: 24 - male habitus, 25 - aedeagus dorsal view, 26 - aedeagus profile.

\section{Otiorhynchus (Tecutinus) lacunosus sp. n.}

(Figs. 24-26)

\section{Material examined}

Holotype male, dissected: 08.06.2006 NW Turkey; Kocakirdağ Tepe; NW Emet; leg. P. BIAŁOOKI [BIAL]. Paratypes: as ht but 09.06.2008, 1 ex.\10.06.2006 NW Turkey; Alacam Dağları; NW Simav; leg. P. BIAŁOOKI; 1 ex.; same but 11.06.2006, 6 exx. [BIAL].

\section{Diagnosis}

The new species (Fig. 24) seems most similar to crinitellus K \& J. DANIEL, 1902; the two species share a very similar general structure of head and rostrum. It differs from crinitellus in the following: smaller body; lack of protruding elytral setae (small raised setae present on declivity only); elytral interstices with minute shiny tubercles several times narrower than interstice width; interspaces with leather-like microrugosity (in $O$. crinitellus interstices and interspaces of strial punctures with large, flat tubercles, its interspaces very 
narrow); strial punctures well expressed, large though shallow and without sharply defined margins (in $O$. crinitellus strial punctures ill-defined, reduced to small, shallow depressions between tubercles); tubercles on pronotal disc larger; elytra less convex, both longitudinally and transversally.

\section{Description (male)}

Size range 6.6-7.4 $\mathrm{mm}$ (ht $6.8 \mathrm{~mm}$ ); black, antennae and legs in part dark brown.

Head very strongly transverse; frons strongly convex transversally, not at all separated from dorsal wall of rostrum, covered with dense longitudinal punctures; frons fovea scarcely perceptible; eyes minute, strongly convex, projecting.

Rostrum subisodiametric; pterygia moderately large, moderately projecting; epistome well-developed; dorsal wall between anterior margins of eyes and epistome with median keel.

Antennae robust; scape moderately, evenly arched, basal half evenly weakly thickened, apical half more strongly swollen; first two funicle segments subequally long and thick, 1.7 $\times$ longer than wide; segments 3-7 strongly transverse; club obovate, $2.1 \times$ longer than wide, as long as almost four distal funicle segments combined.

Prothorax $1.2 \times$ wider than long, sides moderately arched, widest much before middle; longitudinally evenly, very weakly convex; pronotum covered with irregularly shaped tubercles, strongly flattened in centre, gradually more convex towards sides.

Elytra $1.3 \times$ longer than wide; almost regularly short-oval, widest slightly before middle; striae consist of large and shallow pits, interspaces much shorter than puncture diameter; pits covered with rather short sparse recumbent greyish and brownish hairs somewhat raised on declivity; interstices strikingly narrower than striae, zigzag-like in part (as in heinzianus Braun, 1988), covered with sparse punctures, interspaces covered with minute pinholes and irregular rugosity, shiny.

Legs robust; dorsal margin of fore tibiae straight, apically not dilated dorsad; fore tarsi very robust, second segment strongly transverse; hind tibiae indistinctly excised, moderately extended ventrad apically.

Aedeagus with subapical portion subparallel-sided, weakly tapering towards base, apex broadly rounded, tip truncate and indistinctly excised medially; weakly arched (Fig. 26).

Female differs from male in slightly shorter, more robust elytra, and more robust antennae.

\section{Etymology}

The name (adjective) was derived from the Latin lacuna $[=$ small cavity or discontinuity] with reference to the large strial punctures. 


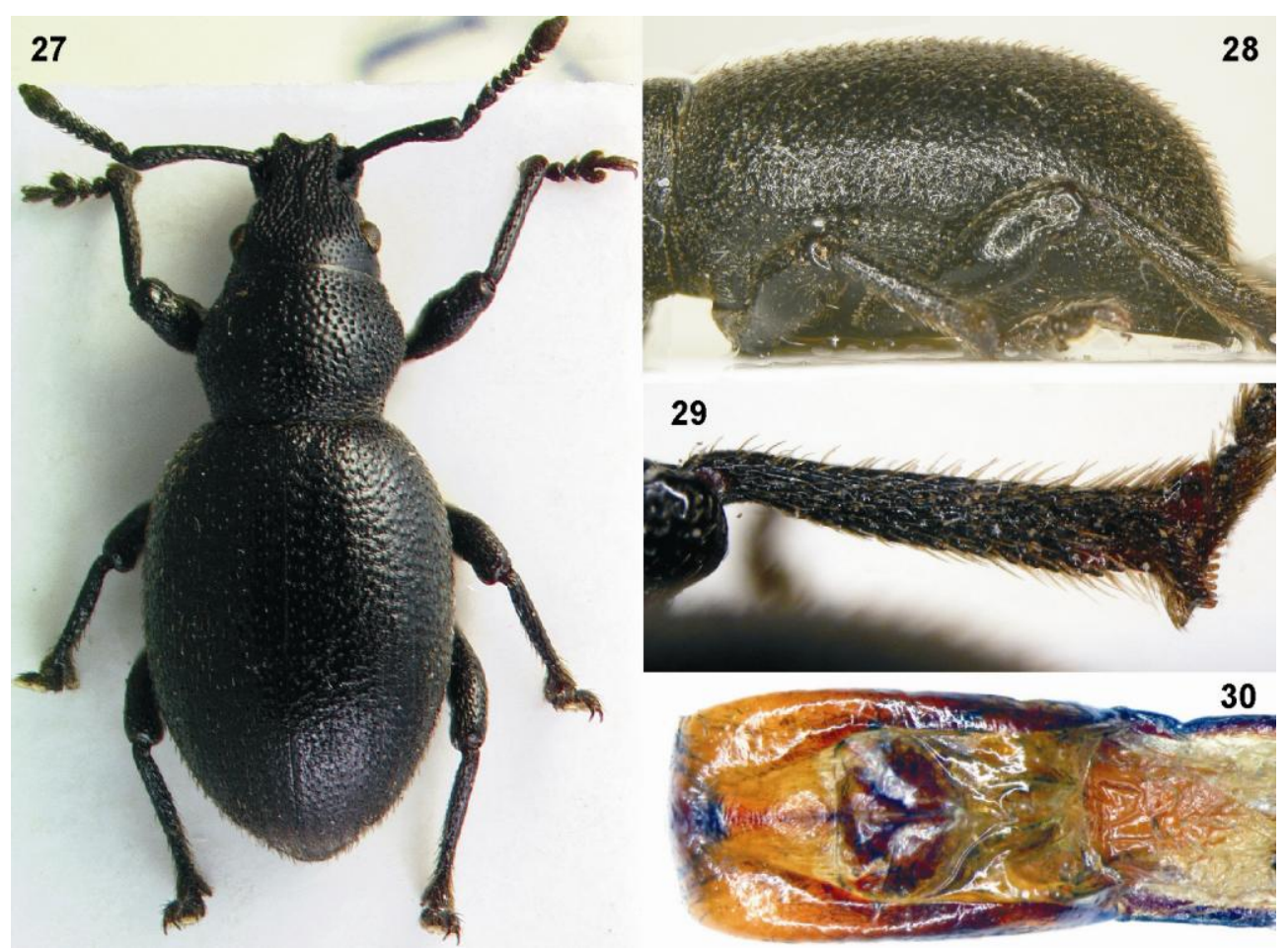

Figs. 27-30. O. (Tecutinus) adopertus sp. n.: 27 - male habitus, 28 - elytra lateral view, 29 - male right hind tibia, 30 - aedeagus dorsal view.

\section{Otiorhynchus (Tecutinus) adopertus sp. n.}

(Figs. 27-30)

\section{Material examined}

Holotype male, dissected: 11.06.2009 N Turkey; Köse Dağ1; S Suşehri; leg. P. BIAŁOOKI [BIAL]. Paratypes: as ht, 23 exx. [BENE; BIAL; WANA].

\section{Diagnosis}

O. adopertus sp. n. (Fig. 27) belongs to the group of species with strongly raised elytral setae. The new species differs from torulensis BENEDIKT, 2000, the species most similar to adopertus in the following: more protruding elytral vestiture (Fig. 28); hairs predominantly dark, not readily visible; general appearance of body black; both pronotal disc and elytra punctate. 
O. paracrinitellus BRAUN differs from the new species in: first two funicle segments elongate, subequally long; segment 3 slightly elongate, segments 4-7 moderately transverse; elytral vestiture consisting of minute, recumbent, rather sparse grey hairs in large strial pit-like punctures, and longer, semiprotruding, sparse, dark hairs on interstices. $O$. crinitellus differs strikingly from the new species in: much larger body; elytra much broader, much more convex; relatively dense elytral recumbent, grey hairs; semiprotruding hairs shorter; quite different sculpture of pronotum and elytra: both covered with well developed, dense, flattened tubercles.

\section{Description}

Size range 6.1-7.0 mm, ht $6.7 \mathrm{~mm}$; dark brown to black, vestiture dark brown.

Head very strongly transverse; frons $1.75 \times$ wider than dorsal wall between antennal insertions, clearly wider than pterygial span; eyes small, strongly convex, projecting, $2.9 \times$ narrower than frons; frons fovea unclear.

Rostrum subisodiametric, dorsal wall covered with moderately large elongate punctures; interspaces thin, fused into longitudinal ribs; epistome triangular, well developed.

Antennae very robust; first funicle segment $1.85 \times$ longer than wide, distinctly longer than second; second segment $1.3 \times$ longer than wide; segments 3-7 strongly transverse; club shortly ovate, base broadly rounded.

Prothorax $1.3 \times$ wider than long, widest before middle; disc of pronotum covered entirely with regular punctures, interspaces flat, shiny, minute tubercles only on lateral wall of prothorax.

Elytra $1.3 \times$ longer than wide, almost regularly oval; declivity strongly convex, subperpendicular (Fig. 28); relatively long, strongly protruding, thin, brown elytral hairs distributed relatively densely and irregularly; narrow, scarcely perceptible striae consisting of small, elongate punctures only slightly larger than punctation of interstices, size of punctures decreasing strongly towards lateral margins of elytra; middle interstices of disc on average $3 \times$ broader than striae, irregularly, rather weakly rugose, distinctly punctate.

Legs; tibiae relatively slender; fore tibiae straight, not expanded outwards at apex, with short, triangular mucro; middle tibiae strongly expanded inwards apically; hind tibiae weakly incised subapically (Fig. 29); tarsi and especially onychium very short.

Aedeagus (Fig. 30).

Female differs from male in wider, more robust elytra; somewhat shorter rostrum; antennae slightly more robust; legs more slender; fore tibiae distinctly dilated apically; hind tibiae not excised subapically. 


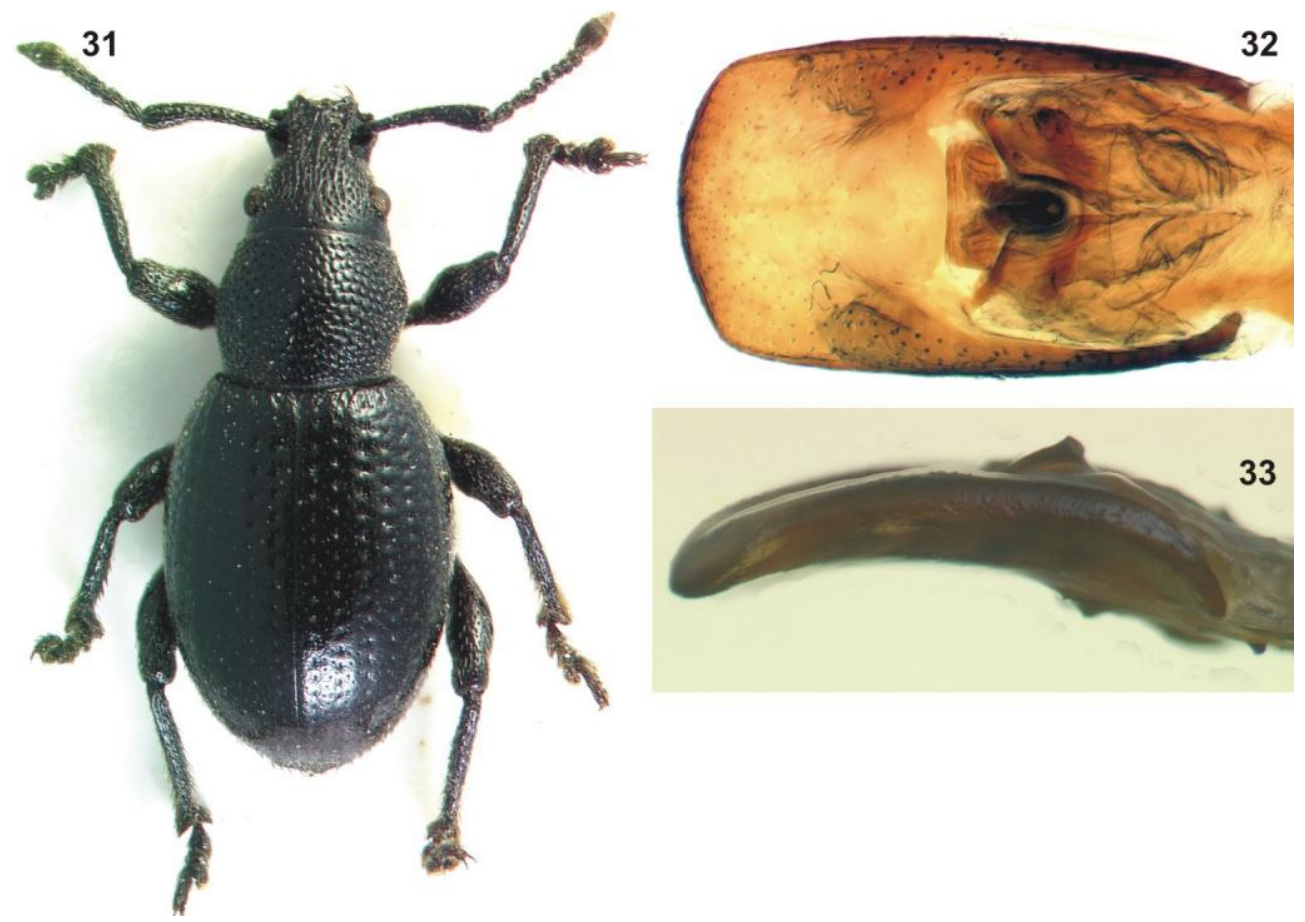

Figs. 31-33. O. (Tecutinus) corpusculus sp. n.: 31 - male habitus, 32 - aedeagus dorsal view, 33 - aedeagus profile.

\section{Etymology}

The name (adjective) is a Latin adjective [= clothed] - an allusion to the distinct vestiture.

\section{Otiorhynchus (Tecutinus) corpusculus sp. n.}

(Figs. 31-33)

\section{Material examined}

Holotype male, dissected [left fore onychium missing]: 19.05.2009 W Turkey, Çakmaktepe Geçidi E Sandıklı, leg. P. BIAŁOOKI [BIAL]. Paratypes: as ht, 17 exx. [BIAL; WANA]. 


\section{Diagnosis}

This is the smallest Tecutinus species known (Fig. 31). Further highly distinctive features of corpusculus sp. $\mathrm{n}$. include the following: male hind tibiae not excised; unusually long antennal club; large strial punctures combined with weakly sculptured interstices; seemingly bare body; aedeagus. It differs from brevicornis BOHEMAN, 1842 in the shiny elytra, and strikingly larger strial punctures; from pseudocribripennis BRAUN, 1988 in the hind tibiae not excised and elytral disc apparently devoid of vestiture; and from heinzianus in strikingly smaller body.

\section{Description (male)}

Size range 5.0-7.4 mm (ht $5.0 \mathrm{~mm}$ ); body black; vestiture scarcely perceptible, mainly on declivity and outer interstices.

Head very strongly transverse, not separated from rostrum, forming a common cone with basal portion of rostrum; frons very wide, covered with longitudinally elongate dense punctures; frons fovea not recognizable; eyes minute, strongly convex, strongly projecting.

Rostrum subisodiametric, tapering strongly towards pterygia; dorsal wall with median keel; epistome well-developed; pterygia rather small, moderately projecting.

Antennae moderately robust; scape rather strongly arched, somewhat stronger in apical portion; basal half weakly evenly thickened, apical half so stronger; first two funicle segments subequally long and thick, ca. $1.3 \times$ longer than wide; third segment moderately transverse; segments 4-7 strongly transverse; club fusiform, exceptionally long, as long as almost five distal funicle segments combined.

Prothorax $1.2 \times$ wider than long, sides evenly, moderately rounded, widest slightly before middle; pronotum covered with irregular in size and shape punctures, interspaces more (laterally) or less (centre) convex, gradually becoming regular tubercles towards lateral wall of prothorax.

Elytra $1.3 \times$ longer than wide, sides moderately, evenly arched, widest in middle; declivity weakly sloped, apex visible from above; striae consist of large, well developed pits strikingly larger than pronotal punctures (twice as large as pronotal tubercles); interspaces clearly shorter than puncture diameter; interstices flat, much narrower than striae (but not zigzag-like), covered with irregular row of punctures and rather weakly developed rugosity, shiny; declivity densely covered with dark-brown, in part slightly raised, microscopic, barely perceptible hairs; outer interstices with recumbent hairs.

Legs relatively slender; dorsal margin of fore tibiae straight, apically not dilated; hind tibiae not excised, rather weakly extended ventrad apically; second segment of fore tarsus moderately transverse.

Aedeagus subparallel-sided, apically widely rounded (Fig. 32); laterally thick, weakly arched (Fig. 33). 
Female differs from male in: much wider, longitudinally stronger convex elytra; less robust legs.

\section{Etymology}

The name (adjective) is coined from the Latin noun corpusculum [= small body, particle] - an allusion to the minute body (the smallest Tecutinus species known to date).

Subgenus Fondajenus REITTER, 1912 (type species Otiorhynchus stierlini GEMMINGER, 1871)

The subgenus Fondajenus ReITTER, 1912 so far consists of 3 species (and one subspecies) (Magnano \& Alonso-Zarazaga, 2013). This is a poorly defined group (diagnostic characters, robust parallel-sided scape and median sulcus of rostrum not reaching frons are scattered among various subgenera) with unclear affinities. The two newly described species are certainly close relatives of forticornis STIERLIN, 1888, but crocotillus is placed here only provisionally.

\section{Otiorhynchus (Fondajenus) amplicornis sp. n.}

(Figs. 34-36)

\section{Material examined}

Holotype male, dissected: 01.06.2011 SW Turkey, Çiçek Dağı, NE Köyceğiz, leg. P. BIAŁOOKI [BIAL]. Paratype: as ht, 1 ex. [BIAL].

\section{Diagnostic description}

The new species (Fig. 34) is very similar and certainly closely related to forficulatus sp. $\mathrm{n}$. from which it differs in: somewhat smaller body (size range 8.4-8.5 mm; ht $8.4 \mathrm{~mm}$ ); pronotal tubercles slightly more strongly convex, relatively widely separated from each other, smaller (ca. 11 tubercles along midline); prothorax almost evenly arched at sides, widest only slightly before middle; elytra widest only somewhat before middle; median keel of rostrum not developed; much less robust funicle (Fig. 35); second funicle segment longer than first one; rostrum at smaller angle to frons; fore tibiae straight; aedeagus (Fig. 36); tubercles between strial punctures much smaller than on interstices; the latter distinctly narrower than width of interstices. 


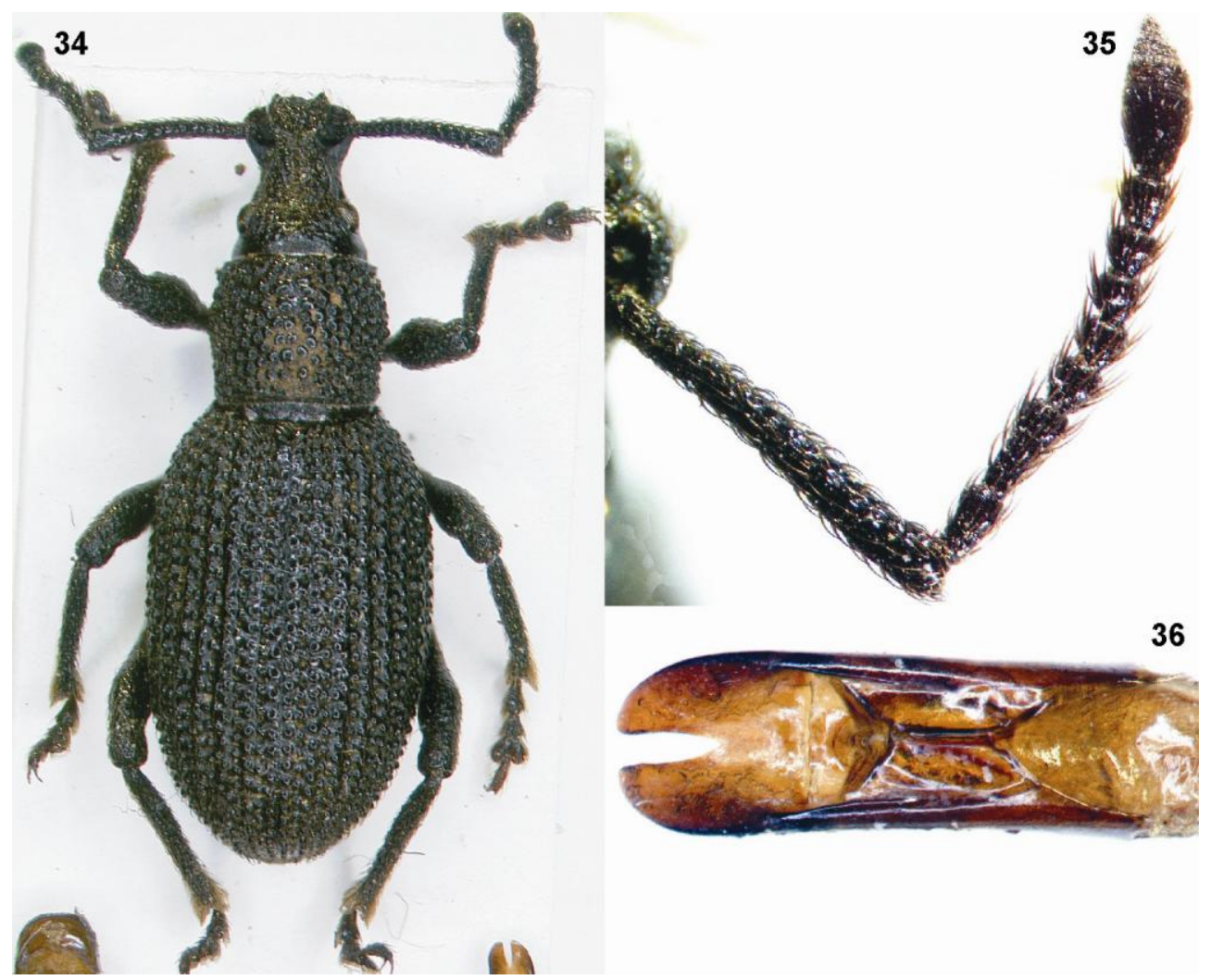

Figs. 34-36. O. (Fondajenus) amplicornis sp. n.: 34 - male habitus, 35 - male antenna, 36 - aedeagus dorsal view.

\section{Ecology}

The two known specimens were collected under stones at a place with extremely sparse vegetation at an altitude of ca. $2100 \mathrm{~m}$.

\section{Etymology}

The name is formed from the Latin words amplus [= large] and cornu [= horn, antenna] referring to the robust antennae. 


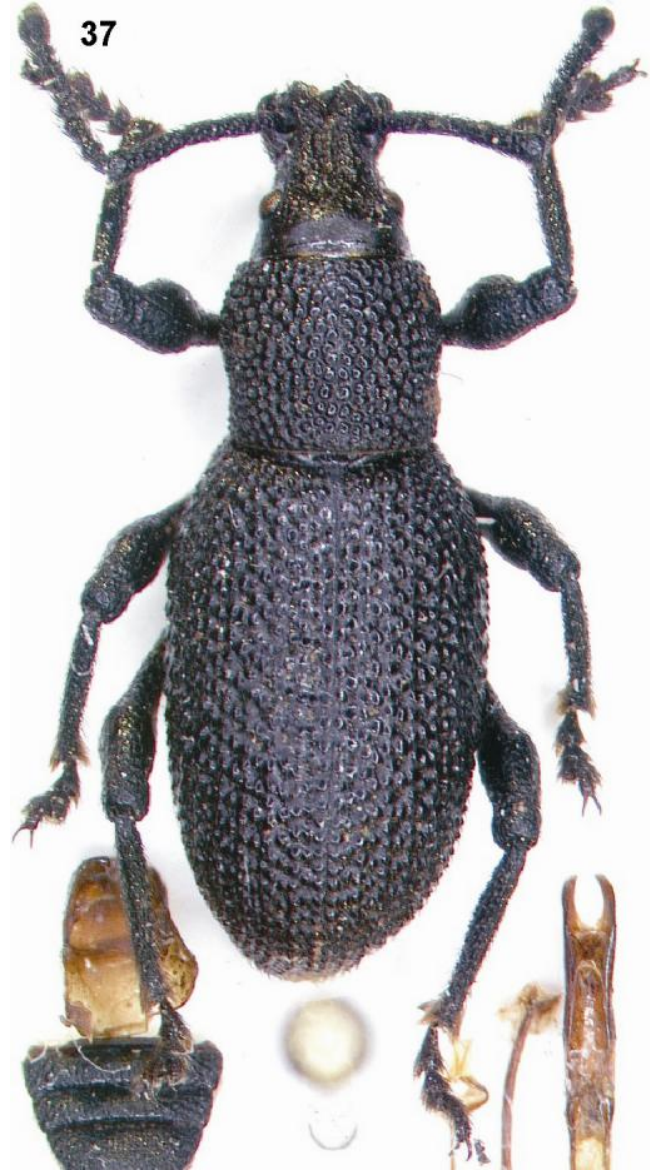

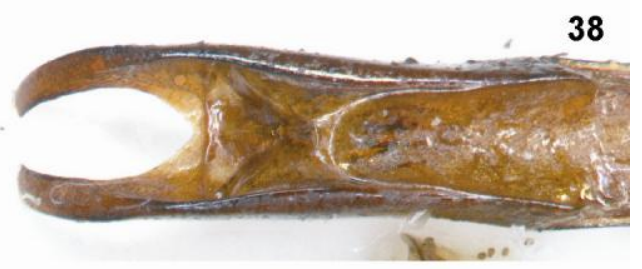

Figs. 37, 38. $O$. (Fondajenus) forficulatus sp. n.: 37 - male habitus, 38 - aedeagus dorsal view.

\section{Otiorhynchus (Fondajenus) forficulatus sp. n.}

(Figs. 37, 38)

\section{Material examined}

Holotype male, dissected: 21.05.2007 SW Turkey; Baba Dağı; SE Fethiye; leg. P. BIAŁOOKI [BIAL]. Paratypes: label as ht, 5 exx.I 26.05.2010 SW Turkey, Boncuk Dağları, Mt. 2418 m, N Fethiye, leg. P. BIAŁOOKI, 5 exx. [BIAL].

\section{Diagnosis}

The new species (Fig. 37) is very close to forticornis from which it differs in: epistome more elongate, narrower; rostrum evidently at angle to frons (in forticornis almost in one 
plane), median sulcus much deeper; funicle strikingly more slender; elytral sculpture; elytral hairs much longer. For differences between forficulatus $\mathrm{sp} . \mathrm{n}$. and implicatus $\mathrm{sp} . \mathrm{n}$., see diagnosis of the latter.

\section{Description (male)}

Body length 8.4-9.1 mm (ht $8.4 \mathrm{~mm}$ ); entirely black. Vestiture consists of sparse, dark brown to black recumbent hairs.

Head very strongly transverse; frons convex, covered with rather small, moderately dense punctures; frons fovea large and deep; eyes small, moderately convex, projecting.

Rostrum slightly transverse; pterygia large, strongly projecting; epistome triangular, delimited by well developed elevated margins, $2.9 \times$ narrower than pterygial span (in forticornis $2.6 \times$ ); dorsal wall relatively strongly constricted at antennal insertions, covered with punctures somewhat larger than on, and well separated from frons; median sulcus very wide and very shallow, with low, narrow median keel.

Antennae robust; scape hardly widened apicad; first two segments each $1.7 \times$ longer than broad, first slightly longer than second; third weakly transverse; 4-6 strongly transverse, segment 7 isodiametric, much longer than each of segments 4-6; club elongate fusiform, $2.55 \times$ longer than wide.

Prothorax $1.15 \times$ wider than long, at sides weakly evenly arched in apical half, basal half subparallel-sided; widest in apical third; pronotum covered with moderately small, moderately convex, subcontiguous tubercles; along midline on average 14 tubercles.

Elytra $1.55 \times$ longer than broad, ovate, widest in anterior third; interstices with large tubercles arranged in single rows, as broad as interstice width, in part fused to each other, strial punctures large, deep, as broad as interstice width, tubercles between strial punctures not strikingly smaller than tubercles on interstices.

Legs; all femora unarmed; fore tibiae clearly curved inwards; tarsi distinctly more slender.

Aedeagus (Fig. 38) similar to forticornis.

\section{Ecology}

All specimens were collected under stones or in the upper layer of soil in the alpine zone at an altitude of about 1900-2200 m.

\section{Etymology}

The name (adjective) intentionally refers to the dermapteran genus Forficula LiNNAEUS, 1758 , and alludes to the shape of the aedeagus resembling the abdominal forceps in that genus. 


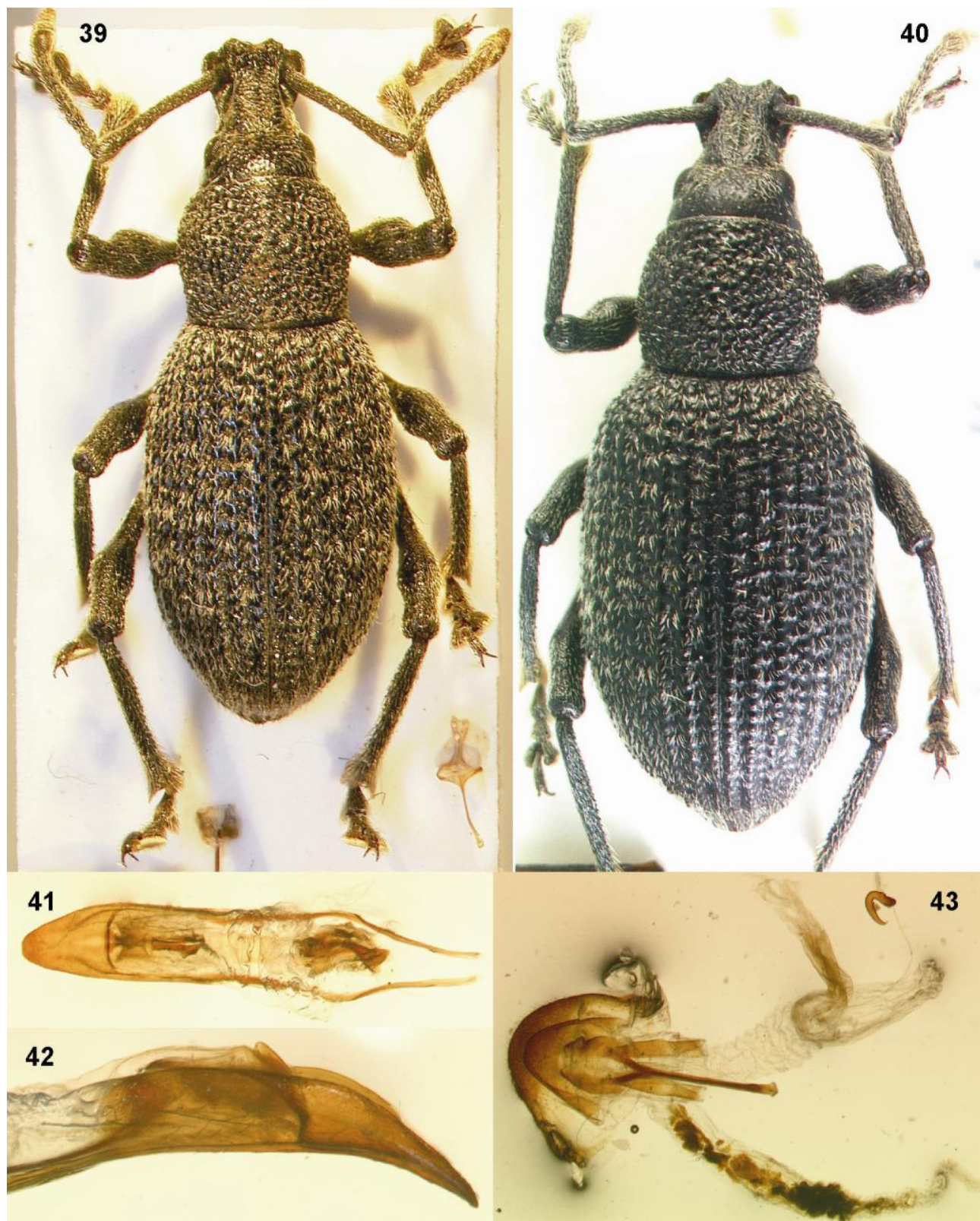

Figs. 39-43. $O$. (Fondajenus) crocotillus sp. n.: 39 - male habitus, 40 - female habitus, 41 - aedeagus dorsal view, 42 - aedeagus profile, 43 - female terminalia. 


\section{Otiorhynchus (Fondajenus) crocotillus $\mathbf{s p .} \mathbf{n}$.}

(Figs. 39-43)

\section{Material examined}

Holotype male dissected: 08.06.2012 C Greece, Mt. Timfristos NE Karpenisi, leg. P. BIAŁOOKI [BIAL]. Paratypes: as ht, 3 exx.I as ht but 09.06.2012, 5 exx.I as ht but 03.06.2016, 14 exx. [BIAL; WANA].

\section{Diagnosis}

This is a strange species (Fig. 39) which cannot be easily compared with any known species. The most striking characters are: frons distinctly separated from rostrum due to hind portion of dorsal wall of rostrum being strongly convex, bearing a striking resemblance to the subgenus Lolatismus in this respect; unusually long and slender legs; all femora unarmed; apex of median lobe of aedeagus not excised, elongate triangular. On the other hand, the species possesses some characters known in Fondajenus: elongate elytra; large pterygia; dorsal wall of rostrum strongly constricted at antennal insertions; stout, subparallel-sided scape; very robust funicle. At first glance the new species differs from forticornis in the head and rostrum being very strongly separated from each other.

\section{Description (male)}

Size range 8.4-9.7 $\mathrm{mm}$, ht $8.7 \mathrm{~mm}$; black; body covered with short, moderately dense light brown and greyish recumbent hairs, and slightly wider scales disposed into small unclear sparse, hardly perceptible spots on elytra.

Head strongly transverse; eyes rather small, moderately convex, projecting; frons slightly convex, covered with dense, moderately large punctures.

Rostrum very robust though slightly longer than wide; pterygia large, moderately projecting; dorsal wall with well-developed median keel, strongly convex in front of eyes, as a result rostrum strongly separate from head.

Antennae moderately robust; scape straight, robust, parallel-sided; second funicle segment somewhat longer than first; remaining segments subisodiametic; club elongate egg-shaped, longer than three distal funicle segments combined.

Prothorax $1.25 \times$ wider than long, rather weakly rounded at sides, widest before middle; pronotum covered with rather small, dense, moderately convex shiny tubercles; anterior margin subequally long as base; recumbent hairs very short, barely perceptible at small magnifications.

Elytra $1.6 \times$ longer than wide, elongate oval, widest in middle, longitudinally weakly evenly convex; striae consist of large, ill-defined, funnel-like punctures; interstices subequally wide as striae, flat, covered with microscopic, moderately dense punctures, with 
single row of shiny tubercles (similar to, but somewhat smaller than on pronotum); recumbent hairs distributed almost evenly; interstices with single row of slightly longer hairs, hardly distinguishable from general vestiture. First two ventrites rather shallowly impressed.

Legs long and slender; femora weakly swollen, unarmed; fore tibiae straight, only apically weakly curved inwards; mucro minute, weakly perceptible; second tarsal segment subisodiametric.

Aedeagus $2.2 \times$ longer than wide, much shorter than apodemes, parallel-sided, apex strongly tapering, tip rounded (Fig. 41); rather weakly arched (Fig. 42).

Female (Fig. 40) differs from male in: slightly wider elytra; first two ventrites not excavated.

$8^{\text {th }}$ sternite less than twice as short as spiculum ventrale, distally relatively strongly excised; spermatheca (Fig. 43).

\section{Ecology}

All specimens were collected under stones at an altitude above $2000 \mathrm{~m}$.

\section{Etymology}

The name is a Latin adjective [crocotillus = very slim, slender] to reflect the elongate body.

Subgenus Otismotilus REITTER, 1912 (type species Otiorhynchus granulatostriatus STIERLIN, 1876)

The subgenus Otismotilus consists of 21 (sub)species, mostly inhabiting the Caucasus; only four of them are known to occur in the easternmost part of the Pontic Mountains. $O$. crassiphallicus sp. n. described here was discovered in the western Pontic Mountains. However, the systematic position of this species has not been definitively established.

\section{Otiorhynchus (Otismotilus) crassiphallicus $\mathbf{s p .} \mathbf{n}$.}

(Figs. 44-48)

\section{Material examined}

Holotype male, dissected (onychium of left fore tarsus missing): Haut Iglaz [correctly: Ilgaz], Paphlagonia, A. M. STANĚ K [NMP]. Paratypes: 38 exx. with the same label [NMP; BIAL]. 


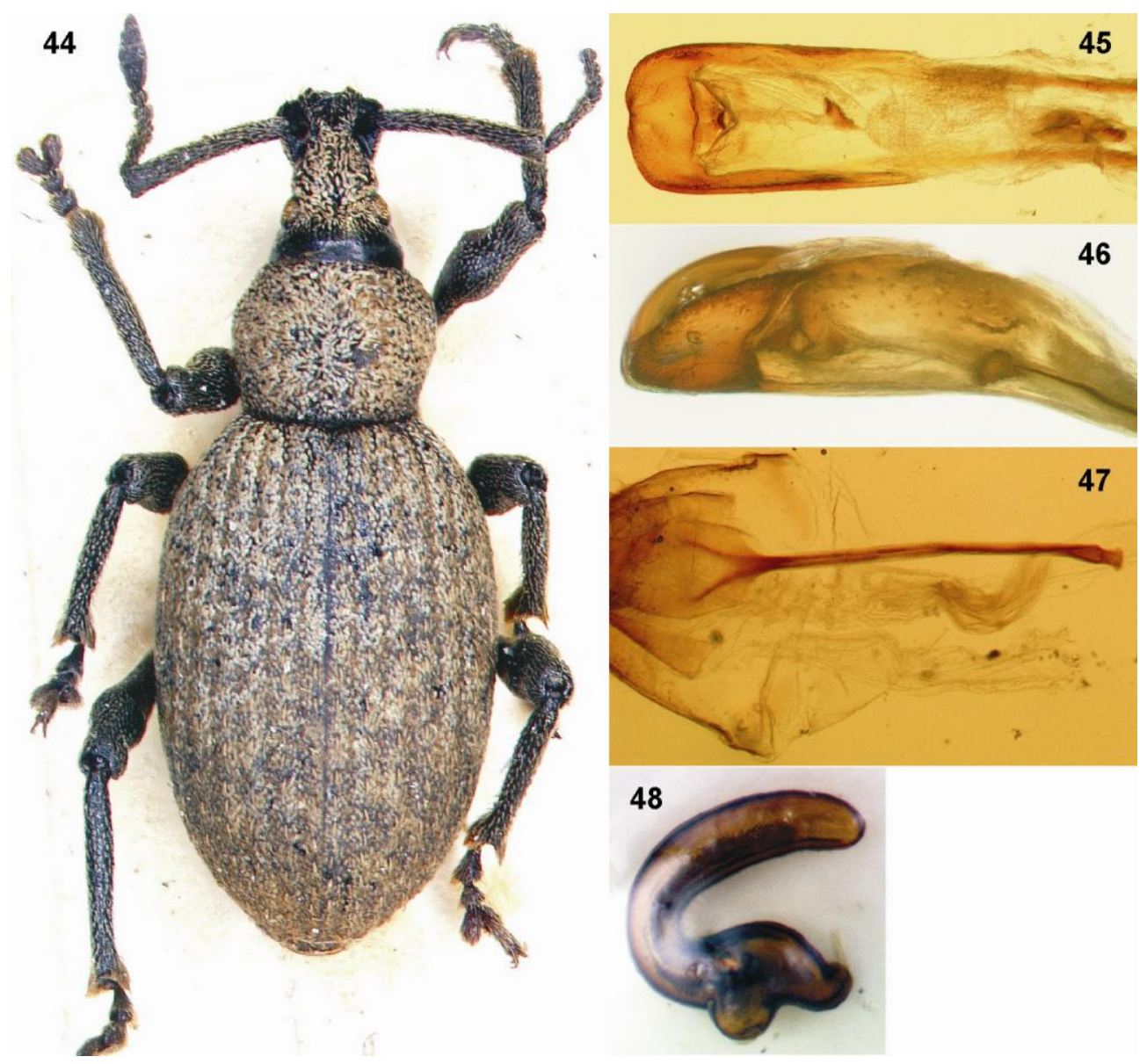

Figs. 44-48. $O$. (Otismotilus) crassiphallicus sp. n.: 44 - male habitus, 45 - aedeagus dorsal view, 46 - aedeagus profile, 47 - female $8^{\text {th }}$ sternite, 48 - spermatheca.

\section{Diagnosis}

This is a very peculiar species (Fig 44), readily recognizable by the following characters: strongly elongated rostrum, its basal portion arcuate at sides in dorsal view; pronotum and elytra covered with recumbent scales completely obscuring body surface; dorsal surface of rostrum strongly constricted at antennal insertions; peculiar aedeagus. It differs moreover, from chaudoirii HoCHHUT, 1851 in: odd interstices equally convex as even ones; longer rostrum; more elongate elytra; strikingly more robust scape; more transverse prothorax, and from granulatostriatus Stierlin, 1876 mainly in the more convex eyes, the more strongly transverse prothorax and the thicker scape. 


\section{Description (male)}

Size range 5.3-6.8 $\mathrm{mm}$ (ht $6.5 \mathrm{~mm}$ ); entirely dark brown to black, tarsi red-brown; vestiture light brown.

Head small, clearly separated from rostrum; frons somewhat convex transversally, longitudinally nearly flat, covered with dense, shallow, small punctures and with dense, weakly elongate recumbent scales, and with small number of elongate, somewhat raised scales; frons fovea large, very much bigger than surrounding punctation, elongate; eyes hardly convex, slightly projecting.

Rostrum $1.1 \times$ longer than broad; basal portion strongly tapered (frons $1.6 \times$ wider than dorsal wall between antennal insertions), with well expressed median sulcus, lateral margins completely unclear, in dorsal view arcuate at sides; pterygia large, moderately strongly projecting, pterygial span $1.55 \times$ broader than frons; dorsal wall between pterygia distinctly declivent; epistome large, subsemicircular, hollowed, strongly declivent, its anterior margin somewhat excised.

Antennae robust, scape abruptly expanded at base, then subparallel-sided, without apical swelling, hardly arcuate, covered with small, dense, arcuate, recumbent hair-like scales; first funicle segment $2.4 \times$ longer than broad, second one $3 \times$ longer than wide, somewhat thinner than segment 1 ; segments 3-4 (sub)isodiametric, 5-7 rather strongly transverse; club $2.5 \times$ longer than broad.

Prothorax small, $1.2 \times$ broader than long, at sides rather strongly rounded, broadest in anterior third; disc covered with dense small recumbent subcircular and weakly elongate scales obscuring completely integument; rather weakly raised, sparse longer scales hardly visible.

Elytra $1.5 \times$ longer than broad, regularly oval, broadest somewhat before middle, declivity less than perpendicular, thus apex visible from above; striae clearly though weakly impressed, furrow-like, punctures hardly perceptible; both striae and interstices covered with very dense recumbent scales resembling pronotal ones but distinctly smaller; interstices with single row of semierect, weakly arcuate scales $3 \times$ longer than wide.

Legs moderately long, robust, covered with dense recumbent minute hair-like scales; all femora unarmed; fore tibiae with dorsal margin straight, clearly expanded apicad, mucro small, obscured by vestiture; tarsi robust, second segment strongly transverse; hind tarsi less robust, second segment weakly transverse.

Aedeagus small, somewhat more than $2 \times$ longer than broad, parallel-sided, apex broadly rounded, slightly narrowly excised (Fig. 45); in lateral view very thick (Fig. 46).

Female differs from male in: more slender legs; shorter, broader elytra; first two ventrites flat; last ventrite flat, with no trace of subapical fovea.

$8^{\text {th }}$ sternite (Fig. 47) short-oval, ca. $2.65 \times$ shorter than spiculum ventrale; the latter with caput weakly expressed; spermatheca (Fig. 48). 


\section{Etymology}

The name - an adjective derived from the Latin crassus [=thick] and the latinized Greek $\varphi \alpha \lambda \lambda \varsigma_{\varsigma}[=$ phallus $\left.]\right)-$ refers to the unusually thick aedeagus.

Subgenus Odelengus ReITTER, 1912 (type species Otiorhynchus aberrans STIERLIN, 1876)

The subgenus Odelengus REITTER, 1912, until recently monotypical, was re-defined by BIAŁOOKI (2015a), raising the number of species to five. DAVIDIAN \& GÜLTEKIN (2016) transferred another species into Odelengus and described two further species, as a result of which eight species have been classified in this subgenus so far. The further nine new species described in this paper raise the number of species to seventeen.

\section{Otiorhynchus (Odelengus) wanati sp. n.}

(Figs. 49-51)

\section{Material examined}

Holotype male, dissected: 17.05.2008 SW Turkey; Mt. 2030 m E Çetmi; SE Taşkent; leg. P. BiaŁOOKi [WANA]. Paratypes: as ht, 10 exx.I 18.05.2008 SW Turkey; Yunt Dağ1; SW Ermenek; leg. P. BIAŁOOKI, 6 exx. [BIAL; WANA].

\section{Diagnosis}

The new species (Fig. 49) is very similar to judaicus STIERLIN, 1875 from which it differs (data concerning this species in parentheses) mainly in the following characters: more slender antennae, funicle segments 3-4 subisodiametric, 5-7 moderately transverse (segments 3-7 strongly transverse); less sculptured, shinier body; fore tibiae of males at apex not at all expanded outwards, rounded (apex relatively strongly expanded outwards); structure of male and female genitalia.

\section{Description (male)}

Size range 3.3-4.1 mm, ht $3.9 \mathrm{~mm}$; black, antenna and legs in part dark brown.

Head moderately transverse, relatively narrow, at sides hardly arched; frons covered with small dense punctures; frons fovea large and deep; eyes weakly convex, not projecting. 


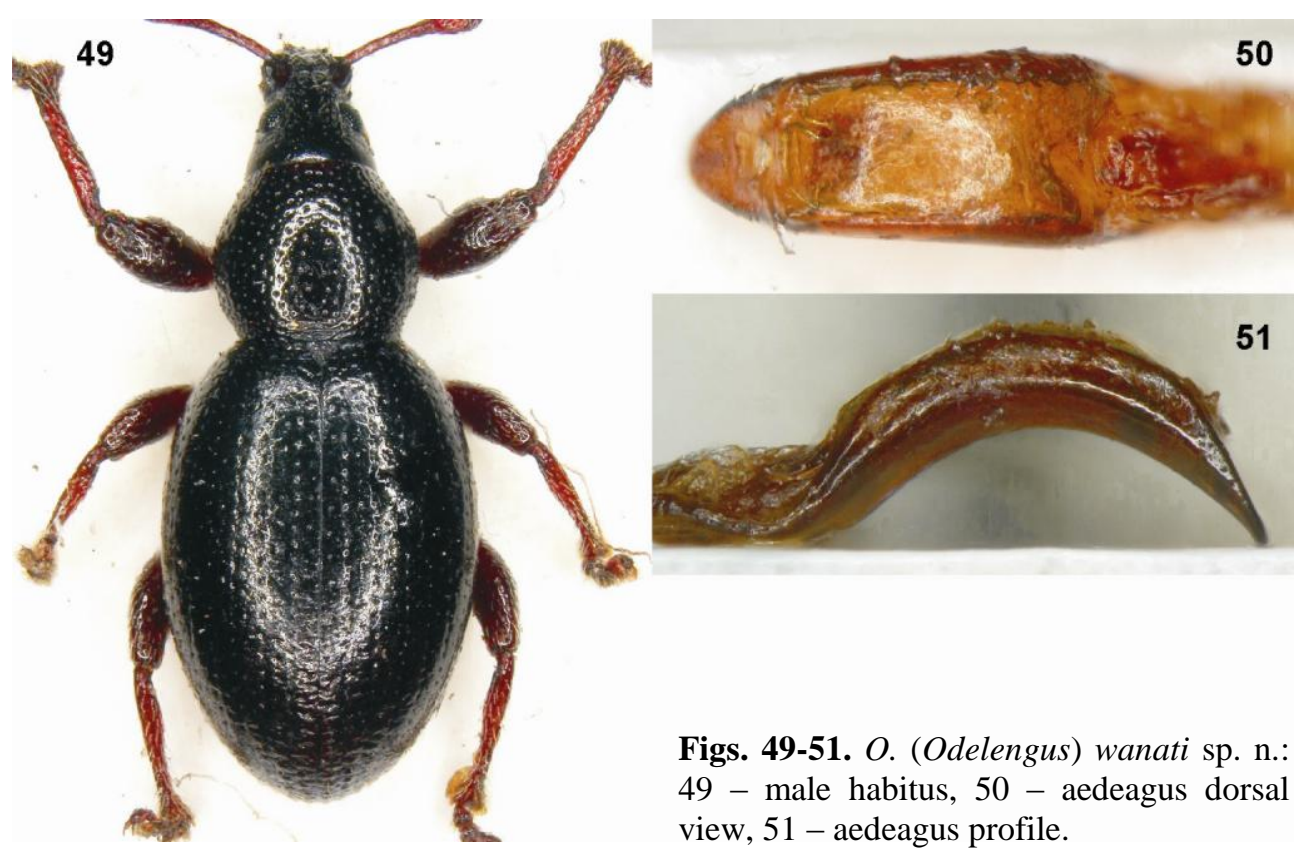

Rostrum slightly elongate, indistinctly widened apicad; pterygia small, not at all projecting; dorsal wall indistinctly stronger convex than frons, weakly tapering, with welldeveloped median keel between relatively well-developed epistome and frons fovea; apical portion of dorsal wall delimited posteriorly by triangular protuberance.

Antennae relatively slender; scape weakly evenly arched, basal two thirds weakly evenly thickened, apical portion much stronger swollen; first funicle segment $2 \times$ longer than wide, $1.35 \times$ longer than second; second segment $1.7 \times$ longer than wide; third slightly elongate; 4-5 slightly transverse; segments 6-7 moderately transverse; club $2.1 \times$ longer than wide, ovate, apically narrowly tapering.

Prothorax slightly transverse, at sides rather weakly evenly arched, widest in middle; pronotum covered with rather small punctures, interspaces subequally wide as punctures diameter, covered with submicroscopic pinholes, shining; impunctate area moderately wide, ca. 4-5 $\times$ wider than puncture diameter; recumbent sparse hairs brown weakly perceptible, better visible on lateroventral wall of prothorax.

Elytra a little less than $1.4 \times$ longer than wide, ovate, widest before middle; striae composed of punctures slightly larger than pronotal; interstices covered irregularly with practically identical punctures, as a result elytra seem evenly but chaotically punctate; interspaces flat and shiny; steep portion of declivity with long greyish semierect hairs, punctures replaced by minute, relatively weakly convex tubercles. 
Legs moderately slender; all femora unarmed although fore ones with hardly perceptible trace of protuberance; fore tibiae slightly curved ventrad, not at all dilated outwards apically; ventral margin devoid of spines; tarsi moderately robust, second segment moderately transverse.

Aedeagus (Fig. 50) much broader than in judaicus, tapering in apical half, apex without subparallel-sided, separated process; in lateral view (Fig. 51).

Females differ from males in somewhat broader body; almost straight fore tibiae, strongly expanded outwards at apex.

Bursa copulatrix with large sclerotization.

\section{Ecology}

All specimens were collected under stones at an altitude of about 1800-2000 m.

\section{Etymology}

The new species is dedicated to the Polish prominent specialist in world Apionidae, Prof. Marek WANAT (Wroclaw University).

\section{Otiorhynchus (Odelengus) cappadocicus sp. $\mathbf{n}$.}

(Figs. 52-56)

\section{Material examined}

Holotype male, dissected: 24.05.2009 C Turkey; Sekkin Geçidi: NW Niğde; leg. P. BIAŁOOKI [BIAL]. Paratypes: as ht, 8 exx. [BIAL] Ihlara; 1.5.[19]79/ Turkey centr.; distr. Niğde; Dr. N. Lodos lgt./ n.sp. aff. judaicus [MERE].। Turkey, [19]90.IV.17 Konya: Yunuslar leg. PodlussánY A./ Otiorhynchus judaicus Stierl. det. A. PodLussánY/ Coll. A. PodLUSSÁNY [PODL].

\section{Diagnosis (male)}

The new species (Fig. 52) is most similar to O. porculus $\mathbf{s p .}$. n. - both species share large, distinctly projecting pterygia and elytra covered with a well-developed vestiture. The two species are known to occur at low elevations in the same region of Turkey, whereas the large majority of species are typically high-alpine species. The new species differs from $O$. porculus in: much smaller body; strikingly shorter, less protruding vestiture; less convex, almost flat eyes; funicle segments 3-7 strongly transverse; aedeagus.

\section{Description (male)}

Size range 3.7-4.4 mm, ht $3.9 \mathrm{~mm}$; entirely brown, legs in part red-brown. 


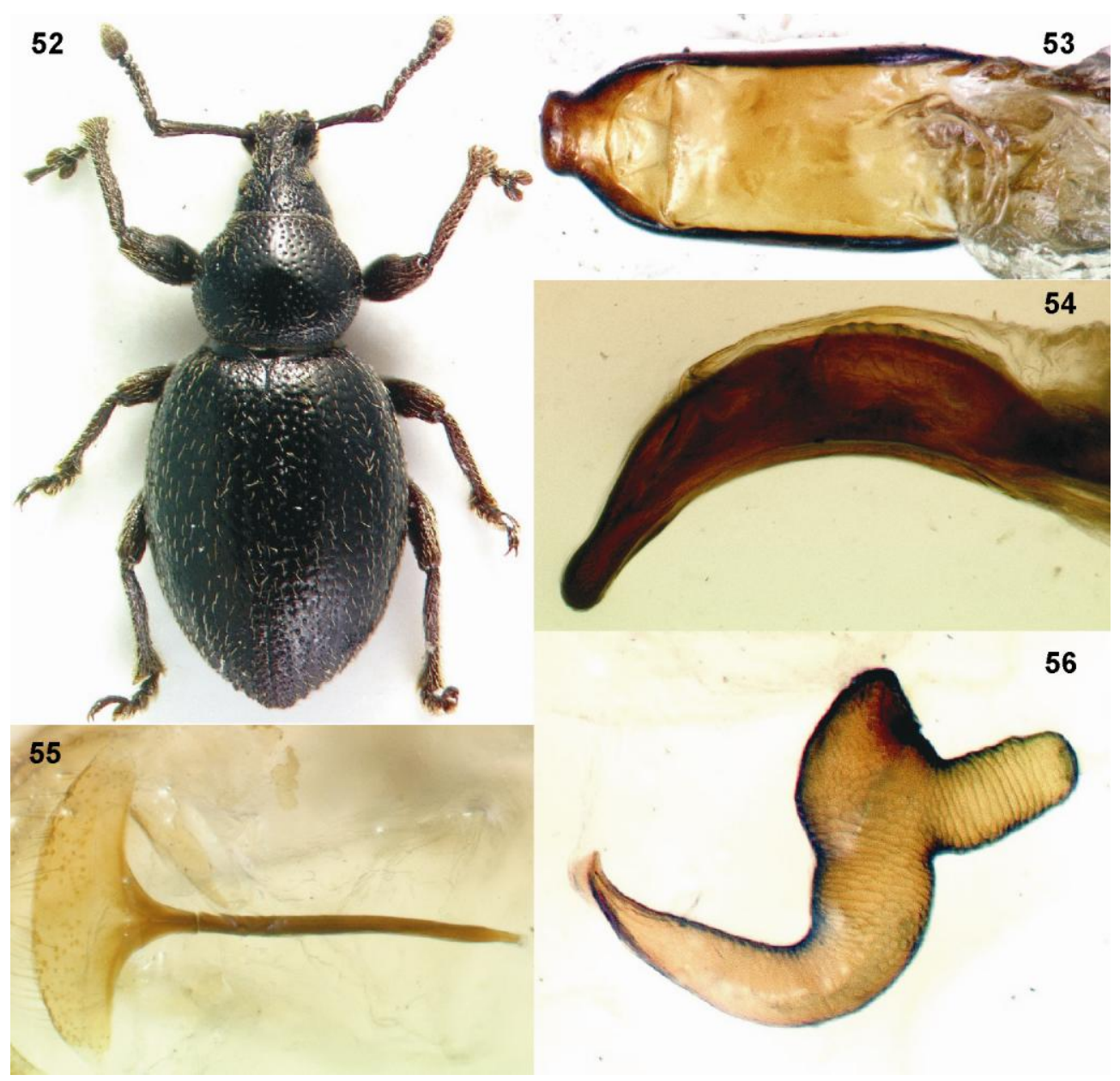

Figs. 52-55. $O$. (Odelengus) cappadocicus sp. n.: 52 - male habitus, 53 - aedeagus dorsal view, 54 - aedeagus profile, 55 - female $8^{\text {th }}$ sternite, 56 - spermatheca.

Head transverse, rather strongly tapering, densely punctate with small punctures; eyes weakly convex, not projecting.

Rostrum subisodiametric; pterygia moderately large, distinctly projecting; dorsal wall of rostrum with relatively dense and long vestiture; median keel in part obscured by vestiture.

Antennae; scape hardly arched, rather thin, only apex strongly thickened; first funicle segment as long as next two segments combined, thick; segments 3-7 strongly transverse, gradually wider; club shortly egg-shaped, relatively large, longer than three distal funicle segments combined. 
Prothorax $1.35 \times$ wider than long, at sides very strongly arched, widest in middle, anterior margin subequally long as base; pronotum sparsely punctate with large impunctate area, shining.

Elytra $1.25 \times$ longer than wide; declivity strongly bent under; first interstice on apical declivity covered with minute and very dense tubercles; punctures of elytral striae small; interstices slightly convex, punctures subequally large as strial ones; covered with moderately dense, moderately long, weakly raised or recumbent hairs shorter than width of interstices, distributed irregularly.

Legs. All femora unarmed; dorsal margin of fore tibiae straight, apically indistinctly expanded dorsad; fore tarsi large and robust, second segment moderately transverse; hind tarsi distinctly smaller than fore ones.

Aedeagus $2.4 \times$ longer than wide; narrow, subparallel-sided along its entire length, except for subparallel-sided apex (Fig. 53), in lateral view (Fig. 54).

Female differs from male in: larger body; elytra slightly more robust, apically tapering more strongly; apex of fore tibiae more strongly expanded outwards; all tarsi much smaller.

$8^{\text {th }}$ sternite (Fig. 55); spermatheca (Fig. 56).

\section{Etymology}

The name is an adjective referring to Cappadocia, a historical region in central Anatolia, where the new species occurs.

Otiorhynchus (Odelengus) crepuscularis $\mathbf{s p .} \mathbf{n}$.

(Figs. 57-61)

\section{Material examined}

Holotype male, dissected: 24.05.2008 SW Turkey; Karacadağ; E Karapinar; leg. P. BIAŁOOKI [BIAL]. Paratypes: as ht, 13 exx. [BIAL; WANA].

\section{Diagnosis}

The new species (Fig. 57) is characterized by: large body; peculiar punctation of pronotum; relatively large, strongly projecting pterygia; fore femora with hardly perceptible acute tubercle. The new species differs from all remaining species of the genus in the unique relief of the pronotal disc. From $O$. porculus sp. n. it also differs in the body covered with minute, weakly visible sparse hairs, and from $O$. malinkai sp. n. in the straight fore tibiae and smaller strial punctures. 


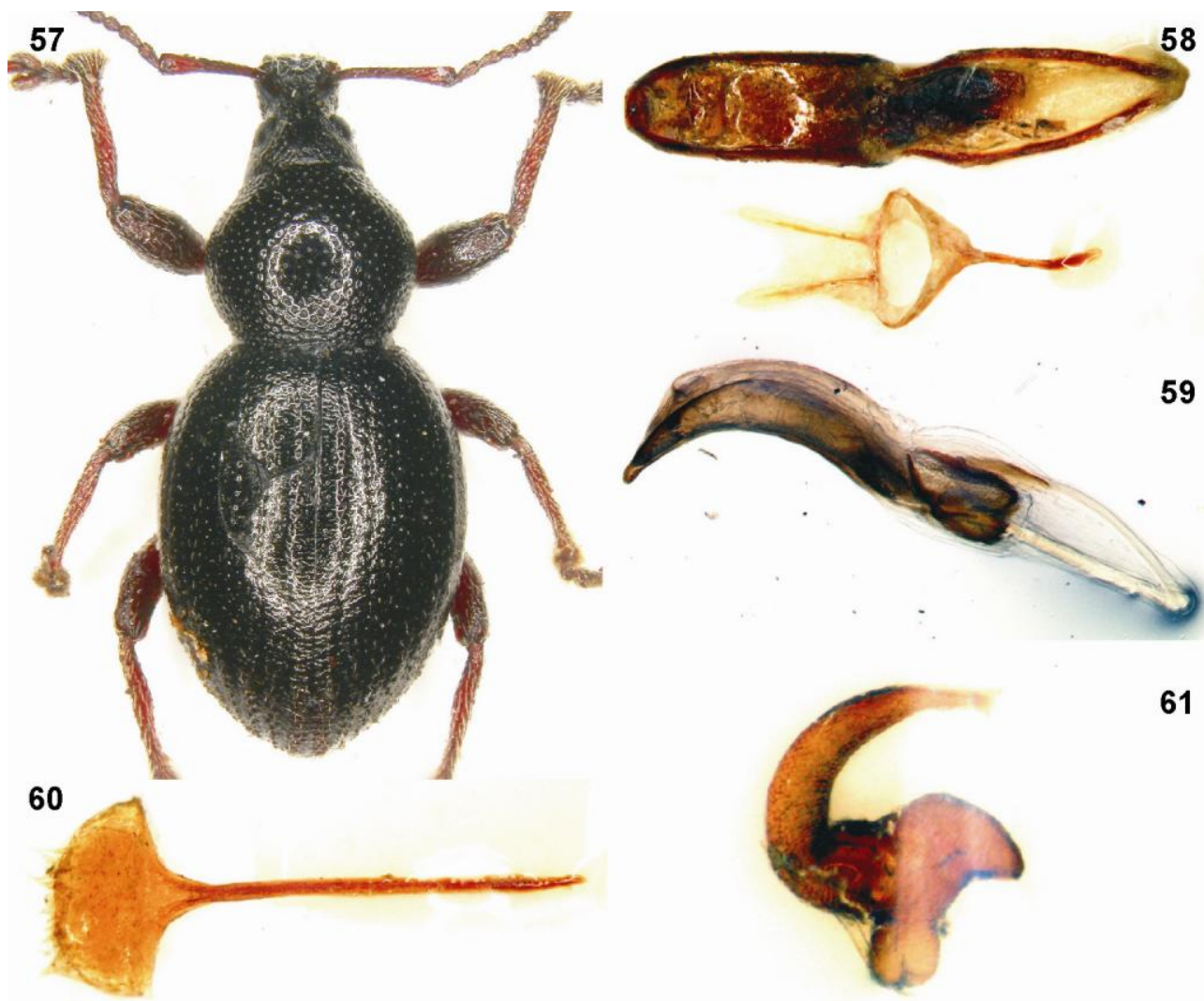

Figs. 57-61. O. (Odelengus) crepuscularis sp. n.: 57 - male habitus, 58 - aedeagus and tegmen dorsal view, 59 - aedeagus profile, 60 - female $8^{\text {th }}$ sternite, 61 - spermatheca.

\section{Description (male)}

Size range 5.3-6.7 $\mathrm{mm}$ (ht $5.4 \mathrm{~mm}$ ); black, tibiae, tarsi and antennae much lighter, brown; very shiny, covered with sparse, minute, recumbent hairs.

Head wide, short, subglobose, covered with dense punctation, short, weakly raised hairs; frons at an angle to rostrum, $1.5 \times$ wider than eye diameter; frons fovea small, not larger than surrounding punctation; temples about as long as eye diameter; vertex with punctation in part forming short longitudinal ribs.

Rostrum subisodiametric; mandibles large, subcircular; pterygia moderately expanded outwards, $1.2 \times$ as broad as rostrum minimum width, well distant from anterior margin of rostrum; elevated edge between antennal insertions; dorsal wall of basal part of rostrum tapering strongly, with no clear lateral margins, covered with rather large punctures; median keel well developed; dorsal wall of rostrum anteriad of antennal insertions 
somewhat divergent anteriad, weakly declivent; epistomal angles strongly elevated above anterior portion of rostrum.

Prothorax weakly transverse, $1.15 \times$ broader than long, strongly rounded at sides, anterior margin distinctly shorter than base, broadest somewhat behind middle; covered with minute, dense tubercles and minute, recumbent hairs directed to centre of disc; disc with extremely flat, sometimes in part scarcely perceptible tubercles, appears punctate; basis of disc always with well-developed tubercles, whereas anterior portion with regular punctation.

Elytra $1.25 \times$ longer than wide, clearly broadest before middle, strongly convex in both directions, apical portion much less arcuate, somewhat acute; striae not impressed, punctures small, interspaces longer than diameter of punctures; interstices several times broader than striae, flat, with weak leather-like sculpture, very shiny, sparsely, irregularly punctate, punctures much smaller than strial ones, subequal to punctation of pronotal disc, covered with minute, sparse, hardly raised hairs; within declivity with well-developed, small, convex tubercles distributed irregularly, only in close to apex in single rows; first interstice within apical declivity somewhat elevated, covered with tubercles distributed irregularly and distinctly denser than on remaining interstices.

Legs. Fore femora with hardly visible, tubercle-like tooth; remaining femora unarmed; dorsal margin of fore tibiae strongly expanded outwards at apex, ventral margins dentate, with long hairs.

Aedeagus robust, $2.35 \times$ longer than wide, broadest basally, then regularly, rather weakly tapered; apex in the form of very short, not very clear, subrectangular appendix; tegmen (Fig. 58); in lateral view (Fig. 59).

Female differs from male on average by its larger body; pterygia less projecting.

Spermatheca typically sickle-shaped; spiculum ventrale bifurcated into strongly bent aside arms of margo basalis, lamina short, transverse, apical margin regularly arcuate, with long hairs (Fig. 60); spermatheca (Fig. 61)

\section{Ecology}

All specimens were collected under stones at an altitude above $2000 \mathrm{~m}$.

\section{Etymology}

The specific epithet (adjective) was coined from the Latin crepusculum [= dusk], an allusion to the collecting circumstances. 


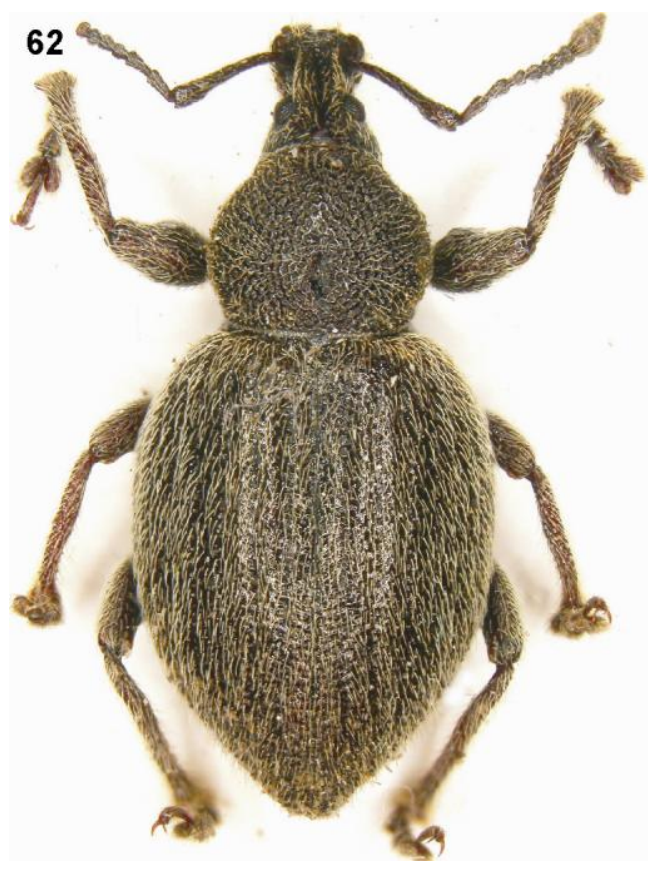

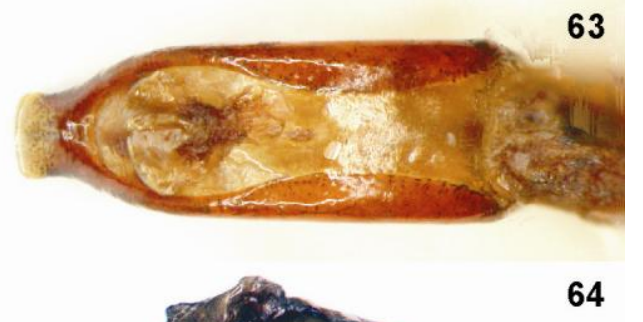

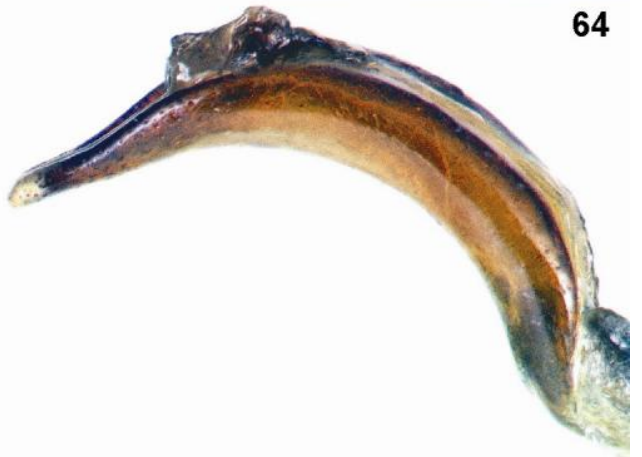

Figs. 62-64. O. (Odelengus) porculus sp. n.: 62 - male habitus, 63 - aedeagus dorsal view, 64 - aedeagus profile.

Otiorhynchus (Odelengus) porculus sp. n.

(Figs. 62-64)

\section{Material examined}

Holotype male, dissected [left funicle segment 7 and club, left middle and right fore onychium missing]: 30.04.1998 W Turkey; Aksaray env.; leg. P. BIAŁOOKI [BIAL].

\section{Diagnosis}

A very peculiar species (Fig. 62), at first glance easily recognizable by several unique features: large body; long, slender rostrum; rather coarse, very dense pronotal punctation; and especially by extraordinary long and dense pubescence of the body, not arranged into single rows on elytral interstices. The majority of congeners are significantly smaller. The subequally large crepuscularis sp. n. differs, among other things, from porculus in the drastically less developed vestiture, and the pronotum covered with very sparse minute punctures.

\section{Description (male)}

Body length $6.2 \mathrm{~mm}$; entirely black, only claws brown; covered with white-grey hairlike scales. 
Head densely, rather coarsely punctured, covered with long, semiprotruding hair-like scales; frons not separated from rostrum, distinctly convex transversally, as broad as eye diameter; frons fovea rather large and deep; eyes moderately convex, not projecting from head outline in dorsal view.

Rostrum subisodiametric; pterygia large, relatively strongly projecting, span $1.3 \times$ broader than rostrum minimum width; median keel well-developed; covered with dense, coarse punctation and long, semiprotruding hair-like scales directed backwards; anterior part of dorsal wall of rostrum strongly declivent, almost bare; edge between basal and distal portions of dorsal wall of rostrum v-shaped, sharp, strongly elevated, much higher than median keel.

Antennae moderately long and slender; scape rather strongly thickened apically, covered with thin, semiprotruding, strongly arched hair-like scales; first funicle segment more than twice as long as wide, second one twice as long as broad, third segment $1.4 \times$ longer than wide, segment 4 weakly elongate, segments 5-7 transverse, gradually wider, segment 7 strongly transverse; club large, with acute apex, $2.1 \times$ longer than broad, as long as four last funicle segments combined.

Pronotum $1.25 \times$ broader than long, at sides rather strongly arcuate, broadest somewhat behind middle, anterior margin much narrower than base; disc rather weakly convex in both directions, covered with very dense, not small punctures, interspaces thin, strikingly shorter than diameter of punctures; each puncture with long, semiprotruding hair-like scale; impunctate midline weakly expressed only in central part of disc.

Elytra $1.3 \times$ longer than wide, broadest before middle; in lateral view weakly convex, declivity very strongly vaulted, almost semicircular; striae clearly impressed, consist of punctures distinctly smaller than punctures on pronotal disc, interspaces somewhat longer than puncture diameter; interstices broad, $3-4 \times$ broader than striae, slightly convex, covered with dense, irregularly arranged rasp-like punctures, somewhat smaller than punctures in striae, replaced in apical half of elytra by single row of small, convex tubercles; interspaces irregularly rugose, shiny; both striae and interstices covered with dense, long, arcuate, semiprotruding hair-like scales, strongly bent backwards, distributed quite irregularly; interstices 1-4 within apical declivity covered very densely, irregularly with minute, strongly convex tubercles (instead of punctures).

Legs moderately long; all femora unarmed; fore tibiae long, outer margin straight, apex weakly, but clearly expanding outwards; inner margin with rather large, acute spines, and long, semiprotruding, almost straight hair-like scales; tarsi slender, second segment elongate, third subisodiametric.

Ventral part of body covered with the same, but more recumbent pubescence as dorsal part. 
Aedeagus relatively short, less than $3 \times$ longer than wide, strongly sclerotized, subparallel-sided, tapered anteriad into relatively large subrectangular process (Fig. 63); in lateral view strongly, regularly arcuate (Fig. 64).

The only known specimen was swept during the night in the dry steppe of the plains surrounding Lake Tuz at an altitude of ca. $950 \mathrm{~m}$.

\section{Etymology}

The name is a noun in apposition - the Latin porculus means "a little pig".

\section{Otiorhynchus (Odelengus) armentalis sp. n.}

(Figs. 65-69)

\section{Material examined}

Holotype male, dissected: 23.05.2009 C Turkey; Sivrihisar Geçidi; SE Aksaray; leg. P. BIAŁOOKI [BIAL]. Paratypes: as ht, 13 exx.I same, but 08.06.2010, 4 exx. [BIAL; WANA] TR mer., province Niğde, Orhaniye, Çamardi env., 19.5.2005, Ala Dağlar Mts., J. VAVRA leg., 1800-2200 m, 1 ex. [VAVR].

\section{Diagnosis}

The new species (Fig. 65) is unique within the group because of the following characters: middle and hind femora dentate, and profemora with additional minute, 1-2 well-visible denticle(s), except for minute, but regular femoral tooth; large body. Most probably this is the closest relative of the very similar agmentosus sp. n. which, however, is easily distinguishable from armentalis in: single tooth on fore femora; elytral striae not impressed, strial punctures subequally large as punctation of interstices, resulting in almost uniform punctation of elytra; and in the genitalia of both sexes. $O$. crepuscularis differs from armentalis, among other things, in: profemora with single minute tooth, middle and hind femora unarmed; pterygia less projecting; pronotum clearly transverse, more arcuate at sides, disc with flat, hardly recognizable tubercles, without distinct impunctate midline; aedeagus.

\section{Description (male)}

Size range 5.3-6.5 mm (ht $5.3 \mathrm{~mm}$ ), entirely dark brown or black, legs and antennae somewhat lighter. Vestiture consists of minute, recumbent, rather sparse hairs.

Head covered with moderately big, moderately dense punctures, and with minute, recumbent, sparse hairs; frons hardly separated from rostrum; frons fovea scarcely perceptible; eyes moderately convex, slightly projecting. 


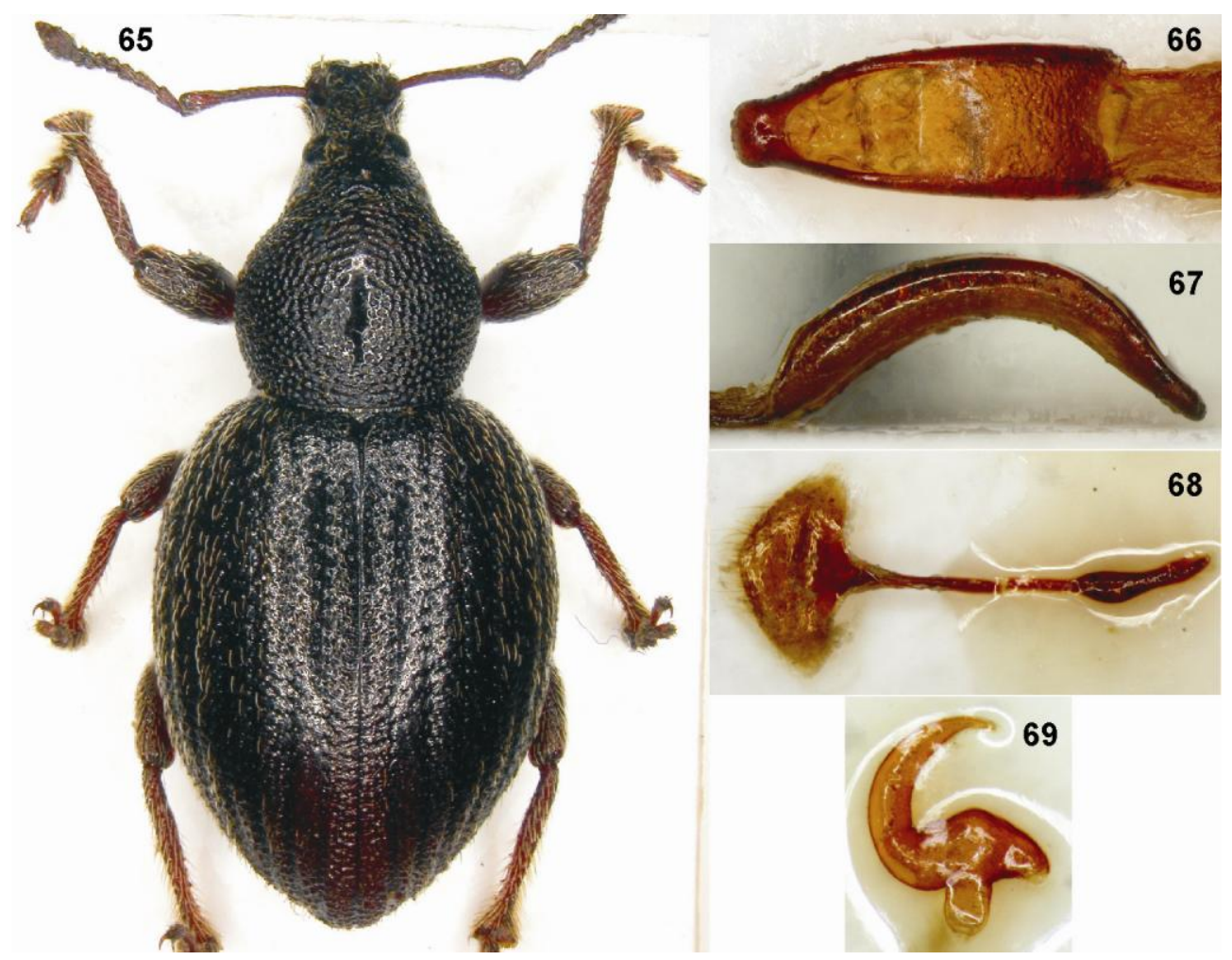

Figs. 65-69. O. (Odelengus) armentalis sp. n. 65 - male habitus, 66 - aedeagus dorsal view, 67 - aedeagus profile, 68 - female $8^{\text {th }}$ sternite, 69 - spermatheca.

Rostrum slightly longer than wide, between eyes and pterygia subparallel-sided; pterygia large, distinctly projecting, $1.35 \times$ broader than minimum rostrum width; covered with irregular, dense, small punctures and with short, sparse, recumbent hairs; median keel and lateral margins well developed.

Antennae slender: scape weakly, evenly expanding in basal portion, apically much more strongly swollen; first two funicle segments $1.7 \times$ longer than broad; segments 3-4 subisodiametric; 5-6 weakly transverse; segment 7 moderately transverse, distinctly broader than preceding segment; club $2.1 \times$ longer than broad, as long as 3.5 distal funicle segments combined.

Pronotum subisodiametric, slightly transverse, moderately rounded at sides, broadest in middle; moderately convex both transversally and longitudinally; anterior margin distinctly shorter than base; disc covered with flattened small tubercles irregular in shape and size, in part fused into irregular, flat, longitudinal ribs; impunctate area well expressed, fusiform, 
limited to the central portion of disc, slightly elevated, shiny, covered with sparse, microscopic pinholes; vestiture consists of sparse, minute, thin, short, recumbent hairs.

Elytra $1.15 \times$ longer than wide, at sides regularly arcuate in dorsal view, apex weakly acute; broadest in middle; in lateral view regularly, rather weakly convex, declivity strongly bent under; striae somewhat impressed, punctures moderately large, interspaces 2-3 $\times$ longer than puncture diameter; interstices $2-3 \times$ broader than striae, slightly convex, covered with moderately dense, small punctures clearly smaller than punctation around pronotal impunctate area, 3-4 $\times$ smaller than strial punctures, and with leather-like sculpture, and microscopic, sparse pinholes; vestiture consists of rather short, recumbent, moderately sparse hairs.

Legs long and slender; profemora with rather small tooth and additional 1-2 smaller denticle(s); middle femora with tooth smaller, but well visible; hind femora with 2-3 minute, weakly perceptible denticles; protibia slender, ventral margin deeply bisinuate, with several spines; mucro rather small; dorsal margin straight; apex distinctly expanded outwards and much more inwards; second tarsal segment weakly transverse.

Aedeagus $2.6 \times$ longer than wide, basal half subparallel-sided; apical half moderately, regularly convexly tapering, apex subrectangular, transverse (Fig. 66); in lateral view subequally broad along its entire length except for regularly tapering and slightly recurved apex (Fig. 67).

Females differ from males in: larger body; slightly broader pronotum and elytra; shorter, broader rostrum; apex of protibiae much stronger expanded outwards.

$8^{\text {th }}$ sternite (Fig. 68 ), ca. $2 \times$ broader than long, distal margin arcuate, indistinctly, obtusely angulate medially, with dense, moderately long hairs; spermatheca with somewhat inflated corpus; cornu strongly tapering, heavily spread out from corpus; ramus large, spread out from corpus towards base of cornu (Fig. 69).

\section{Ecology}

All specimens at both locations were collected under stones, at an altitude above 2000 $\mathrm{m}$.

\section{Etymology}

Latin adjective armentalis means "connected with cattle, herds; bucolic" - an allusion to the habitat of the new species (alpine pastures). 


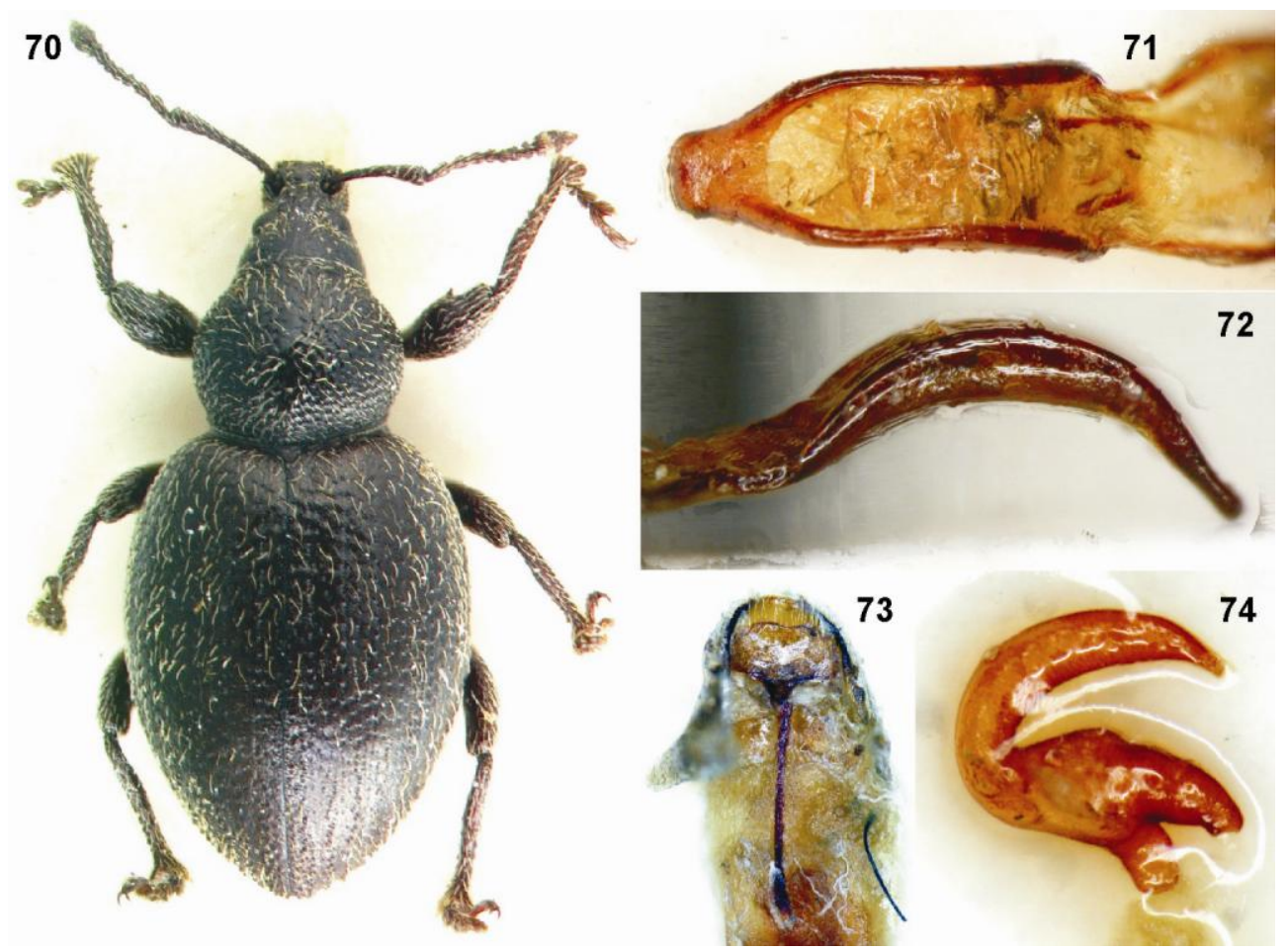

Figs. 70-74. O. (Odelengus) agmentosus sp. n.: 70 - female habitus, 71 - aedeagus dorsal view, 72 - aedeagus profile, 73 - female $8^{\text {th }}$ sternite, 74 - spermatheca.

\section{Otiorhynchus (Odelengus) agmentosus sp. n.}

(Figs. 70-74)

\section{Material examined}

Holotype male, dissected: 25.05.2009 C Turkey; Pozanti Daği; W Ç amardi [SE Niğde]; leg. P. BIAŁOOKI [BIAL]. Paratypes: as ht, 24 exx. [BIAL; WANA].

\section{Diagnosis (male)}

The new species (fig. 70) is most similar to armentalis (see diagnosis of that species). However, agmentosus sp. n. differs from armentalis sp. n. in the median lobe of the aedeagus (Fig. 71). 


\section{Description (male)}

Size range 5.7-6.2 mm, ht 5.9 mm; black, legs and antennae dark-brown; body covered with moderately long greyish sparse hairs.

Head weakly transverse, at sides weakly arched; frons covered with moderately large dense punctures, only somewhat wider than dorsal wall between antennal insertions; frons fovea hardly perceptible amongst punctation; eyes moderately large, weakly convex, not projecting.

Rostrum well separated from head, somewhat longer than wide, slightly widened apicad; pterygia rather small, not projecting; dorsal wall clearly constricted at antennal insertions, here with triangular elevated protuberance.

Antennae moderately slender; scape slightly arched, basal two thirds weakly evenly thickened, apical portion moderately strongly swollen; first funicle segment $2.1 \times$ longer than wide, $1.25 \times$ longer than second; second segment $2.3 \times$ longer than wide; third slightly elongate; segments 4-5 subisodiametric; 6-7 moderately transverse; club ovate, $1.9 \times$ longer than wide, apically pointed.

Prothorax $1.15 \times$ broader than long, at sides evenly strongly arched, widest in middle, anteriorly distinctly constricted; pronotum covered with rather small flattened dense tubercles, replaced by punctures only very close to small median impunctate area (at most as wide as width of two punctures); latero-ventral wall covered with very flat tubercles replaced towards coxae by punctation.

Elytra slightly less than $1.3 \times$ longer than wide, ovate, clearly widest before middle, apically narrowly rounded; longitudinally evenly moderately strongly convex, declivity abruptly, very strongly bent under; striae perceptible with difficulty due to interstices covered with moderately dense punctures subequally large as strial ones; as a result elytra nearly uniformly covered with moderately dense punctures subequally large as pronotal punctures; covered with moderately long arched moderately sparse greyish hairs; hairs on declivity only slightly raised, not longer than hairs on disc; punctation on declivity replaced by minute tubercles.

Legs moderately slender; fore femora with small triangular, somewhat outcurved, well developed tooth; middle femora with minute pointed tooth; hind femora unarmed; fore tibiae straight, apically weakly dilated outwards, ventral margin with relatively large spines; tarsi rather slender, second segment weakly transverse.

Aedeagus (Fig. 71) subparallel-sided along basal half, apex slightly more elongate and thinner in profile than in armentalis (Fig. 72).

Female differs from male in somewhat more robust, stronger convex elytra; legs slightly less robust; fore tibiae stronger dilated outwards apically. 
Apical margin of female $8^{\text {th }}$ sternite distinctly incised (Fig. 73); spermatheca with ramus spread out in opposite direction than in armentalis i.e. towards nodulus; cornu weakly deviating from corpus (Fig. 74).

\section{Ecology}

All specimens were collected under stones at an altitude above $2100 \mathrm{~m}$.

\section{Etymology}

The name (adjective) is coined from the Latin noun agmen [= crowd] - an allusion to the relatively large population density at the locus typicus.

\section{Otiorhynchus (Odelengus) vavrai sp. n.}

(Figs. 75-77)

\section{Material examined}

Holotype male, dissected: TR mer., prov. Niğde, Orhaiye, C amardi env. 19.05.2005 Ala Dağlari mts. J. VÁVRA leg. 1800-2200 m [BIAL]. Paratypes: as ht, 3 exx. [BIAL; VAVR].

\section{Diagnosis}

The new species (Fig. 75) is similar to O. heinzi and shares the following characters with it: large body; distinct impunctate median line of pronotum; punctation of elytral interstices distinctly smaller than punctures in striae; vestiture consisting of minute, recumbent, sparse hairs; interstices within elytral declivity covered with minute tubercles arranged irregularly, not in single row; dentate ventral margin of fore tibiae; elytra broad, apex broadly rounded, hardly angulate. It differs from $O$. heinzi in: shorter rostrum, somewhat more expanded apicad; anterior margin of scrobes rather deeply excised; thin, regular keel behind epistome; median keel of basal part of rostrum less pronounced; dorsal wall of rostrum at antennal insertions distinctly narrower, clearly less than half of rostral minimum width, only slightly, less than $1.1 \times$ narrower than frons (in $O$. heinzi dorsum wall of rostrum at antennal insertions clearly broader than half of rostral minimum width, $1.33 \times$ narrower than frons); elytra much more strongly convex longitudinally; pronotum slightly less transverse, less rounded at sides, disc covered with dense, flat, variously sized tubercles, punctate only close to impunctate midline; impunctate median area broader, subequally broad as maximum width of antennal scape; fore tibiae longer, more slender, less expanded apically outwards; fore femora with much bigger, outwardly directed acute tooth; median lobe of aedeagus strikingly broader, strongly tapering apically. Female unknown. 


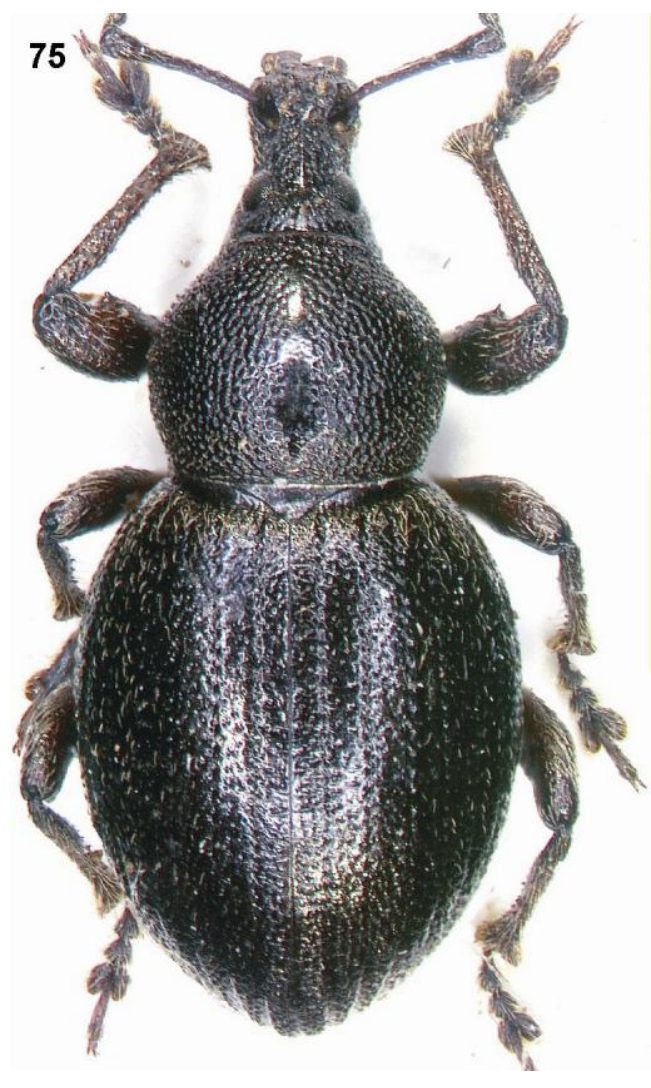

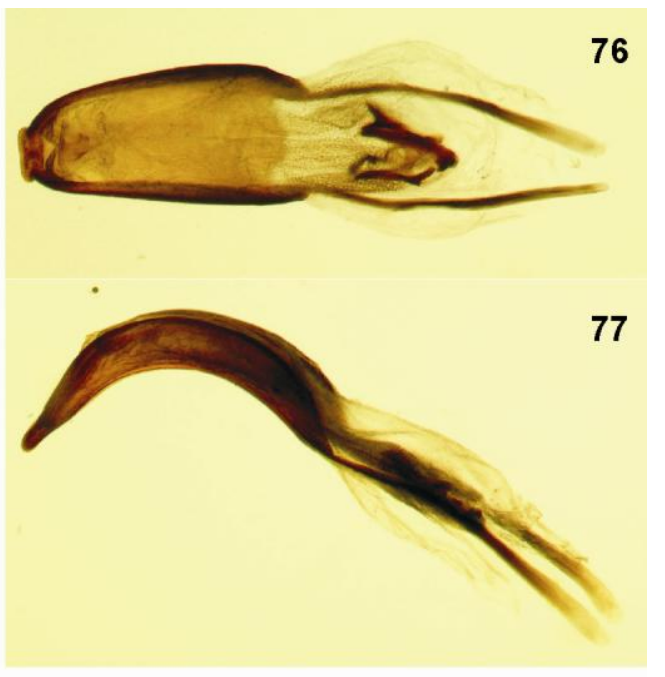

Figs. 75-77. O. (Odelengus) vavrai sp. n.: 75 - male habitus, 76 - aedeagus dorsal view, 77 - aedeagus profile.

\section{Description (male)}

Size range 6.1-6.9 mm, ht $6.6 \mathrm{~mm}$; black, legs and antennae in part brown; body covered with sparse, short, recumbent brown, weakly perceptible hairs.

Head transverse, at sides weakly yet clearly arched, covered with dense, moderately large punctures; frons fovea minute; eyes weakly convex, not projecting.

Rostrum slightly elongate, basally parallel-sided, then weakly widened apicad, punctation denser and smaller than on frons; pterygia large, weakly projecting; median keel well-developed, narrow.

Antennae moderately robust; scape nearly straight, thin, apex rather strongly thickened; first funicle segment only slightly longer than second; third slightly elongate; segment 4 subisodiametric; 5-7 moderately transverse; club rather unclearly egg-shaped, relatively slender, apically not strikingly more tapered than basally, longer than three distal funicle segments combined. 
Prothorax $1.1 \times$ wider than long, longitudinally evenly moderately convex, at sides strongly arched, more strongly apically than towards base, widest slightly behind middle; anterior margin distinctly shorter than base; disc covered with small, dense punctures replaced on lateroventral walls by dense minute tubercles; spindle-shaped impunctate area well-developed, in middle as wide as several punctures combined.

Elytra $1.25 \times$ longer than wide, sides evenly rather strongly arched, widest in middle; longitudinally evenly moderately convex, declivity strongly bent under; striae somewhat impressed, punctures much larger than pronotal ones; interstices ca. twice as broad as striae, distinctly convex, covered with weakly expressed microrugosity, shining, with single row of small punctures replaced by minute tubercles on declivity.

Legs; fore femora with small, well-developed triangular tooth; middle femora with minute, weakly perceptible tooth; hind ones unarmed; fore tibiae slender, straight, apex slightly expanded outwards; ventral margin hardly bisinuate, with small but well-developed spines; tarsi relatively slender, second segment weakly transverse.

Aedeagus (Fig. 76), moderately evenly arched (Fig. 77).

Female unknown.

\section{Etymology}

The new species is named in honour of Dr Jiři Ch. Vávra, the collector of all the type material.

Otiorhynchus (Odelengus) malinkai sp. n.

(Figs. 78-80)

\section{Material examined}

Holotype male, dissected: TR-prov. Niğde, Ala Dağlar mts. Kavlaktepe, Çamardi env., 1750-2200m, 19.05.2005, Z. MALINKA lgt. [BIAL].

\section{Diagnosis}

The new species (Fig. 78) is best diagnosed, except for the genitalia, by its relatively large body, the very short, subglobular elytra, and all the femora unarmed. It differs from $O$. vavrai in: aedeagus subparallel-sided, in lateral view much less arcuate; elytra shorter, somewhat stronger vaulted longitudinally, posterior portion of elytra slightly broader, rounded; weaker sculpture of elytra: interstriae with irregular single row of sparse small punctures, disc without tubercles; the latter within anterior portions of apical declivity relatively big, sparse, in single row on each (except for sutural one) interstice; all femora unarmed; tarsi more robust: second segment clearly transverse; apical portions of fore tibiae 
distinctly curved ventrad; pterygia less distant from anterior margin of rostrum, more strongly projecting, its length only slightly shorter than distance between anterior margin of an eye and posterior margin of pterygium; rostrum slightly shorter; head slightly broader; frons fovea clearly bigger than surrounding punctation; pronotal disc covered with moderately big, very dense punctures, interspaces somewhat convex; impunctate area hardly expressed only in the centre. The new species differs from $O$. armentalis sp. n. in: aedeagus; elytra somewhat more strongly bent under; club much more robust; rostrum much shorter; frons broader; spermatheca (cornu deviating much more weakly from corpus, ramus large, much longer and thicker); last ventrite much less impressed along its hind margin; prothorax considerably more convex longitudinally; eyes somewhat more strongly convex.

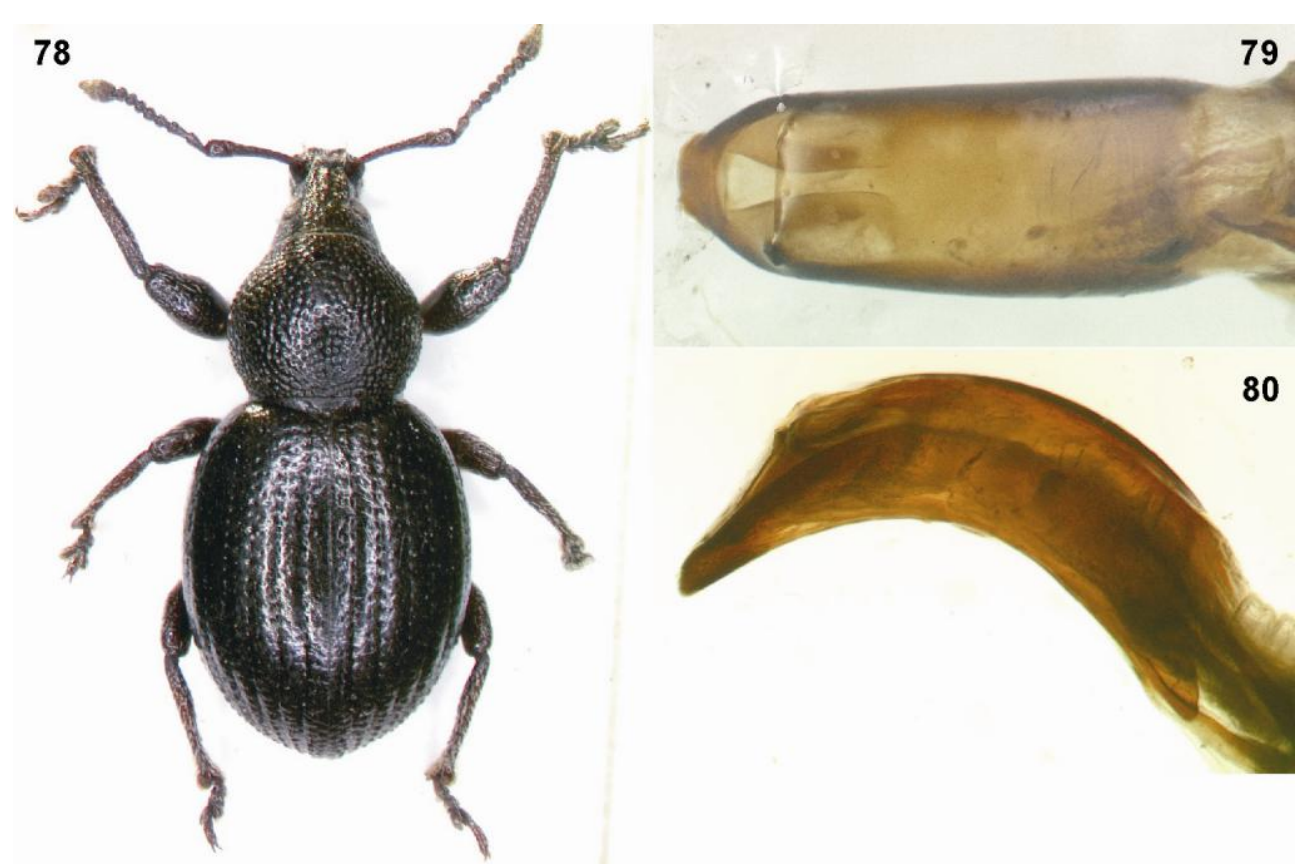

Figs. 78-80. $O$. (Odelengus) malinkai sp. n.: 78 - male habitus, 79 - aedeagus dorsal view, 80 - aedeagus profile.

\section{Description (male)}

Size $5.5 \mathrm{~mm}(\mathrm{ht})$; black, legs and antennae in part red-brown; covered with minute recumbent hardly perceptible dark hairs, seemingly bald. 
Head moderately transverse, linearly tapering together with basal part of rostrum; densely covered with moderately large punctures; frons $1.5 \times$ wider than dorsal wall between antennal insertions; eyes weakly convex, not projecting.

Rostrum subparallel-sided, slightly elongate, covered with similar punctures as frons; pterygia moderately large, hardly projecting; median keel well-developed, wide but low; frons fovea well-developed.

Antennae moderately robust; scape weakly widened, apex strongly swollen; first funicle segment shorter than next two segments combined; third segment subisodiametric; segments 4-7 moderately transverse, gradually wider; club egg-shaped, apically narrowly tapering, $1.9 \times$ longer than wide.

Prothorax $1.15 \times$ wider than long, longitudinally evenly moderately convex, at sides evenly rather strongly arched, widest in middle; anterior margin distinctly shorter than base; disc covered with dense deep punctures replaced on lateroventral walls by dense minute tubercles; impunctate area hardly marked.

Elytra $1.15 \times$ longer than wide, at sides rather strongly evenly arcuate, widest in middle, longitudinally evenly moderately convex, declivity strongly bent under; striae very narrow, punctures somewhat larger than pronotal ones; interstices twice as broad as striae, flat, shining, with single row of small punctures replaced by minute tubercles on declivity.

Legs; all femora unarmed; fore tibiae straight, only apically weakly curved inwards and here somewhat expanded outwards; ventral margin bisinuate, with minute spines; tarsi robust, second segment strongly transverse.

Aedeagus subparallel-sided, apically weakly tapering, tip rounded (Fig.79); rather strongly arched (Fig. 80).

Female unknown.

\section{Etymology}

The new species is named in honour of the Czech coleopterologist RN Dr. Zdeněk MALINKA, the collector of many interesting species that I had the opportunity to examine, including this one.

\section{Otiorhynchus (Odelengus) fracticornis sp. n.}

(Figs. 81-83)

\section{Material examined}

Holotype male, dissected: Türkei, Antalya Taurus, Seydesehir [correctly: Seydişehir] 40 km, S., $1600 \mathrm{~m}$ leg. KIELHORN 29.3.97 [WINK]. Paratypes: as ht, 1 ex. [BIAL] 4 specimens from BMNH with additional museum label: "L. MAGNANO MHNH(E) 2014- 
154"; moreover, locality label underside with handwritten "leg. WINKELMANN KLÖCK coll." [BMNH; BIAL]\ Turchia - Antalya Imrasan gec., m 1300 G. SAMA leg. 22/24.VI.[19]97/ Coll. L. MAGNANO (underside of museum label as above), 1 ex. [BMNH].
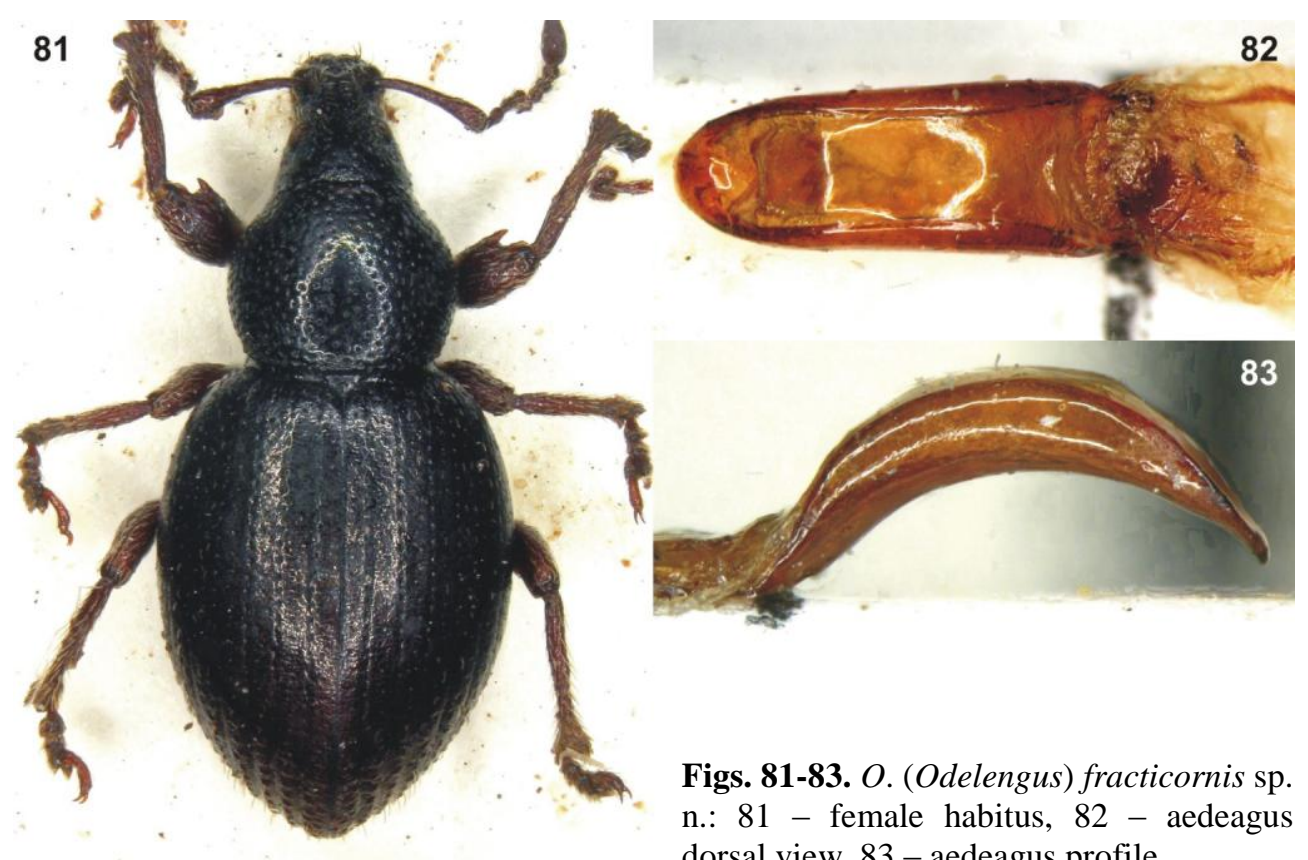

Figs. 81-83. O. (Odelengus) fracticornis sp. n.: 81 - female habitus, 82 - aedeagus dorsal view, 83 - aedeagus profile.

\section{Diagnosis}

The new species (Fig. 81) belongs to the informal group of species within Odelengus having fore femora with large, hook-like tooth. At first glance, it differs from aberrans in: drastically smaller pronotal punctures, lack of semierect elytral scales; from dudkoi in: femoral tooth much larger, lack of massive sclerotization in bursa copulatrix, shorter, longitudinally stronger convex elytra, more robust antennae, more transverse prothorax, in presence of males (dudkoi is a parthenogenetic species); from maximi in: shorter, obovate elytra; femoral tooth smaller; pronotum stronger transverse, covered with somewhat less dense punctures, strongly shining; antennae more robust; lack of large sclerotization inside bursa copulatrix; in details of aedeagus. 


\section{Description (male)}

Size range 7.1-8.1 mm, ht 7.1 mm; black, legs and antennae in part brown; vestiture submicroscopic, hardly discernible except for declivity (here as long as width of interstices, semierect).

Head moderately transverse, tapering, well separated from rostrum when viewed from above; frons only slightly wider than dorsal wall of rostrum minimum width; frons fovea well developed; eyes relatively large, $1.3 \times$ narrower than frons, clearly convex, not projecting.

Rostrum isodiametric, basally subparallel-sided, apical portion weakly gradually divergent; pterygia small, not at all projecting; dorsal wall basally weakly yet clearly convex, not levelled with frons; median keel well developed.

Antennae moderately robust; scape hardly arched, apically weakly swollen; first two funicle segments elongate, first much longer than second; third segment slightly elongate; segments 4-5 weakly, 6-7 moderately transverse; club large, twice as long as wide, as long as four distal funicle segments combined.

Prothorax only $1.1 \times$ wider than long, widest in middle, sides evenly moderately arched; pronotum strongly shiny, covered with moderately small punctures; interspaces subequally wide as puncture diameter, flat, covered with microscopic punctures; covered with sparse recumbent short weakly perceptible hairs.

Elytra almost $1.3 \times$ longer than wide, shortly ovate, apically strongly tapering, subacute; widest before middle; longitudinally moderately, evenly convex; declivity very strongly, abruptly bent under; striae composed of punctures subequally large as strial ones; interstices wider than striae, flat, shiny, covered with single irregular row of punctures twice as small as strial ones, interspaces covered with moderately dense minute punctures; vestiture consists of minute recumbent short weakly perceptible hairs; along declivity hairs markedly longer, semierect.

Legs; fore femora with large outcurved tooth; remaining femora unarmed; fore tibiae relatively long and robust, apically somewhat dilated outwards; ventral margin devoid of spines.

Aedeagus weakly, evenly tapering, apex moderately narrowly rounded, without separate process (Fig. 82); moderately evenly arched (Fig. 83); transfer apparatus in part inside pedon.

Female differs from male in: wider, less elongate elytra; fore tibiae less robust, apically stronger dilated outwards; tarsi thinner.

$8^{\text {th }}$ sternite subisodiametric, apically rounded, not excised. 


\section{Etymology}

The name (adjective) is derived from the Latin fractus [= broken] and cornus [= horn, antenna] in reference to the antennae broken in the two specimens originally available.

\section{Otiorhynchus (Odelengus) hebetes sp. n.}

(Figs. 84-88)

\section{Material examined}

Holotype male, dissected: 29.05.2009 S Turkey, Mt Tahtafirlatan W Bahçecik, NW Feke, leg. P. BIAŁOOKI [BIAL]. Paratypes, as ht, 5 exx. [BIAL].

\section{Diagnosis}

The new species (Fig. 84) differs from all species of the subgenus in elytra covered with a very subtle microsculpture resulting in semi-matt elytra with a silky gloss, whilst in the remaining Odelengus species the elytra are shiny. Because of the unarmed femora and coarsely punctate pronotum, hebetes should be compared with judaicus and pipitzi STIERLIN, 1884: it differs from both of them in the shape of the female $8^{\text {th }}$ sternite, from the former in the more robust antennae, and from the latter in the shorter elytra.

\section{Description (male)}

Size range 4.6-5.4 mm, ht $4.7 \mathrm{~mm}$; black, legs and antennae brown, in part red-brown; vestiture submicroscopic, hardly discernible.

Head relatively weakly elongate; eyes slightly convex; frons fovea hardly larger than surrounding punctures; frons only somewhat wider than dorsal wall of rostrum at antennal insertions.

Rostrum clearly separated from head, slightly tapering basally, apical portion slightly widened; pterygia relatively large, indistinctly projecting; dorsal wall densely minutely punctate, interspaces covered with microscopic pinholes, as a result rostrum not as shiny as head.

Antennae moderately robust; scape slightly arched, evenly thickened distad, apical portion rather abruptly thickened; first funicle segment ca. $1.3 \times$ longer than second; second moderately elongate; third subisodiametric; 4-5 weakly transverse; 6-7 moderately transverse; club elongately ovate, $2.1 \times$ longer than wide.

Prothorax just $1.1 \times$ wider than long, sides evenly strongly rounded, widest indistinctly behind middle, longitudinally weakly evenly convex; pronotum covered with large punctures, interspaces flat, covered with microscopic dense pinholes; lateral walls covered with minute, rather weakly convex, well delimited matt tubercles. 


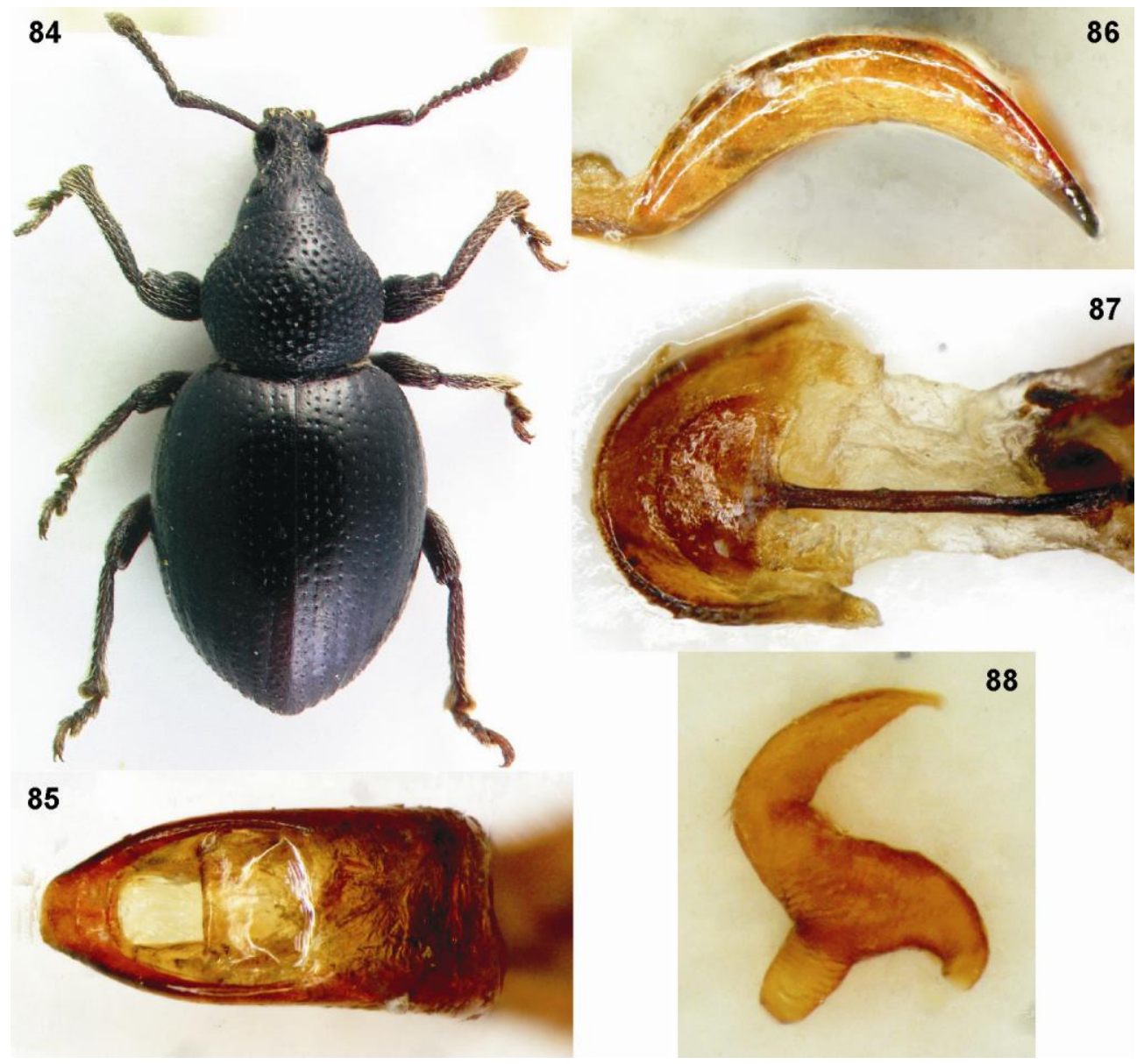

Figs. 84-88. $O$. (Odelengus) hebetes sp. n.: 84 - female habitus, 85 - aedeagus dorsal view, 86 - aedeagus profile, 87 - female $8^{\text {th }}$ sternite, 88 - spermatheca.

Elytra $1.3 \times$ longer than broad, widely egg-shaped, widest distinctly before middle; striae composed of dense (interspaces shorter than punctures diameter) punctures, much smaller than pronotal ones; interstices $1.5-2 \times$ wider than striae, with single irregular row ofpunctures twice as small as strial ones, on declivity replaced with minute well-developed tubercles; surface with very subtle microsculpture, as a result elytra semi-matt, not as shiny as prothorax.

Legs long and moderately robust; all femora with no trace of tooth; fore tibiae long, dorsal margin straight, in middle indistinctly concave, apically slightly dilated; second tarsal segment rather strongly transverse; hind tarsi only slightly more slender. 
Aedeagus (Fig. 85) subparallel-sided, apically widely rounded, weakly evenly arched (Fig. 86); transfer apparatus in part within pedon.

Female differs from male in: indistinctly shorter rostrum; fore tibiae somewhat more strongly dilated dorsad; slightly less robust tarsi.

Margo apicalis of female $8^{\text {th }}$ sternite almost semicircular (Fig. 87); spermatheca (Fig. 88); bursa copulatrix with moderately large sclerotization.

\section{Etymology}

The name is a Latin adjective [= matt] referring to the microsculptured, matt elytra.

Subgenus Aequipennis MAGNANO, 1998 (type species Otiorhynchus aksekianus MAGNANO, 1977)

The subgenus Aequipennis MAGNANO, 1998 has not yet been satisfactorily defined. It now consists of four species, including spectativus sp. n. All are large-sized, elongate species, superficially resembling Podonebistus. However, they have an unusually elongate, subparallel-sided rostrum and a peculiarly thick aedeagus, with a very thin membranous dorsal wall.

\section{Otiorhynchus (Aequipennis) spectativus sp. n.}

(Figs. 89-91)

\section{Material examined}

Holotype male, dissected: 29.05.2008 SW Turkey, Rize Beli Gecidi, NW Seydişehir, leg. P. BIAŁOOKI [BIAL]. Paratypes: as ht, 35 exx.I same but 13.05.2008, 1 exx.। 11.05.2008, SW Turkey, Akseki env., NW Alanya, leg. P. BIAŁOOKI, 11 exx.I same but 12.05.2008, 16 exx.[BIAL; WANA]\ Tur. Antalya, Yarpuz 1200 m, 17-25.5.[19]88, leg. I. RYDH/ ex. coll. RYDH/ Ot. aksekianus MAGN., FrEMUTH det. 1989, 1 ex.I Turkei: Prov. Antalya, Yarpuz 1200 m, 26.V.1988, leg. S. LundBERG/ Ex coll. LundBERG/ O. (Tour.) aksekianus MAGN., det. FREMUTH 1989, 2 exx. (one specimen with additional label: Tu. Yarpuz: $1200 \mathrm{~m}$ S. LUNDBERG) [BEHN]\ TK [i.e. Turkey], Konya prov., Seydişehir 28.iv.2001 env., I. SMATANA lgt., 3 exx. [BENE]. 


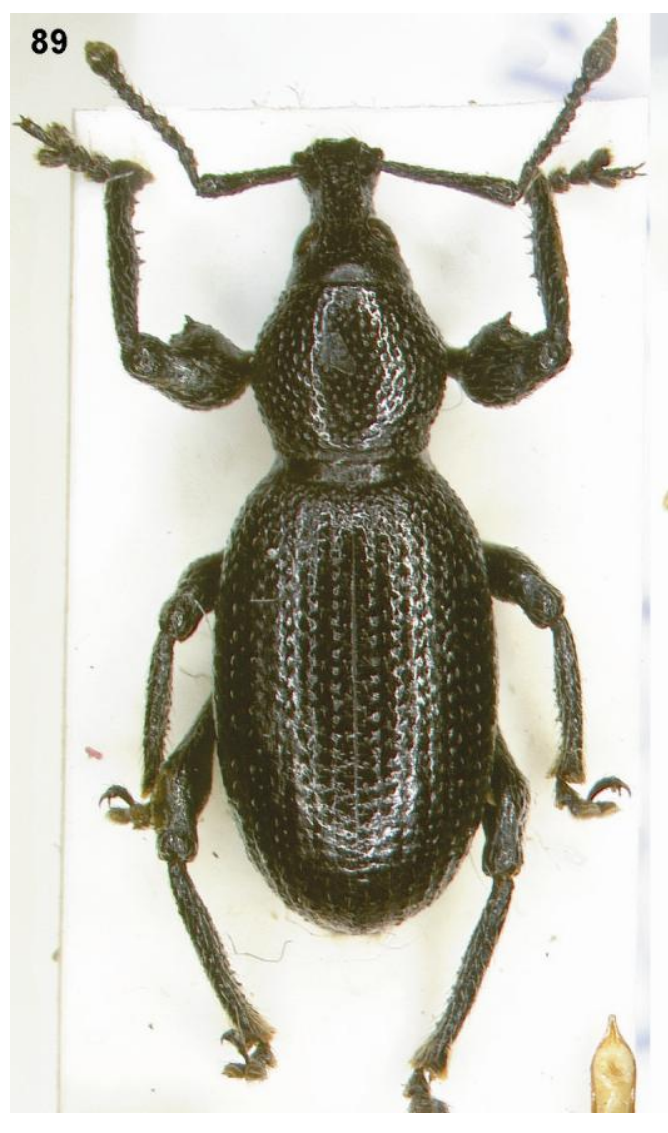

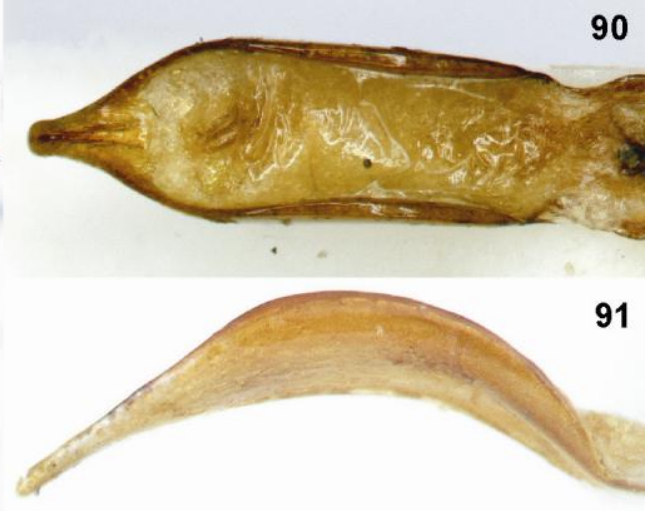

Figs. 89-91. $O$. (Aequipennis) spectativus sp. n.: 89 - male habitus, 90 - aedeagus dorsal view, 91 - aedeagus profile.

\section{Diagnosis}

The new species is strikingly different from all the other species of the group, from which it is distinguishable at first glance by the small body and the lack of distinct pronotal and elytral tubercles (Fig. 89). It also differs from aksekianus Magnano in the elytral vestiture reduced to a single row of short, sparse arcuate recumbent hair-like scales on the interstices, and longitudinally flat elytra.

\section{Description (male)}

Size range 7.2-8.9 mm, ht 7.2 mm; black, vestiture greyish.

Head small, relatively weakly transverse; eyes weakly yet clearly convex, projecting, $1.25 \times$ shorter than width of frons; frons fovea minute, poorly visible among punctation.

Rostrum slightly elongate; pterygia large, relatively strongly projecting; epistome short, crescentic; median keel thin but well developed from epistome to level of anterior margins 
of eyes; anterior part of dorsal wall declivent; hind part with very shallow, wide median sulcus.

Antennae long and rather slender; scape straight, subparallel-sided, apex weakly thickened; first funicle segment ca. $1.5 \times$ longer than second; segments 3-7 slightly elongate; club fusiform, $2.7 \times$ longer than wide.

Prothorax moderately transverse, sides evenly, rather strongly arched, widest in middle, longitudinally weakly evenly convex; pronotum covered with large, irregular in shape and size punctures, interspaces slightly convex; sides covered with moderately small, flattened tubercles; short, recumbent hairs weakly perceptible.

Elytra $1.65 \times$ longer than wide, sides evenly weakly arched, widest in middle; longitudinally flat; declivity subperpendicular; strial punctures large, well developed; interstices much narrower than striae, shiny, covered with minute, sparse punctures; each interstice with single row of very short (shorter than diameter of strial punctures) recumbent, sparse hairs; declivity with single row of small low tubercles.

Legs long; fore femora moderately robust, with three minute denticles distally of small tooth; middle femora with hardly perceptible denticle; hind ones unarmed; fore tibiae long, apically strongly curved inwards; inner margin with large spines; fore tarsi moderately robust, second segment somewhat transverse.

First two ventrites moderately impressed; last ventrite weakly convex, with shallow subapical impression, covered with similar hairs as on elytra.

Aedeagus $2.9 \times$ longer than wide, distinctly expanded from base to subapical portion strikingly resembling remaining species of the subgenus (Fig. 90), in lateral view (Fig. 91).

Female differs from male indistinctly, merely in first two ventrites not impressed; last ventrite slightly less convex.

\section{Ecology}

All specimens were beaten from conifers at altitudes between 1200 and $2200 \mathrm{~m}$.

\section{Etymology}

The name is a Latin adjective [= speculative] - an allusion to the rather unclear taxonomic position of the species in an early analysis.

Subgenus Pterygodontus BIAŁOOKI, 2015 (type species Otiorhynchus bleusei FAUST, 1889)

The subgenus Pterygodontus has only recently been established to accomodate a group of species formerly placed in subgenera Melasemnus and Podonebistus, now comprising eight species (including anabolicus sp. n. and pulcher sp. n. described below). 


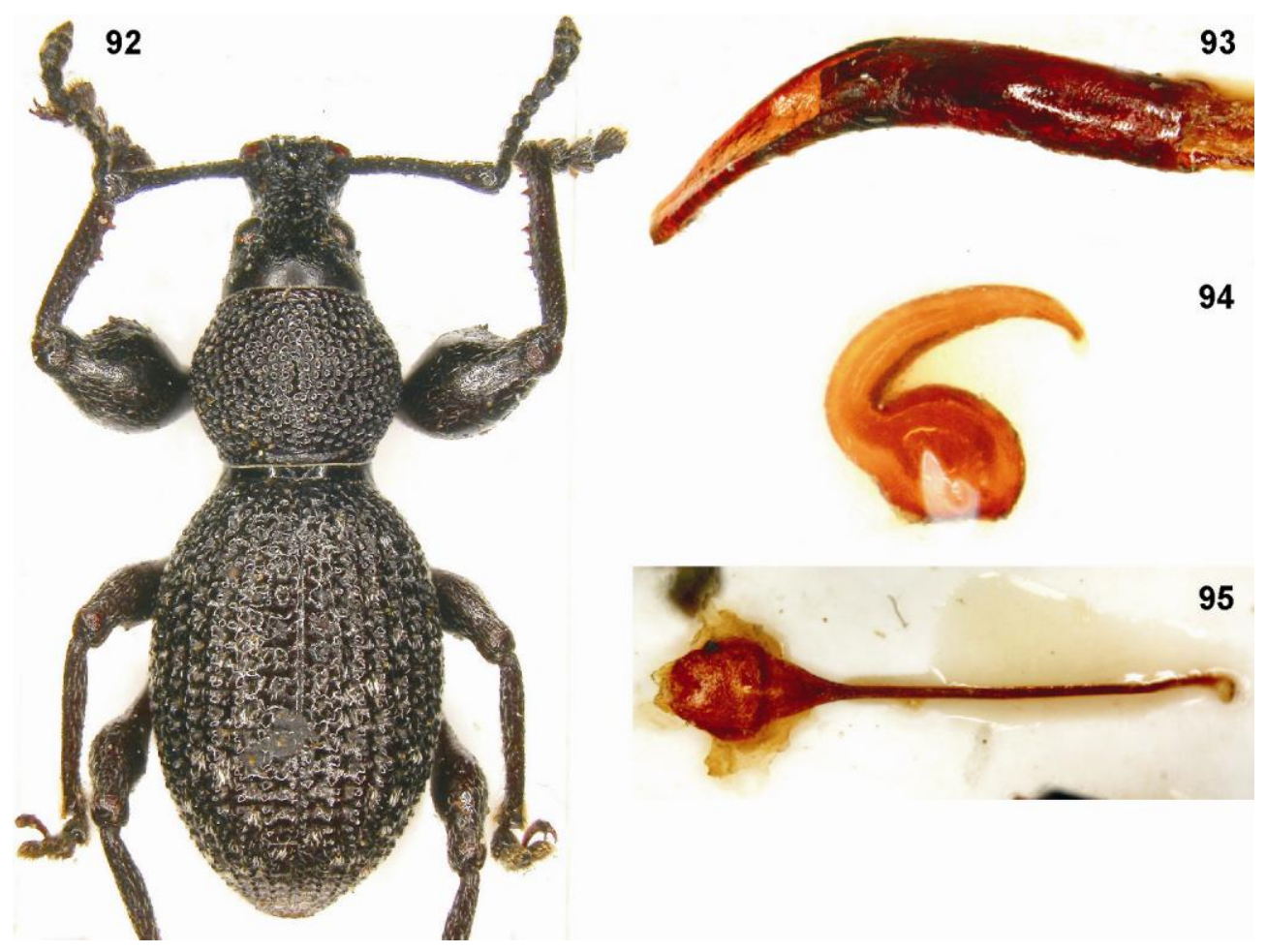

Figs. 92-95. O. (Pterygodontus) anabolicus sp. n.: 92 - male habitus, 93 - aedeagus profile, 94 - spermatheca, 95 - female $8^{\text {th }}$ sternite.

Otiorhynchus (Pterygodontus) anabolicus sp. n.

(Figs. 92-95)

\section{Material examined}

Holotype male, dissected: 14.05.2007 SW Turkey; N Beycik; Tahtali Dağlari; leg. P. BIAŁOOKI [BIAL]. Paratypes: as ht, 7 exx. [BIAL] TR.-Antalya; Beldibi-Kemer; Hadulla 10.6.[19]92/ 1 male in coll. HADULLA/ Melasemnus sp. cf. spinifer/ DEI coll. L. BeHNE/ Otiorhynchus (Aequipennis) n.sp.; L MAGNANO det. 03, 1 ex.I TR-40km S. Antalya; Kemer 1600 m 91.05.20; leg. W. SUPPANTSCHITSCH/ O. (Tour.) sp. cf. spinifer DAN.; BEHNE det. 1991/ Otiorhynchus (Melasemnus) spinifer DAN. L. MAGNANo det. 03, 1 ex. [SDEI].। Güllük D.; 24.5.1988; Querqus [sic!] sp./ Turkey-S.; distr. Antakya; Dr. N. LoDos lgt./ Ot. (Melasemnus) aff. dawricus LONA; Fremuth det. 1987/ Paratypus; Ot. (Melasemnus) pulcher spec.nov.; FREMUTH design. 1996, 1 ex.I TR vill. Antalya; Bey Dağlari; Termessos 9.6.[19]86; KADLEC + VOŘIŠEK leg. [with identification labels as the above specimen] 
[MERE]\Turkey m.[eridionalis], 10.5.2001 vill. [i.e. vil.] Antalya, 36 32N-29 59E Avlanbeli pass, $1120 \mathrm{~m} 25 \mathrm{~km} \mathrm{~S}$ of Elmali, S. KADLEC leg., 1 ex.I TR vil. Antalya 25.5.2001, $12 \mathrm{~km} \mathrm{~N}$ of Akseki, Irmasan Geçidi env. Josef MERTLIK lgt., 1 ex. [BENE].

\section{Diagnosis}

The new species (Fig. 92) is easily distinguishable within Pterygodontus in the extremely swollen male fore femora, the wide rostrum and the unique shape of the aedeagus. It differs from the very similar davricus Lona in (the characters pertinent to this species in parentheses): broader, less elongate elytra $(1.55 \times$ longer than wide); prothorax more transverse (hardly transverse); rostrum subisodiametric (distinctly elongate).

\section{Description (male)}

Size range 6.6-7.4 mm, ht $7.0 \mathrm{~mm}$. Black, legs and antennae in part dark brown, vestiture greyish.

Head wrinkled; microscopic punctures sparse, poorly visible; pterygia moderately projecting; rostrum $1.15 \times$ broader than long; frons strongly at angle to rostrum; frons fovea moderately large; eyes rather weakly convex, small, $1.4 \times$ narrower than frons, hardly projecting; rostrum with somewhat unclear median keel; its surface irregularly longitudinally wrinkled, and densely, minutely punctured, covered with minute, sparse, recumbent, grey hairs.

Antennae relatively slender. Scape almost straight, apex relatively strongly swollen; first funicle segment slightly more than twice as long as wide, somewhat longer than segment 2 ; second segment $2.5 \times$ longer than broad, third $1.8 \times$ longer than wide, segments 4- 6 weakly elongate, seventh $1.4 \times$ longer than broad; club minute, shorter than three distal funicle segments combined.

Pronotum $1.25 \times$ wider than long, strongly, regularly rounded at sides; moderately convex in both directions; covered with dense, moderately large, flattened, shiny tubercles bearing minute, recumbent, grey hairs; impunctate area minute, flat.

Elytra $1.4 \times$ longer than wide, regularly oval, at shoulders weakly expanded, apex slightly truncate; strongly convex basally, disc hardly convex; declivity less than perpendicular; striae not impressed, with large, rather deep but not clearly delimited punctures; interspaces shorter than diameter of punctures; interstices distinctly narrower than striae, with irregular single row of small, shining tubercles; both striae and interstices covered with sparse, recumbent, grey hair-like scales; moreover with sparse, distinctly broader, recumbent white scales creating irregular, unclear maculation.

Legs. Fore femora extremely swollen, as wide as pterygial span, with minute outcurved tooth, and with several microscopic, hardly detectable tubercles between main tooth and 
knee; fore tibiae thin, apical portion distinctly curved inwards; mucro large; inner margin with 4-5 large spines; tarsi robust, second segment strongly transverse.

Ventral part of body with well-developed microsculpture, semi-matt, covered with sparse, somewhat raised hairs; last ventrite broad, apex broadly rounded.

Aedeagus strongly bent to the left and strongly twisted clockwise (Fig. 93).

Female differs from male in elytra larger and broader, much stronger convex at shoulders, disc much more strongly flattened; fore femora much less swollen, markedly narrower than pterygial span.

Spermatheca with subglobular corpus, ramus as hardly perceptible protuberance (Fig. 94); ovipositor weakly sclerotized, with minute subapical styli; spiculum ventrale $2.3 \times$ longer than $8^{\text {th }}$ sternite; the latter subrhomboidal, excised apically (Fig. 95).

\section{Distribution}

The new species is known from south-western Turkey (Bey Dağları in Antalya province); the data from the Antakya [Antalya?] region need confirmation.

\section{Etymology}

The name (adjective) intentionally refers to anabolic steroids - an allusion to the "unnaturally" large male fore femora.

\section{Otiorhynchus (Pterygodontus) pulcher BIAŁOOKI \& FREMUTH sp. n.}

(Figs. 96-99)

\section{Material examined}

Holotype male, dissected: Tur. Antalya; Başkonak; 25.5.88; leg. J.R. BERGWALL/ Holotypus; Ot. pulcher m. n.sp.; FrEmUTH det. 1989/ Ex. Coll. RYDTH/ Holotype; Pterygodontus pulcher sp. n.; BIAE.[OOKI] \& FREM.[UTH] des. 2008 [ZMLU]. Paratypes: 11.05.2008 SW Turkey, Akseki env., NW Alanya, leg. P. BIAŁOOKI, 8 exx. [BIAL] Tur. Antalya; N Geris; 26.5.1988; leg. J.R. BergVALL, 1 ex.I Tur. Antalya: Yarpuz 1200 m; 1723/5-88/ leg. I. Rydh, 1 ex.I Tur. Antalya; Akseki N 1200 m; 4-5/6-92/ leg. I. RYDH, 1 ex. [ZMLU] Turcia mer. Alanya $15 \mathrm{~km} \mathrm{~S}$, Beldibi 800-1200 m 02.IV.1996 leg. A. WeIGEL/ $O$. pulcher FREM. i.l. BeHNE det. 1996/ Ot. (Melasemnus) pulcher sp. n. FREMUTH, J. det. 2008, 1 ex.I TR: Antalya. Yarpuz 21.V.1998 Leg. S. Lundberg Otiorhynchus Podonebistus sp. BeHNE det. 2002, 1 ex. [MERE] Turcia m. Prov. Antalya 16 km NE Demirtas 36 30N 32 20E $1200 \mathrm{~m}$ 26,V.006 leg. A. Weigel, 5 exx.I Turcia m. Prov. Antalya 13 km NE Mahmutlar, Pass bei 1100 m 25.V.2006 3631 43N 3214 09E leg. A. WeIGEL Ei-Ki-Wald, 
3 exx. [NKME] TR vil.Antalya 25.5.2001 $12 \mathrm{~km} \mathrm{~N}$ of Akseki Irmasan Geçidi env. Josef MERTLIK lgt., 1 ex. [BENE].

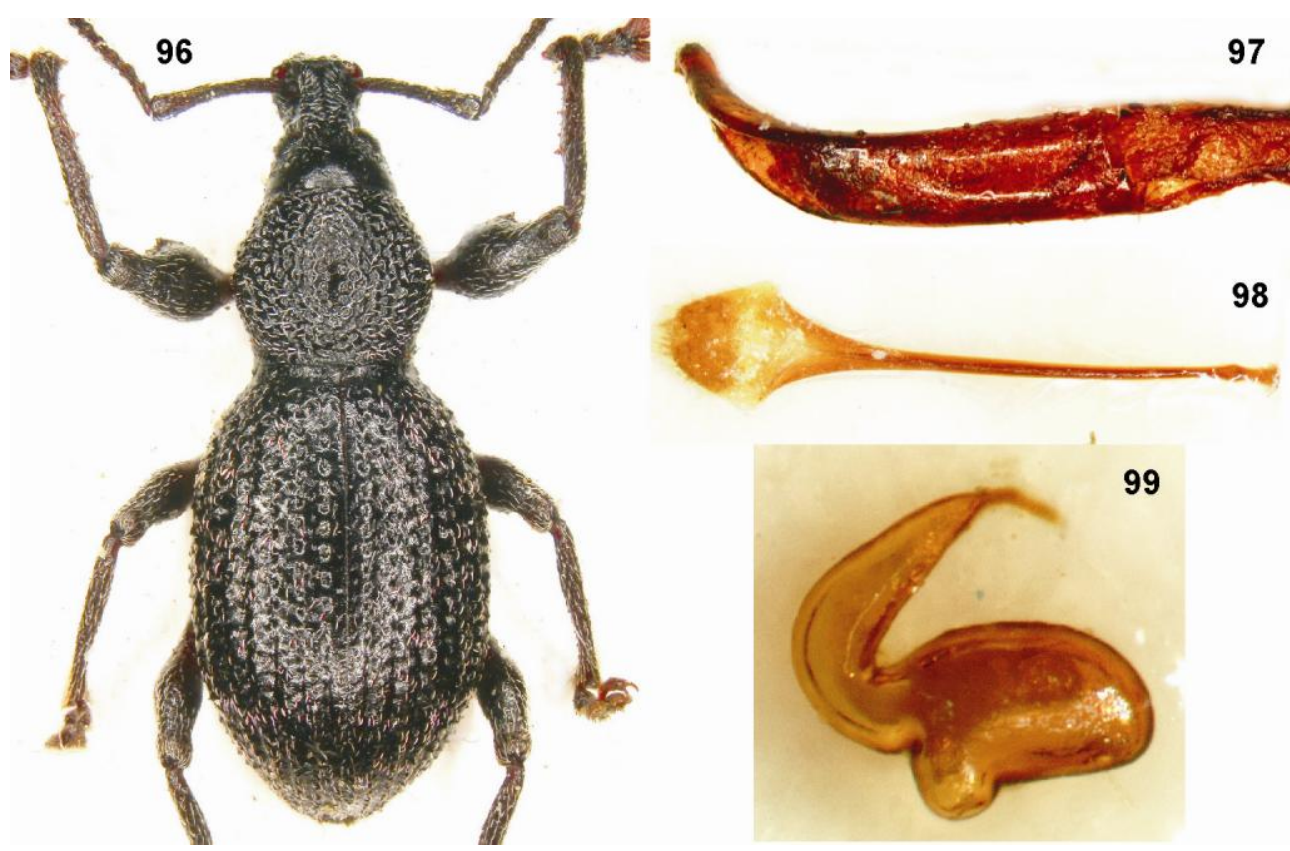

Figs. 96-99. $O$. (Pterygodontus) pulcher sp. n.: 96 - male habitus, 97 - aedeagus profile, 98 - female $8^{\text {th }}$ sternite, 99 - spermatheca.

\section{Diagnosis}

The new species (Fig. 96) is easily distinguishable within Pterygodontus by the relatively short, not elongate, heavily sculptured elytra, the strongly enlarged male fore femora, only somewhat narrower than the pterygial span, and the unique shape of aedeagus. It differs from anabolicus mainly in the strikingly less robust fore femora and the aedeagus.

\section{Description (male)}

Size range 6.5-7.1 $\mathrm{mm}$ (ht 7,0 $\mathrm{mm}$ ); black.

Head strongly transverse, strongly tapering, sides hardly arched; frons narrow, weakly broader than longitudinal diameter of an eye, strongly at angle to rostrum, covered with rather small, dense punctation fused into longitudinal wrinkles, and with minute, grey, recumbent hairs; eyes weakly convex, not projecting; frons fovea large, deep, elongate. 
Rostrum weakly elongate, hardly tapering, with thin median keel, covered with very dense, small punctures fused in part into longitudinal rows, and with minute, recumbent, sparse, grey hairs; pterygia moderately projecting.

Antennae; scape slightly arcuate, gradually thickened apicad; first funicle segment slightly longer than segment 2, segments 3-7 weakly to moderately elongate; club small, $2.7 \times$ longer than broad, as long as three distal funicle segments combined.

Pronotum $1.15 \times$ wider than long; moderately, evenly arcuate at sides, broadest in middle, moderately, regularly convex in both directions; covered with dense, shiny, moderately large, flattened tubercles, somewhat irregular in size and shape, replaced in the centre by irregular punctation.

Elytra $1.4 \times$ longer than wide, rather weakly convex at shoulders, broadest somewhat behind middle, covered with sparse, irregularly distributed, elongate, arcuate, recumbent, narrow grey scales causing irregular, unclear maculation; apex narrowly rounded; declivity almost perpendicular; striae not impressed, with large, deep punctures; interspaces shorter than puncture diameter; interstices on disc flat, subequally broad as striae, with minute, not quite regular tubercles bearing thin, recumbent or hardly raised hair-like scales; outer interstices with much larger tubercles, well visible on elytral outline in dorsal view.

Legs. Fore femora strongly swollen, weakly narrower than pterygial span, with minute, outcurved tooth, and with several microscopic tubercles between tooth and knee; fore tibiae thin; mucro large; tarsi robust, second segment transverse.

Ventral part of body with strongly developed microsculpture, semi-matt, covered with sparse, weakly raised hairs; last ventrite truncate, moderately, regularly convex, with unclear apical impression.

Aedeagus peculiar (Fig. 97), strongly bent to the right, and strongly twisted anticlockwise; apex strongly elongate. Width of apex, and generally proportions of entire median lobe, degree of bend and twisting moderately variable.

Females differ from males in: much broader elytra, distinctly more convex at shoulders, strongly flattened on disc; fore femora strikingly less swollen; last ventrite nearly flat, obtusely triangular.

Female $8^{\text {th }}$ sternite (Fig. 98); spermatheca (Fig. 99).

\section{Distribution}

The new species seems to be restricted to south-western Turkey (Antalya province).

\section{Etymology}

The Latin adjective pulcher means "beautiful", an appropriate name for this species. 
Subgenus Podonebistus ReITTER, 1912 (type species Otiorhynchus prolongatus STIERLIN, 1861)

The subgenus Podonebistus has not yet been clearly defined, even though BIAŁOOKI (2015a) provided a preliminary diagnosis of the group, distinguishing several species moved into the newly created subgenus Podorhynchus. I describe another two new, morphologically very interesting species from Greece below. I prefer not to describe certain morphological structure of rhinorostris here, as it has not yet been taken into account in Otiorhynchini (publication in preparation). The morphological curiosity of curiosus consists in a mixture of characters typical of Podonebistus and Pterygodontus, unknown in any other species of the two subgenera.

\section{Otiorhynchus (Podonebistus) rhinorostris sp. n.}

(Figs. 100-102)

\section{Material examined}

Holotype male, dissected: 02.06.2016 S Greece, Gavros SSW Karpenissi, leg. P. BIAŁOOKI [BIAL]. Paratypes: same as ht, 3 exx. [BIAL] Graecia Veluchi/ coll. E. CsIKI/ Otiorhynchus (Melasemnus) ?sp. n. L. MAGnANo det. [20]01/ coll. PODLussánY A. [PODL].

\section{Diagnosis}

The new species (Fig. 100) is readily distinguishable from all species of the subgenus by the following combination of characters: male with epistomal horns; elytra elongate, at sides nearly evenly arched, not (sub)parallel-sided, very weakly convex at humeri. $P$. jovis differs strikingly from rhinorostris in: larger body; subparallel-sided elytra; shorter rostrum; much sparser pronotal punctation. P. prolongatus (of similar body size) differs from the new species in the lack of epistomal horns and the distinctly sparser pronotal punctation.

\section{Description (male)}

Size range 6.1-7.6 mm; ht $6.8 \mathrm{~mm}$; entirely brown; vestiture greyish.

Head together with basal part of rostrum forming common cone; frons covered with dense punctures fused into irregular, not very clear longitudinal rows, and hair-like scales; frons fovea unclear, hardly different from surrounding punctation; eyes large, nearly $1.2 \times$ narrower than frons, weakly convex, not at all projecting. 


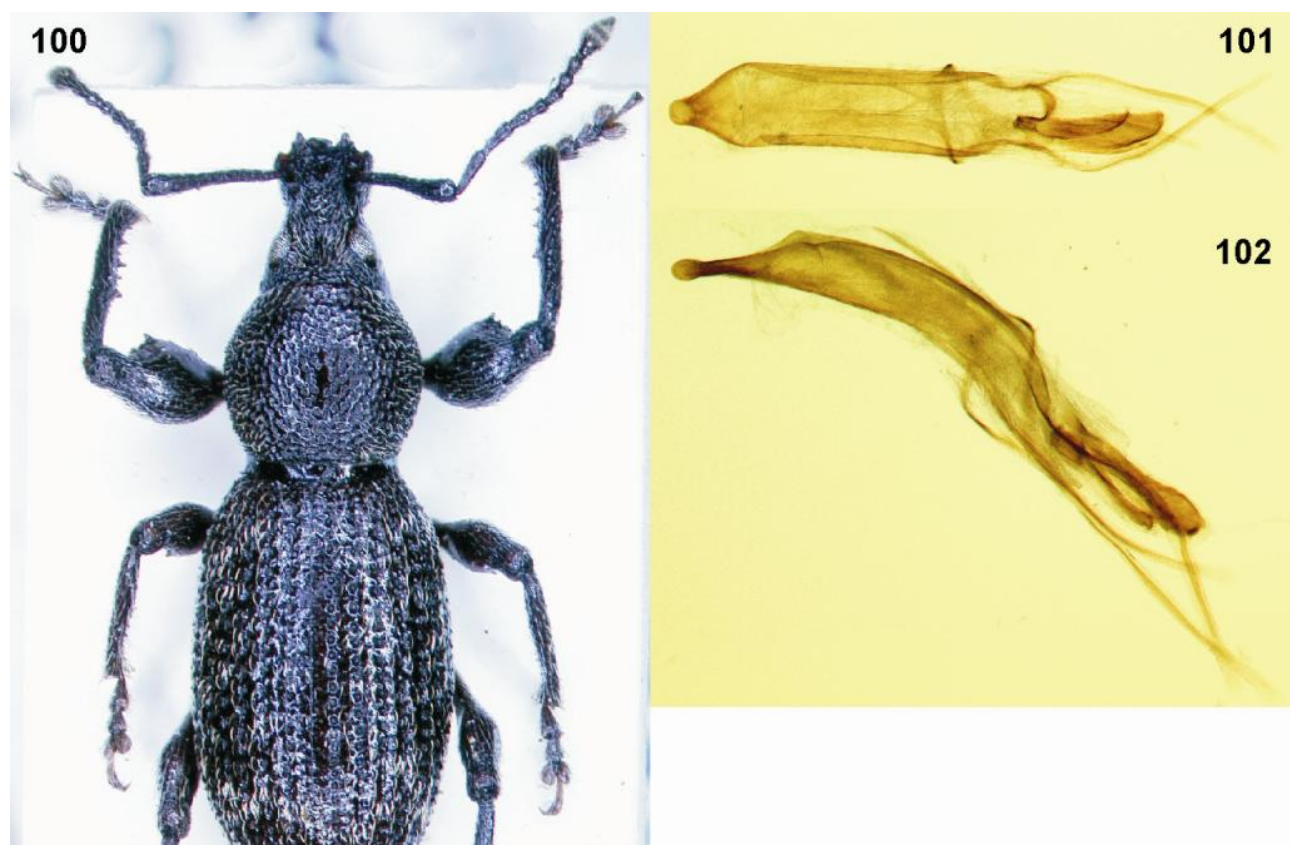

Figs. 100-102. O. (Podonebistus) rhinorostris sp. n.: 100 - male habitus, 101 - aedeagus dorsal view, 102 - aedeagus profile.

Rostrum slightly transverse, weakly at angle to frons, hind part of dorsal wall parallelsided, covered with dense small irregular punctation, and short sparse hair-like scales; median keel unclear; lateral margins gradually less sharply expressed backwards; pterygia small, moderately projecting, pterygial span $1.4 \times$ wider than rostrum minimum width; epistome moderately hollowed, sharply delimited but keels not developed, horns moderately developed.

Antennae slender; scape straight, basal portion very thin, then weakly gradually widened, apical quarter weakly evenly swollen; first funicle segment distinctly longer than second; second $2.5 \times$ longer than broad; remaining segments subequally long, ca. $1.5 \times$ longer than wide; club narrowly fusiform, $2.8 \times$ longer than wide, as long as distal 3 and half funicle segments combined.

Prothorax $1.1 \times$ broader than long, moderately, evenly convex in both directions, at sides evenly moderately arched, broadest in middle, covered with dense, moderately large, unevenly sized punctures, interspaces shorter than puncture diameter; impunctate midline flat, shiny, irregularly delimited. 
Elytra $1.7 \times$ longer than wide, at sides evenly weakly arched, not parallel-sided; base moderately convex, middle portion flattened, declivity moderately convex, only short apical portion perpendicular, apical mucro well developed; transversally evenly moderately convex; strial punctures slightly elongate, ca. twice as large as biggest pronotal punctures, interspaces narrower than length of punctures; interstices subequally wide as striae, flat, covered with sparse microscopic tubercles and single row of long subrecumbent thin scales; moreover, mainly on declivity, unclear spots of broader recumbent scales.

Legs moderately slender; fore femora with small tooth and several microscopic denticles between tooth and knee; remaining femora with subequally small, acute triangular tooth; ventral margin of fore tibiae with large spines.

Ventral side of body covered with moderately sparse minute tubercles bearing moderately long semierect hairs; last ventrite $1.8 \times$ broader than long; hardly convex, with unclear apical impression.

Aedeagus (Fig. 101) subparallel-sided, $2.1 \times$ longer than wide, apex extended into long and narrow, swollen apically process; weakly arched (Fig. 102), projecting portion of endophallus with large, complex, well-sclerotized transfer apparatus.

Female unknown.

\section{Ecology}

In contrast to all the other species of the subgenus, $O$. rhinorostris seems to be associated with moist, shady habitats.

\section{Etymology}

The specific name (adjective) reflects the rostrum ending in epistomal horns; it is derived from the latinized Greek pıvó- [= nose] and Latin rostrum.

\section{Otiorhynchus (Podonebistus) curiosus sp. n.}

(Figs. 103-109)

\section{Material examined}

Holotype male, dissected: GR: Cent. Greece, Euboia (Evia) centr., Mt. Dirfis, 2 km S Stropones, $646 \mathrm{~m}, 38^{\circ} 36^{\prime} \mathrm{N} 23^{\circ} 53^{\prime} \mathrm{E}, 05.06 .2015$, leg. BAHR (FO7 $\backslash$ Abies [BAHR]. Paratypes: Greece: Central Euboea, $2 \mathrm{~km} \mathrm{~S}$ of Stropones village, 38.595365N 23.904974E, on Abies twigs, 06.05.2017, leg. G. KAKIOPOULOS, 9 exx. [KAKI]; same label, 2 exx. [MCZR]; same label, 1 ex. [BAHR]; same label, 1 ex. [MESS]\ 19.05. 2017 E Greece, Euboea, Stropones valley, leg. P. BIAŁOOKI, 111 exx. [BIAL; BAHR; HNHM; MESS; PODL; WANA; WINK]. 


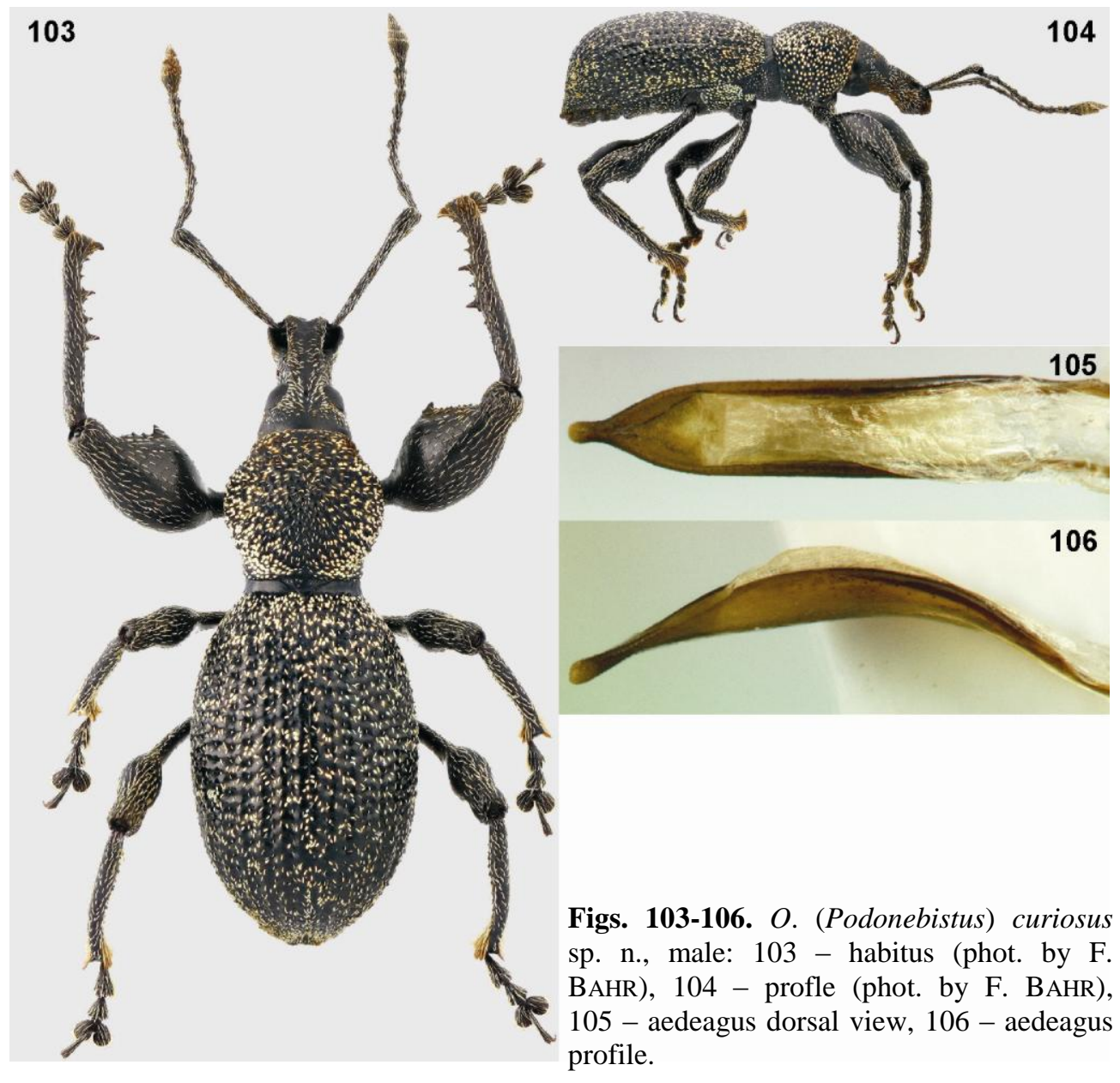

\section{Diagnosis}

The new species (Figs. 103, 107) is distinguishable at first glance from all other species of the subgenus by the following characters: moderately dense true broad recumbent scales; long, subparallel-sided rostrum; rather short, oval, not (sub)parallel-sided elytra; elytral disc evenly moderately convex transversally, not flattened; enormously thickened fore femora; different transfer apparatus. $O$. atticus has similarly convex, oval elytra but differs from curiosus in the strikingly smaller body. The new species is superficially somewhat similar to $O$. (Pterygodontus) anabolicus sp. $\mathrm{n}$. but the two species differ from each other according to the diagnoses of the two subgenera, the genitalia of both sexes in particular (Białooki 2015b). 


\section{Description (male)}

Body length 7.4-9.0 mm, ht $8.1 \mathrm{~mm}$; black; vestiture entirely recumbent, bright greyish (Fig. 103).

Head small, weakly transverse; eyes weakly convex, indistinctly projecting, large, $1.1 \times$ wider than frons.

Rostrum almost $1.15 \times$ longer than wide, subparallel-sided; pterygia moderately large, moderately projecting; epistome rather small, weakly hollowed, keels not expressed; apical portion of dorsal wall of rostrum weakly declivent; basal part parallel-sided, moderately strong at angle to frons, lateral margins obtuse; hind half with very low and unclear median keel; vestiture consists of sparse hair-like scales.

Antennae long and slender; scape straight, covered with hardly raised moderately dense bright hair-like scales; first two funicle segments strongly elongate, first $2.8 \times$, second $3.2 \times$ longer than wide, first slightly shorter than second; segments 3-7 moderately elongate; club fusiform, $2.4 \times$ longer than wide, as long as three distal funicle segments combined.

Prothorax weakly $(1.1 \times)$ transverse, strongly uniformly convex in both directions, strongly rounded at sides, broadest much before middle; covered with dense, moderately convex tubercles; disc covered with moderately sparse short hair-like scales, with few elongate broader scales; lateral walls covered with moderately dense, strikingly bigger, subcircular and moderately elongate scales.

Elytra $1.55 \times$ longer than wide, at sides weakly evenly arched; transversally clearly roof-sloped, longitudinally evenly moderately convex, declivity less than perpendicular (Fig. 104), apex weakly mucronate; striae composed of big, rather irregular, moderately deep punctures, interspaces distinctly shorter than diameter of punctures, each with small tubercle, better developed posteriorly; each puncture with short hair-like scale; interstices somewhat narrower than striae, covered with irregular single row of large, irregular, weakly convex tubercles, and single irregular row of narrow scales twice as long as strial ones, broadly separated from each other; elytra also covered with sparse recumbent small subcircular and oval scales.

Legs long and slender except fore femora extremely strongly swollen, with minute tooth and several minute denticles between tooth and knee; fore tibia long and slender, slightly arched ventrad in middle; ventral margin with two large spines and several smaller ones, each tibia mucronate; tarsi average, second segment slightly transverse; hind tarsi indistinctly more slender.

Aedeagus parallel-sided, apex strongly tapering, extended into thin process swollen apically (Fig.105); weakly arched (Fig. 106); transfer apparatus large, complex, dissimilar to all remaining species of the subgenus. 


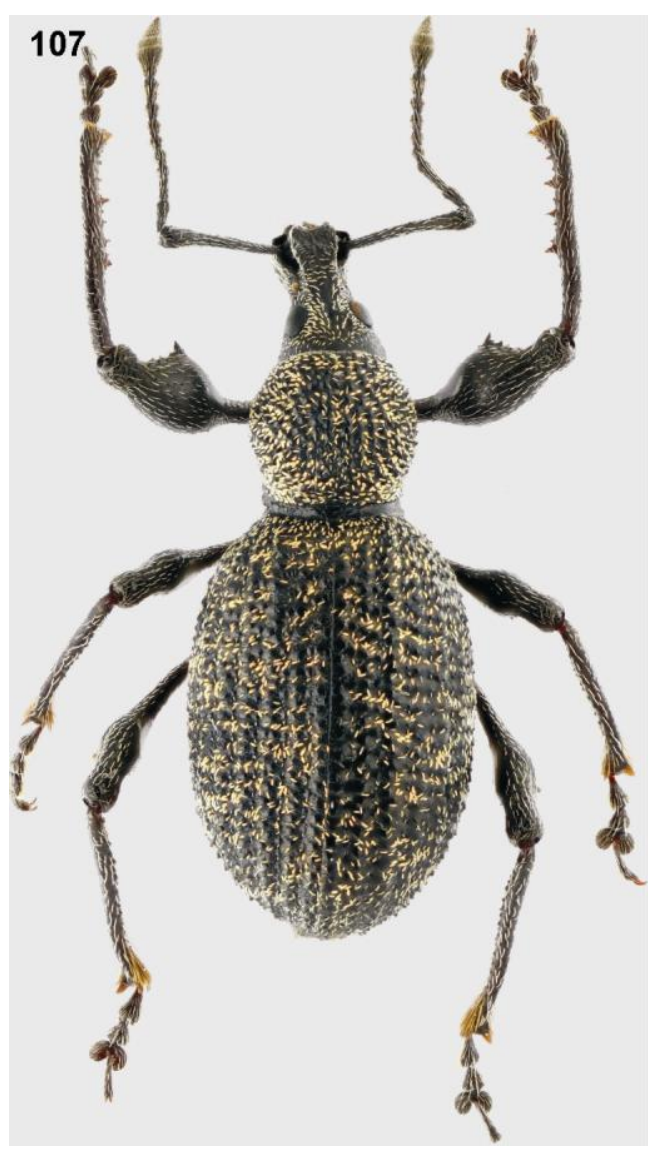

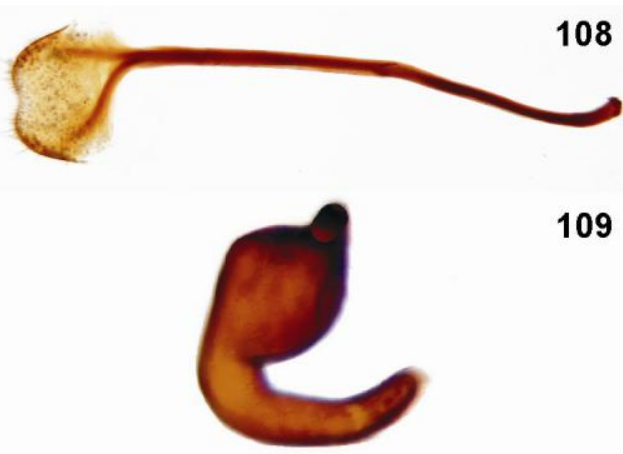

Figs. 107-109. O. (Podonebistus) curiosus sp. n., female (phot. by F. BAHR): 107 - habitus, $108-8^{\text {th }}$ sternite, $109-$ spermatheca.

Female (Fig. 107) differs from male in: strikingly less swollen fore femora; wider elytra, with declivity stronger convex; first two ventrites not impressed; fore femora teeth larger.

$8^{\text {th }}$ sternite somewhat emarginate apically (Fig. 108), spermatheca with swollen corpus and hardly pronounced ramus (Fig. 109).

\section{Ecology}

All the known specimens were beaten from Abies at an altitude of ca. 650-900 m.

\section{Distribution}

So far, known exclusively from Euboea [= Euboia, = Evia] (western Aegean Sea); possibly endemic to this island. 


\section{Etymology}

The Latin adjective curiosus means "curious" - an allusion to the unclear position of this really bizarre species.

Subgenus Arnoldinus DAVIDIAN, GÜlteKIN \& KoROTYAEV, 2017 (type species Otiorhynchus ceratoniae DAVIDIAN, GÜLTEKIN \& KOROTYAEV, 2017)

Although the authors listed only the characters of the external morphology when comparing Arnoldinus with Crataegodes Białooki, 2015 in the original description, the most important diagnostic traits in fact concern the genitalia of both sexes. This will be discussed in detail in a forthcoming paper.

Otiorhynchus (Arnoldinus) ceratoniae DAVIDIAN, GÜLTEKIN \& KOROTYAEV, 2017

\section{Material examined}

Turcia, mer.; Avşallar b. Incekum; 22 km W Alanya; 9.-23.5.1995; leg. A. PÜTZ, 2 exx. [BEHN; BIAL] 10.05.2008 SW Turkey; S. GÜZELBAG; S Gündogmuş; leg. P. BIAŁOOKI, 1 ex. [BIAL].

The authors of the species believe it to be closely associated with Ceratonia siliqua $\mathrm{L}$. but there are evidences that this may not be correct. I collected this species from ground litter under Quercus ilex (or similar oak-species) where no Ceratonia was growing nearby. I tried to compile a botanical inventory in order to understand the ecological preferences of this bizarre species; apart from herbaceous vegetation and Quercus sp., I listed Cistus sp. and two species of conifers forming a compact assemblage in an otherwise predominantly open habitat. I noticed leaves with characteristic evidence of Otiorhynchus-feeding, and no other species of this genus was collected simultaneously. Bearing in mind the fact that all Otiorhynchini species are evidently polyphagous, and no case of monophagy is known in the whole tribe, $O$. ceratoniae is also most likely just associated with xeric habitats rather than with a single host-plant. Moreover, the second Arnoldinus species described below O. microcornis - inhabits a steppe biotope where no Ceratonia is present. The only shrubs or trees at the locus typicus were junipers. 


\section{Otiorhynchus (Arnoldinus) microcornis sp. n.}

(Figs. 110-112)

\section{Material examined}

Holotype male, dissected: 13.05.2008 SW Turkey, Rize Beli pass NW Seydişehir; leg. P. BIAŁOOKI [BIAL]. Paratypes: as ht, 55 exx. $\backslash$ 29.05.2008 SW Turkey; S Rize Beli pass; NW Seydişehir; leg. P. BIAŁOOKI, 58 exx. [BIAL; TALA; WANA].

\section{Diagnosis}

The new species (Fig. 110) differs from $O$. ceratoniae in: body black; antennal scape much stouter, strongly flattened dorso-ventrally, very densely covered with semiprotruding, broad scales; funicle short and thin; pronotum less transverse, covered with much smaller tubercles; elytra much less convex; interstices with sparse microtubercles not arranged in rows; vestiture consisting of short, broad, semiprotruding scales; legs shorter and stouter, fore femora with smaller tooth, middle and hind femora with tooth weakly visible, tuberclelike. Surprisingly, despite the strong differences in its outer morphology, the aedeagus of the two species is practically identical, including the large subapical frena.

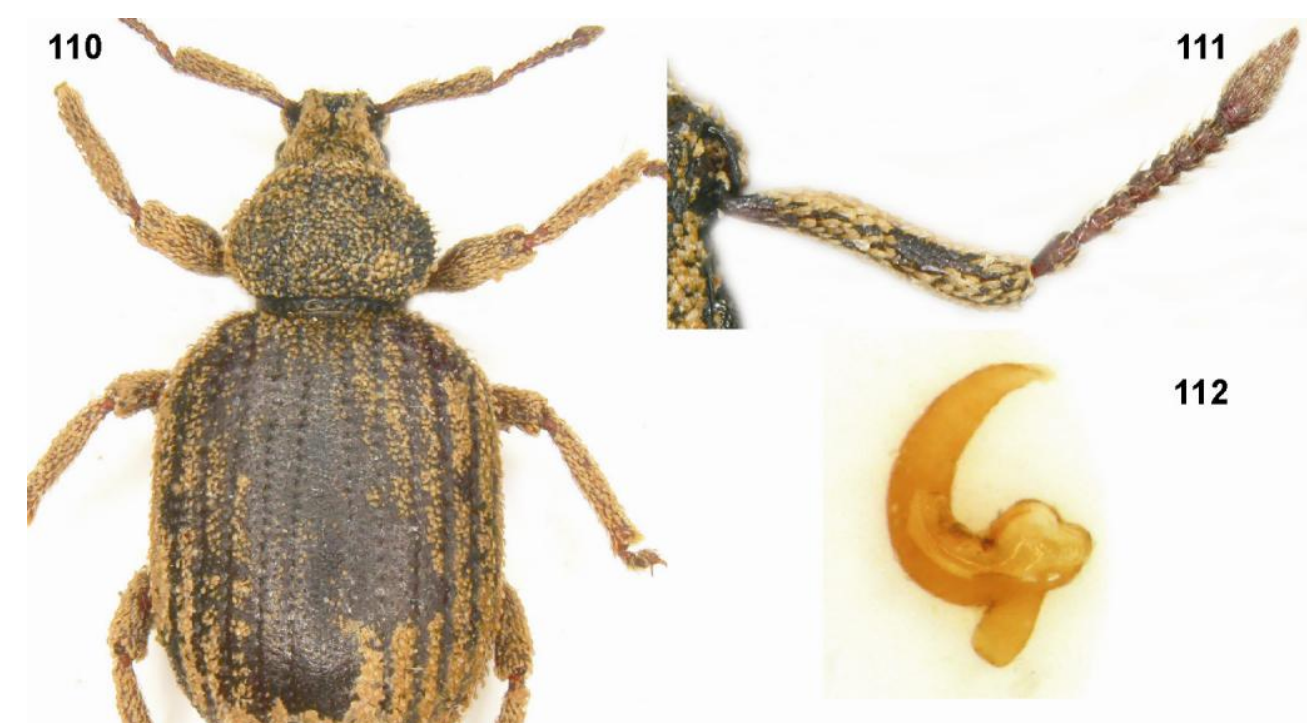

Figs. 110-112. O. (Arnoldinus) microcornis sp. n.: 110 - male habitus, 111 - antenna, 112 - spermatheca. 


\section{Description (male)}

Body length 4.5-5.1 mm (ht 5.0 mm); black; very densely covered with short, subisodiametric subtrapezoidal, narrowest basally, somewhat raised scales obscuring body almost completely; moreover, nearly always body heavily encrusted with loam.

Head moderately transverse, rather strongly tapering; eyes small, $2.1 \times$ narrower than frons, lateral, weakly yet clearly convex, not very weakly projecting; frons only slightly broader than dorsal wall of rostrum between antennal insertions.

Rostrum very short, subequally long as head, strongly transverse; dorsal wall weakly tapering, longitudinally finely densely striated; median keel well developed; pterygia relatively large, moderately projecting.

Antennae peculiar (Fig. 111); scape thick, flattened dorso-ventrally, basally abruptly widening, then subparallel-sided; funicle strikingly slenderer, first segment as long as next two segments combined; second segment ca. $1.6 \times$ longer than wide; third subisodiametric; 4-5 also isodiametric but larger than third; 6-7 moderately transverse; club very slender, fusiform.

Prothorax $1.45 \times$ wider than long; sides regularly, extremely strongly curved; widest slightly behind middle; longitudinally flat except for basal portion; basal constriction as in ceratoniae; pronotum covered with very dense, minute, strongly convex tubercles.

Elytra slightly less subrectangular than in ceratoniae (Fig. 110), $1.25 \times$ longer than wide; broadest in middle; disc flattened; declivity very strongly bent under; striae composed of moderately large but shallow punctures very strongly decreasing backwards: interstices subequally wide as striae basally, whereas in midlength several times wider than striae; each interstice with three irregular rows of scales.

Legs moderately robust; fore femora with moderately large, triangular, wide bidentate tooth; middle and hind femora with minute simple tubercle-like tooth; fore tibiae straight, basally strongly widened; apical comb consisting of relatively long yellowish setae.

Aedeagus strikingly similar to that in O.ceratoniae.

Female is distinguishable from male only with difficulty; it differs merely in somewhat more robust antennae.

Female $8^{\text {th }}$ sternite with well-developed basal margin; spermatheca (Fig. 112) similar to ceratoniae i.e. with short, somewhat inflated corpus; cornu long; nodulus hardly differentiated; ramus moderately long.

\section{Ecology}

All specimens were collected under stones or in the ground litter under cushion plants on mountain steppe. 


\section{Etymology}

The name (adjective) refers to the small antennae of the new species, the funicle in particular.

Subgenus Nubidanops subgen. n. (type species Otiorhynchus tumidicollis STIERLIN, 1861); gender masculine

The type species of the new subgenus $O$. tumidicollis has remained completely unknown since its description and has always been placed in incertae sedis (WINKLER 1932, MAGNANo \& Alonso-ZaraZAGA 2013) or ignored (LonA 1936). It is represented by just two specimens in the collections: the male lectotype, here designated by the labels: "Tokat coll. E. FRIVALDSZKY/ Holotypus Otiorhynchus tumidicollis STIERLIN, 1861 [museum label with an orange frame]/ Friv. 6246/ Otiorhynchus tumidicollis STIERLIN, 1861 Lectotype, des. P. BiAŁOOKI 2010" deposited in the Natural History Museum of Budapest, Hungary (the lectotype is in a poor condition: the left antenna, both fore legs, right middle leg and left middle onychium are missing), and the paralectotype female in the Finnish Museum of Natural History in Helsinki, Finnland, bearing the following labels: "Tokat Frivaldszky/ Tokat/[museum label as above]/ http://id.luomus.fi/GAC.10722 Otiorhynchus tumidicollis STIERLIN, 1861 unknown det./ Otiorhynchus tumidicollis Stierlin, 1861 Paralectotype des. P. BIAŁOOKI 2016" (the paralectotype is in an even worse condition: the left scape with club, left fore onychium, left middle leg, right middle onychium and both hind legs are missing). The species is indeed difficult from the taxonomic viewpoint. Although its affinity to Nubidanus has been obvious to me for a long time, the differences have not allowed a straightforward placement in this subgenus (DAVIDIAN et al. (2017) also placed torosicus in Nubidanus only tentatively); the lack of additional material has not permitted a conclusive decision. Only the discovery of another, still undescribed species, as well as $O$. torosicus DAVIDIAN et al. (2017) finally provided the necessary information.

\section{Etymology}

The name is derived from Nubidanus by replacing the suffix - us with -ops to reflect the presumably close relationship of the two taxa. 


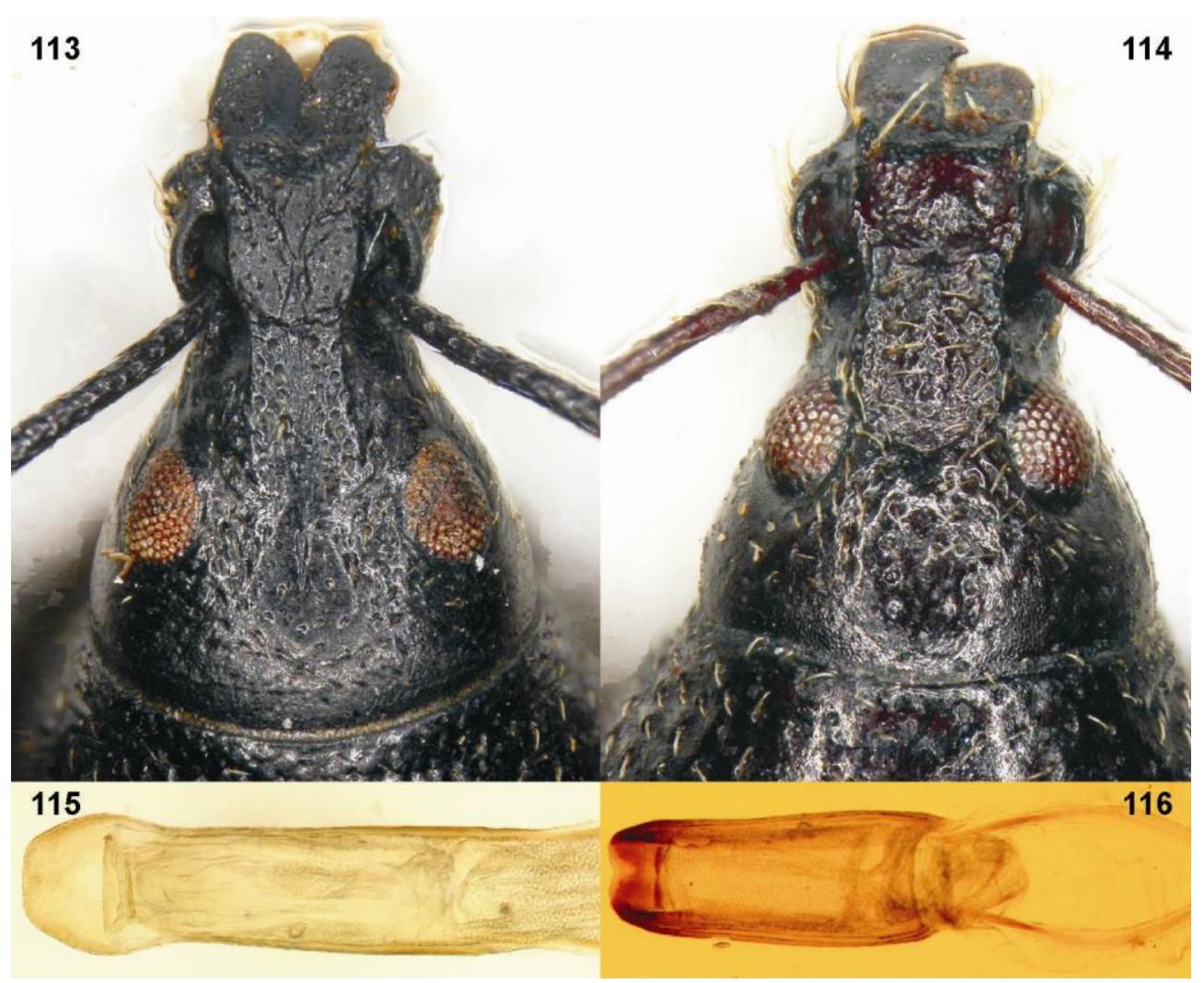

Figs. 113-116. 113 - O. (Nubidanops) sp., head, $114-O$. (Nubidanus) sp., head, 115 - O. (Nubidanops) tumidicollis, aedeagus dorsal view, 116 - O. (Nubidanus) hebraeus, aedeagus dorsal view.

\section{Diagnosis}

The new subgenus is thought to be closely related to the subgenus Nubidanus Reitter because of the small pterygia/scrobes, distant from the anterior margin of the rostrum, and the female terminalia. Nubidanops differs from Nubidanus in the following characters: eyes large, weakly convex, frons much wider than dorsal wall of rostrum at antennal insertions, as well as in front of eyes due to eyes being more lateral (Fig. 113) (in Nubidanus eyes small, moderately convex, unambiguously dorso-lateral, as a result frons subequally wide as dorsal wall of rostrum, Fig. 114); elytral surface devoid of peculiar reticulation, welldeveloped in Nubidanus; elytral vestiture arranged quite irregularly; male last ventrite devoid of process of its distal margin (well developed in Nubidanus); aedeagus (Fig. 115) rather strongly widening apically, broadest subapically (in Nubidanus subparallel-sided, 
subapically tapering, Fig. 116). Nubidanops differs from Odelengus (which also has small distant pterygia) in disparate structure of aedeagus, devoid of sclerotized transfer apparatus in particular (large complex strongly sclerotized in Odelengus); normally developed long and sclerotized ovipositor (obsolete, membranous in Odelengus); bursa copulatrix devoid of sclerotized structure (large in Odelengus). Since the above-mentioned differences are evidently phylogenetically significant, I hereby establish a new subgenus including the following species: Otiorhynchus tumidicollis STIERLIN, 1861; Otiorhynchus torosicus DAVIDIAN, GÜlteKIn \& Korotyaev, 2017 and one undescribed species. A more detailed discussion will be presented in a forthcoming paper.

\section{ACKNOWLEDGEMENTS}

I am greatly indebted to the following persons who helped me in various ways during the preparation of this article: Friedhelm BAHR, Viersen, Germany for the loan of his unidentified specimens, as well as providing some photographs [103, 104; 107-109]; Maxwell BARCLAY and Michael GeISER, British Museum, London, United Kingdom; Lutz BEHNE, Senckenberg Deutsches Entomologisches Institut, Müncheberg, Germany; Stanislav BeNedikT, Plzeň, Czech Republic; Jan Fremuth, Hradec Králové, Czech Republic; Jiří HÁJEK, National Museum, Prague, Czech Republic; George KaKIOPOUlos, Athens, Greece; Zdeněk MalinKa, Opava, Czech Republic; Massimo Meregalli, University of Torino, Italy; Ottó MERKL, Gyözö Szél, and Attila PODLuSSÁNY, Hungarian Natural History Museum, Budapest, Hungary; Jochen MEssuTAT, Preussisch Oldendorf, Germany; Jiří Ch. VÁVRA, Ostrava Museum, Czech Republic; Herbert WinkelmanN, Berlin, Germany, for loans of material from their collections/institutions; and to Marek WANAT, University of Wroclaw, Poland for the opportunity to take photographs and his great hospitality during my visits to Wroclaw. My thanks also go to the two anonymous referees.

\section{REFERENCES}

BIAŁOOKI P.Z. 2015a. Descriptions of new taxa in Otiorhynchus GERMAR, 1822 (Coleoptera: Curculionidae: Entiminae: Otiorhynchini). Polish Journal of Entomology 84(2): 85-99.

BıАŁoOKI P.Z. 2015b. Descriptions of new taxa of Otiorhynchini and related tribes (Coleoptera: Curculionidae: Entiminae) from the Middle East and Balkans. Israel Journal of Entomology 44-45: $13-50$. 
BRAUN W. 1988. Beschreibung zweier neuer Arten der Gattung Otiorhynchus GERM. und kritische Bemerkungen zum taxonomischen Rang der mit Otiorhynchus brevicornis BoH. verwandten Arten. Nachrichtenblatt der Bayerischen Entomologen 37(2): 29-41.

DAVIDIAn G., GÜLtekin L. 2016. Three new species of Otiorhynchus GeRMAR, 1822 (Coleoptera: Curculionidae: Entiminae) from southern Turkey. Journal of Insect Biodiversity 4(10): 1-17.

Davidian G.E., Gültekin L., Korotyaev B.A. 2017. A new subgenus of the weevil genus Otiorhynchus GERMAR, 1822 (Coleoptera: Curculionidae: Entiminae) for a new species from Mediterranean Turkey associated with the carob tree, Ceratonia siliqua L. (Fabaceae). Journal of Insect Biodiversity 5(4): 1-14.

Germann C. 2016. A new Otiorhynchus Germar, 1822 subgenus Tecutinus ReITter, 1912 from Anatolia (Coleoptera, Curculionidae). Contributions to Natural History, Scientific Papers from the Natural History Museum Bern 33: 1-10.

Germann C. 2017. Two new Otiorhynchus (Tecutinus) from southern Anatolia (Coleoptera, Curculionidae). Journal of Insect Biodiversity 5(2): 1-11.

Lona C. 1936. Curculionidae: Otiorrhynchinae I. Pars 148. [in:] S. SchENKLING (ed.). Coleopterorum Catalogus. W. Junk, Berlin.

Magnano L. 2002. Due nuove specie di Otiorhynchus e note su altre species del sottogenere Nihus ReitTer, 1912 (Coleoptera Curculionidae Polydrusinae). Redia 84: 23-31.

Magnano L. 2003. Una nuova specie di Parameira di Turchia (Coleoptera, Curculionidae). Bollettino della Societa Entomologica Italiana 134: 245-252.

Magnano L., Alonso-Zarazaga M.A. 2013. Tribe Otiorhynchini Schoenherr, 1826. [in:] I. LöBl, A. Smetana (eds.). Catalogue of Palaearctic Coleoptera. Volume 8. Curculionoidea II. Brill, Leiden and Boston, 302-347.

REITTER E. 1912. Übersicht der Untergattungen und der Arten-Gruppen des Genus Otiorrhynchus GERM. Wiener Entomologische Zeitung 31(2): 45-67.

WinkLeR A. 1932. Catalogus Coleopterorum regionis palaearcticae. Pars 12. Albert Winkler, Wien, $1393-1520$

Received: 10 March 2017

Accepted: 1 September 2017 